\title{
Sobre a redução do óxido nítrico em complexos de tetraaminas de rutênio (II)
}

Eliane Vasconcelos Stefaneli

Dissertação apresentada ao Instituto de Química de São Carlos da Universidade de São Paulo como requisito parcial para a obtenção do título de Mestre em Ciências. Área de concentração: Química Analítica.

Orientador: Prof. Dr. Douglas Wagner Franco

São Carlos 
À minha mãe, Maria José, que sempre confiou em minha capacidade, dando-me incentivos e forças durante esse período de ausência, e às minhas irmãs, Elaine e Aline.

Dedico este trabalho 
"Nada na vida pode substituir a PERSISTÊTNCIA:

Nem o talento o fará, pois o mundo está cheio de homens de talento, fracassados. Nem a genialidade o fará, pois gênios desempregados é quase um provérbio. $\mathcal{N} e m$ o conhecimento o fará, pois encontramos muitos diplomados medíocres".

Autor desconhecido

É preciso ter paciência e esperar o momento certo...

...E nunca levar a vida muito a sério! 


\section{AGRADECIMENTOS}

A Deus, por ter me dado força e coragem o suficiente para superar todas as dificuldades e sempre seguir em frente.

À minha mãe, Maria José Vasconcelos, por ter me dado o seu apoio sempre que precisei e por sua total confiança.

Às minhas irmãs, Elaine Cristina e Aline, pelo carinho, amizade e apoio transmitidos em nossos encontros; e aos meus cunhados Vicente e Lindomar pelo apoio e amizade.

Aos meus lindos sobrinhos, Luís Henrique e Lucas, pelas alegrias de seus nascimentos.

Ao prof. Dr. Douglas Wagner Franco pela orientação, amizade e motivação..

À prof ${ }^{\mathrm{a}}$. Dra Teresa Benita Iwasita de Vielstich (IQSC/USP) por disponibilizar o equipamento de espectroeletroquímica para a realização de parte deste trabalho.

À prof $^{a}$ Dra Márcia Temperini (IQ/USP) pela atenção dispensada para a realização dos experimentos em seu laboratório. Ao prof. Dr. Sérgio Antônio Spinola Machado (IQSC/USP) pelas várias discussões sobre eletroquímica proporcionada no decorrer deste trabalho.

Ao prof. Dr. Luiz Henrique Mazo (IQSC/USP) pelos experimentos de Voltametria de Onda Quadrada e pelas valiosas discussões sobre eletroquímica.

Ao prof. Dr. Elia Tfouni (FFCL-RP) pelo composto $[\mathrm{Ru}(\mathrm{NO}) \mathrm{Cl}(\mathrm{cyclam})]\left(\mathrm{PF}_{6}\right)_{2}$ gentilmente cedido.

Ao Francisco das Chagas Alves Lima pelos cálculos teóricos baseados em DFT. 
À Patrícia, Clayston, Jean e Renata, pelo auxílio em vários experimentos, pela leitura e correção criteriosa da dissertação e monografia, mas principalmente pela paciência, companheirismo e incentivo durante todo este tempo.

Aos meus amigos em São Carlos: Daniela, Karen, Chris e Marsele, pela sincera amizade. À Márcia por seus conselhos e palavras de incentivo, e seus email que sempre me trouxeram alegria.

Ao Bruno, Roberto, Andréia (IQSC/USP) e Gustavo (IQ/USP) pelo auxílio em alguns experimentos. Ao Haruo pelo auxílio em alguns experimentos e pelas ótimas discussões sobre eletroquímica.

Aos demais amigos e colegas do Laboratório de Química Inorgânica e Analítica, atuais e do passado: Fefê, Gustavo, Heloísa, Mariana, pela agradável convivência, amizade e companheirismo, tornando-se pessoas muito importantes na minha vida. Valeu mesmo!

Aos amigos e colegas do Laboratório de aguardente, em especial Luciana, Wendel e Itapira.

A todos que aqui conheci e com quem convivi, como se fosse a minha própria família, durante esse tempo longe do convívio familiar, pois "O laço que une a sua verdadeira família não é de sangue, mas de respeito e alegria pela vida um do outro" (Richard Bach). Aos que me apoiaram, me incentivaram, e principalmente, me aceitaram da maneira que sou, o meu "Muito Obrigado" e meu carinho eterno.

Aos funcionários do Instituto de Química de São Carlos/USP, em especial à Veroneide.

Ao Instituto de Química de São Carlos/USP, pelo apoio e oportunidade.

A CNPq (Conselho Nacional de Pesquisa Química) pelo auxílio financeiro. 


\section{SUMÁRIO}

Lista de Figuras

Lista de Tabelas

Lista de Abreviaturas e Siglas

iii

Lista de Símbolos e Fórmulas

iv

Resumo

Abstract

1 - Introdução 1

1.1- Aspectos gerais da química do HNO......................................... 4

1.2- Compostos nitrosilos de rutênio.......................................... 12

$2-$ Objetivos............................................................................ 14

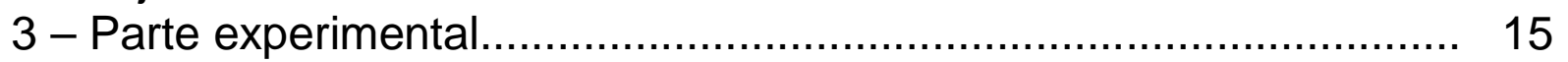

3.1- Reagentes e Soluções............................................................ 15

3.2- Sínteses...................................................................... 18

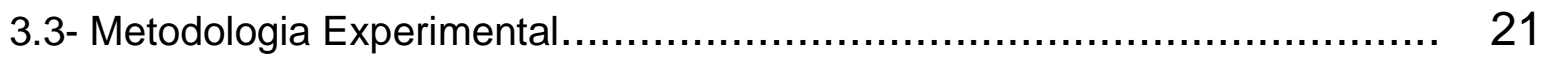

3.4- Métodos e Cálculos.............................................................. 25

4 - Resultados e Discussões............................................... 29

4.1- Perfil voltamétrico do íon complexo trans-[Ru(NH$\left.\left.{ }_{3}\right)_{4} \mathrm{P}(\mathrm{OEt})_{3} \mathrm{NO}\right]^{3+} \ldots \ldots \ldots \ldots . .29$

4.2- Espectroscopia vibracional vs Potencial..................................... 42

4.3- Cálculos de DFT para os complexos trans- $\left[\mathrm{Ru}\left(\mathrm{NH}_{3}\right)_{4} \mathrm{P}(\mathrm{OEt})_{3} \mathrm{~L}^{\mathrm{n}}\right]^{\mathrm{n}+2}$, onde

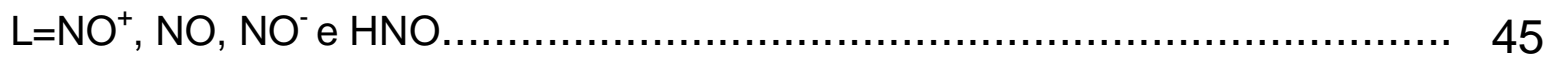

4.4- Redução química por reação com o a-cetoglutarato............................. 49

4.5- Reação com a metmioglobina............................................... 56

5 - Considerações Finais..................................................... 60

6 - Referências Bibliográficas.............................................. 62

7 - Apêndices......................................................................... 71 


\section{LISTA DE FIGURAS}

FIGURA 1.1 - Diagrama simplificado dos orbitais moleculares para o monóxido de nitrogênio, contendo o átomo de nitrogênio em diferentes estados de oxidação .....

FIGURA 1.2 - Descrição simplificada da interação entre os orbitais da molécula de NO com os orbitais $d_{\pi}$ do metal. Doação de um par de elétrons $\sigma$ do nitrogênio do NO para o metal, seguido de uma retrodoação do metal para o monóxido de nitrogênio.

FIGURA 1.3 - Esquema redox para o óxido nítrico. Estados formais de oxidação dos átomos de nitrogênio são mostrados em números romanos.

FIGURA 1.4 - Espécies de nitroxil.

FIGURA 1.5 - Diagrama de energia das várias espécies de nitroxil em fase gasosa

FIGURA 1.6 - Esquema das rotas de ação de NO versus HNO.

FIGURA 2.1 - Forma da onda tempo/potencial para a voltametria de onda quadrada, mostrando a escada de potencial, $E_{s}$, o potencial de pulso, $E_{p}$, e o tempo entre as escadas aplicadas.

FIGURA 4.1 - Voltamograma cíclico do complexo trans-[RuNO $\left.\left(\mathrm{NH}_{3}\right)_{4} \mathrm{P}\left(\mathrm{OC}_{2} \mathrm{H}_{5}\right)_{3}\right]^{3+}$ em solução de $\mathrm{CF}_{3} \mathrm{COOH} / \mathrm{NaCF}_{3} \mathrm{COO}$, mostrando o perfil voltamétrico.

FIGURA 4.2 - Voltamograma cíclico do complexo $t$-[RuNO$\left.\left(\mathrm{NH}_{3}\right)_{4} \mathrm{P}\left(\mathrm{OC}_{2} \mathrm{H}_{5}\right)_{3}\right]\left(\mathrm{PF}_{6}\right)_{3}$ (一) $v=0,005 \mathrm{~V} . \mathrm{s}^{-1} ;(-) \mathrm{v}=0,5 \mathrm{~V} / \mathrm{s}$.

FIGURA 4.3 - Voltamograma cíclico do complexo $t$-[Ru(Hedta)NO].

FIGURA 4.4 - Deconvolução do voltamograma cíclico $(0,5 \mathrm{~V} / \mathrm{s})$ do íon complexo $t$ $\left[\mathrm{RuNO}\left(\mathrm{NH}_{3}\right)_{4} \mathrm{P}\left(\mathrm{OC}_{2} \mathrm{H}_{5}\right)_{3}\right]^{3+}$.

FIGURA 4.5 - Voltamogramas de onda quadrada mostrando a influência da variação da freqüência de aplicação dos pulsos de potenciais $(f)$ sobre o segundo pico de redução do íon complexo trans- $\left[\mathrm{RuNO}\left(\mathrm{NH}_{3}\right)_{4} \mathrm{P}\left(\mathrm{OC}_{2} \mathrm{H}_{5}\right)_{3}\right]^{3+}$.

FIGURA 4.6 - Gráfico da variação da corrente de pico $\left(I_{p c 2}\right)$ em função da freqüência de onda quadrada $(f)$ para o segundo pico de redução do complexo trans- $\left[\mathrm{RuNO}\left(\mathrm{NH}_{3}\right)_{4} \mathrm{P}\left(\mathrm{OC}_{2} \mathrm{H}_{5}\right)_{3}\right]^{3+}$....

FIGURA 4.7 - Gráfico da variação da corrente de pico $\left(I_{p c 2}\right)$ em função da raiz quadrada da freqüência de onda quadrada $\left(f^{1 / 2}\right)$ para o segundo pico de redução do complexo trans- $\left[\mathrm{RuNO}\left(\mathrm{NH}_{3}\right)_{4} \mathrm{P}\left(\mathrm{OC}_{2} \mathrm{H}_{5}\right)_{3}\right]^{3+}$

FIGURA 4.8 - Gráfico da variação da corrente de pico $\left(I_{p c 2}\right)$ em função do logaritmo da freqüência de onda quadrada $(\log (f))$ para o pico de redução do complexo trans-[RuNO $\left.\left(\mathrm{NH}_{3}\right)_{4} \mathrm{P}\left(\mathrm{OC}_{2} \mathrm{H}_{5}\right)_{3}\right]^{2+}$.

FIGURA 4.9 - Espectro eletrônico na região do IR vs potencial para o complexo 
trans-[RuNO $\left.\left(\mathrm{NH}_{3}\right)_{4} \mathrm{P}\left(\mathrm{OC}_{2} \mathrm{H}_{5}\right)_{3}\right]^{3+}$; a) $\mathrm{E}_{\mathrm{S}}=-0,02 \mathrm{~V}$; b) $\left.\mathrm{E}_{\mathrm{S}}=-0,22 \mathrm{~V} ; \mathrm{c}\right) \mathrm{E}_{\mathrm{S}}=-0,82 \mathrm{~V} .$.

FIGURA 4.10 - Espectro eletrônico na região do IR vs potencial de pico para o complexo trans-[RuNO(NH$\left.)_{4} n i c\right]^{3+}$; a) $E_{S}=0,05 \mathrm{~V}$; b) $E_{S}=-0,25 \mathrm{~V}$; c) $E_{S}=-0,35 \mathrm{~V}$; d) $E_{S}=-0,55 \mathrm{~V} ;$ e) $E_{S}=-0,65 V$

FIGURA 4.11 - Esquema de algumas formas do ácido a-cetoglutárico em solução.

FIGURA 4.12 - Voltamograma cíclico (一) do íon complexo $t$ -

$\left[\mathrm{Ru}\left(\mathrm{NH}_{3}\right)_{4} \mathrm{NOP}\left(\mathrm{OC}_{2} \mathrm{H}_{5}\right)\right]^{3+} ;(-)$ após 45 min de reação do complexo com o $\alpha-$

Cetoglutarato; (-) Após 90 min de reação

FIGURA 4.13 - Voltamograma cíclico de uma solução de NaTFA saturada com o gás $\mathrm{N}_{2} \mathrm{O}$

FIGURA 4.14 - Voltamograma cíclico de uma solução de NaTFA saturada com NO

FIGURA 4.15 - Monitoramento espectrofotométrico da reação do complexo trans$\left[\mathrm{RuNO}\left(\mathrm{NH}_{3}\right)_{4} \mathrm{P}\left(\mathrm{OCH}_{2} \mathrm{CH}_{3}\right)\right]^{3+}$ e a-CG.

FIGURA 4.16 - RMN ${ }^{31} \mathrm{P}$ do produto final da reação do íon complexo trans-

$\left[\mathrm{Ru}(\mathrm{NO})\left(\mathrm{NH}_{3}\right)_{4} \mathrm{P}\left(\mathrm{OCH}_{2} \mathrm{CH}_{3}\right)\right]^{3+}$ e $\alpha-\mathrm{CG}$ (em água deuterada e $\mathrm{NaTFA}$ ).

FIGURA 4.17 - Monitoramento espectrofotométrico da reação do complexo trans$\left[\mathrm{Ru}(\mathrm{NO})\left(\mathrm{NH}_{3}\right)_{4} \mathrm{P}\left(\mathrm{OCH}_{2} \mathrm{CH}_{3}\right)\right]^{3+}$, $\alpha-\mathrm{CG}$ e metMb.

FIGURA 4.18 - Espectro eletrônico do produto da reação da metmioglobina e NO a) metMb - 502 e $630 \mathrm{~nm}$ e b) produto da reação - 534 e $567 \mathrm{~nm}$.

FIGURA 4.19 - Voltamograma cíclico de uma solução contendo íons trans-

$\left[\mathrm{Ru}(\mathrm{NO})\left(\mathrm{NH}_{3}\right)_{4} \mathrm{P}\left(\mathrm{OCH}_{2} \mathrm{CH}_{3}\right)\right]^{3+}$, $\alpha-\mathrm{CG}$ e metmioglobina. 


\section{LISTA DE TABELAS}

TABELA 1.1 - Propriedades de monóxidos de nitrogênio...................................

TABELA 4.1 - Variação do potencial e corrente de pico em função da freqüência para o segundo pico de redução do íon trans-[RuNO $\left.\left(\mathrm{NH}_{3}\right)_{4} \mathrm{P}\left(\mathrm{OC}_{2} \mathrm{H}_{5}\right)_{3}\right]^{3+}$

TABELA 4.2 - Comprimentos de ligação e ângulos de ligação do Complexo trans$\left[\mathrm{Ru}\left(\mathrm{NH}_{3}\right)_{4} \mathrm{P}\left(\mathrm{OC}_{2} \mathrm{H}_{5}\right)_{3} \mathrm{~L}\right]^{\mathrm{n+}}\left(\mathrm{L}=\mathrm{NO}, \mathrm{NO}^{+}, \mathrm{NO}^{-}\right.$e $\left.\mathrm{HNO}\right)$ em água e a sua comparação com dados cristalográficos para o complexo.

TABELA 4.3 - Cálculo das cargas atômicas derivadas do potencial eletrostático para o complexo contendo o monóxido de nitrogênio em diferentes estados formais de oxidação. 


\section{LISTA DE ABREVIATURAS e SIGLAS}

4-pic - 4-Picolina

a-CG - a-Cetoglutarato

Abs - Absorbância

Aquofosfito - Refere-se ao complexo trans-[Ru( $\left.\left.\mathrm{NH}_{3}\right)_{4}\left(\mathrm{H}_{2} \mathrm{O}\right) \mathrm{P}\left(\mathrm{OCH}_{2} \mathrm{CH}_{3}\right)_{3}\right]\left(\mathrm{PF}_{6}\right)_{3}$

Cyclam - Ácido 1,4,8,11-tetraazaciclopentaacético

cGMP - Monofosfato cíclico de guanosina

ECS - Eletrodo de Calomelano Saturado

edta - Ácido etilenodiamintetraacético

Et - Etanol

ImN - Imidazol

Isn - Isonicotinamida

Mb - Mioglobina

nic - Nicotinamida

Py - Piridina

$\mathbf{P z}$ - Pirazina

RMN - Ressonância magnética nuclear

sGC - Guanilato ciclase solúvel

UV-Vis - Ultravioleta visível

VC - Voltametria cíclica 


\section{LISTA DE FÓRMULAS e SIMBOLOS}

$\boldsymbol{\varepsilon}$ - Coeficiente de absortividade molar

v - Número de onda

t - Tempo

$\mathbf{T}$ - Temperatura em ${ }^{\circ} \mathrm{C}$

$\mathbf{v}$ - Velocidade de varredura em V.s ${ }^{-1}$

$\mathrm{H}_{3} \mathrm{~N}=(\gamma)^{\prime}=\mathrm{NH}_{3}$

$\mathrm{H}_{3} \mathrm{~N}^{\mathrm{Ru}}>\mathrm{NH}_{3}$

$\mathrm{EtO}^{\prime} \stackrel{\mathrm{OEt}}{\mathrm{P}} \mathrm{OEt}_{\mathrm{O}}$

$\Rightarrow$ Íon complexo trietilfosfito tetraamina de rutênio<smiles>c1ccncc1</smiles>

py - Piridina<smiles>Cc1ccncc1</smiles>

4-pic - 4-picolina

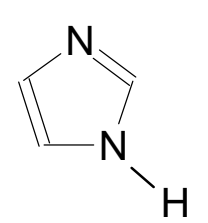

ImN - Imidazol<smiles>NC(=O)c1cccnc1</smiles><smiles>c1cnccn1</smiles>

nic - Nicotinamida

pz - Pirazina 


\section{RESUMO}

A redução eletroquímica de íons complexos do tipo trans-[Ru( $\left.\left(\mathrm{NH}_{3}\right)_{4} \mathrm{LNO}\right]^{2+}$, foi investigada com o intuito de verificar a possibilidade desses complexos atuarem como doadores de nitroxil (HNO/NO${ }^{-}$). Neste trabalho foi dada uma ênfase especial no estudo da espécie em que $\mathrm{L}=\mathrm{P}(\mathrm{OEt})_{3}$. Aplicando-se as técnicas de voltametria cíclica e de pulso diferencial, voltametria de onda quadrada e espectroeletroquímica, foi possível verificar que a espécie trans- $\left[\mathrm{Ru}\left(\mathrm{NH}_{3}\right)_{4} \mathrm{P}(\mathrm{OEt})_{3} \mathrm{NO}\right]^{2+}$ sofre redução monoeletrônica gerando 0 íon complexo trans-[Ru( $\left.\left(\mathrm{NH}_{3}\right)_{4} \mathrm{P}(\mathrm{OEt})_{3} \mathrm{NO}\right]^{+}$. Foram analisadas as estabilidades relativas das espécies possivelmente formadas, trans$\left[\mathrm{Ru}\left(\mathrm{NH}_{3}\right)_{4} \mathrm{P}(\mathrm{OEt})_{3} \mathrm{NO}\right]^{+}$e trans- $\left[\mathrm{Ru}\left(\mathrm{NH}_{3}\right)_{4} \mathrm{P}(\mathrm{OEt})_{3} \mathrm{HNO}\right]^{2+}$, baseadas na Teoria de Densidade Funcional (DFT). Após a transferência eletrônica, de acordo com a equação abaixo, a espécie formada sofre isomerização de spin, ocorrendo posteriormente a dissociação do grupo NO:

$$
\begin{gathered}
t_{-}\left[\mathrm{Ru}^{\prime \prime}\left(\mathrm{NH}_{3}\right)_{4}(\mathrm{NO}) \mathrm{P}(\mathrm{OEt})_{3}\right]^{2+}+1 \mathrm{e}^{-} \longrightarrow t_{-}\left[\mathrm{Ru}\left(\mathrm{NH}_{3}\right)_{4} \mathrm{P}\left(\mathrm{OC}_{2} \mathrm{H}_{5}\right)_{3}\left(\mathrm{NO}^{-}\right)\right]^{+} \\
t_{-}\left[\mathrm{Ru}\left(\mathrm{NH}_{3}\right)_{4} \mathrm{P}\left(\mathrm{OC}_{2} \mathrm{H}_{5}\right)_{3}\left({ }^{1} \mathrm{NO}^{-}\right)\right]^{+} \stackrel{\text { Rápida }}{\longrightarrow} t_{-}\left[\mathrm{Ru}\left(\mathrm{NH}_{3}\right)_{4} \mathrm{P}\left(\mathrm{OC}_{2} \mathrm{H}_{5}\right)_{3}\left({ }^{3} \mathrm{NO}^{-}\right)\right]^{+} \\
t_{-}\left[\mathrm{Ru}\left(\mathrm{NH}_{3}\right)_{4} \mathrm{P}\left(\mathrm{OC}_{2} \mathrm{H}_{5}\right)_{3}\left({ }^{3} \mathrm{NO}^{-}\right)\right]^{+}+2 \mathrm{H}_{2} \mathrm{O} \stackrel{\text { Rápida }}{\longrightarrow} t_{-}\left[\mathrm{Ru}\left(\mathrm{NH}_{3}\right)_{4}\left(\mathrm{H}_{2} \mathrm{O}\right) \mathrm{P}\left(\mathrm{OC}_{2} \mathrm{H}_{5}\right)_{3}\right]^{2+}+{ }^{1} \mathrm{HNO}^{+} \mathrm{OH}^{-}
\end{gathered}
$$

O processo apresenta-se como irreversível no espectro voltamétrico devido às restrições de spin.

A reação do íon complexo trans- $\left[\mathrm{Ru}\left(\mathrm{NH}_{3}\right)_{4} \mathrm{P}(\mathrm{OEt})_{3} \mathrm{NO}\right]^{3+}$ com 0 alfacetoglutarato $\left(E_{\text {red }}=-0,90 \mathrm{~V}\right)$, composto capaz de agir como redutor de dois elétrons por transferência de elétrons de esfera externa, foi monitorada eletroquímica e espectrofotometricamente utilizando a metmioglobina, Mb - Fe(III), captador seletivo de nitroxil. Os resultados obtidos sugerem o complexo supracitado como um possível doador de niroxil. 


\section{ABSTRACT}

The electrochemical reduction behavior of the complexes trans- $\left[\mathrm{Ru}\left(\mathrm{NH}_{3}\right)_{4} \mathrm{P}(\mathrm{OEt})_{3} \mathrm{NO}\right]^{2+}$ was investigated in order to determine the possibility of these complexes to serve as nitroxyl donors $\left(\mathrm{HNO} \mathrm{NO}^{-}\right)$. Special emphasis was given when $\mathrm{L}=\mathrm{P}(\mathrm{OEt})_{3}$. Using cyclic voltammetry and differential pulse, square wave voltammetry and spectroelectrochemistry techniques was possible to infer that the ion complex trans- $\left[\mathrm{Ru}\left(\mathrm{NH}_{3}\right)_{4} \mathrm{P}(\mathrm{OEt})_{3} \mathrm{NO}\right]^{2+}$ suffers an one electron reduction generating the ion complex trans-[Ru( $\left.\left(\mathrm{NH}_{3}\right)_{4} \mathrm{P}(\mathrm{OEt})_{3} \mathrm{NO}\right]^{+}$. Analyzing the behavior of the cyclic voltammetry spectra, is possible to conclude that the process is irreversible by spin restrictions.

$$
\begin{gathered}
t-\left[\mathrm{Ru}^{\prime \prime}\left(\mathrm{NH}_{3}\right)_{4}(\mathrm{NO}) \mathrm{P}(\mathrm{OEt})_{3}\right]^{2+}+1 \mathrm{e}^{-} \longrightarrow t_{-}\left[\mathrm{Ru}\left(\mathrm{NH}_{3}\right)_{4} \mathrm{P}\left(\mathrm{OC}_{2} \mathrm{H}_{5}\right)_{3}\left(\mathrm{NO}^{-}\right)\right]^{+} \\
t_{-}\left[\mathrm{Ru}\left(\mathrm{NH}_{3}\right)_{4} \mathrm{P}\left(\mathrm{OC}_{2} \mathrm{H}_{5}\right)_{3}\left({ }^{1} \mathrm{NO}^{-}\right)\right]^{+} \stackrel{\text { Rápida }}{\longrightarrow} t_{-}\left[\mathrm{Ru}\left(\mathrm{NH}_{3}\right)_{4} \mathrm{P}\left(\mathrm{OC}_{2} \mathrm{H}_{5}\right)_{3}\left({ }^{3} \mathrm{NO}^{-}\right)\right]^{+} \\
t-\left[\mathrm{Ru}\left(\mathrm{NH}_{3}\right)_{4} \mathrm{P}\left(\mathrm{OC}_{2} \mathrm{H}_{5}\right)_{3}\left({ }^{(} \mathrm{NO}^{-}\right)\right]^{+}+2 \mathrm{H}_{2} \mathrm{O} \stackrel{\text { Rápida }}{\longrightarrow} t_{-}\left[\mathrm{Ru}\left(\mathrm{NH}_{3}\right)_{4}\left(\mathrm{H}_{2} \mathrm{O}\right) \mathrm{P}\left(\mathrm{OC}_{2} \mathrm{H}_{5}\right)_{3}\right]^{2+}+{ }^{1} \mathrm{HNO}^{+} \mathrm{OH}^{-}
\end{gathered}
$$

The reaction of the ion complex trans- $\left[\mathrm{Ru}\left(\mathrm{NH}_{3}\right)_{4} \mathrm{P}(\mathrm{OEt})_{3} \mathrm{NO}\right]^{+}$with the reductor agent alpha-ketoglutarate $\left(E_{\text {red }}=-0,90 \mathrm{~V}\right)$, a two electron reductor by outersphere pathway, was monitored by electrochemistry and UV-vis spectroscopy techniques using Mb-Fe(III) as a selective nitroxyl scavenger. The results obtained with these experiments confirm the original purpose of this study. 


\section{INTRODUC Ã O}




\section{1- INTRODUÇÃO}

Dois fatos ocorridos na década de 80 fizeram ressurgir o interesse pela química do NO. O primeiro foi o seu reconhecimento como responsável pelo relaxamento vascular e o segundo foi a constatação de sua produção por macrófagos ativados ${ }^{[1,2]}$. Desde então, tem ocorrido importantes descobertas sobre a sua implicação em processos biológicos ${ }^{[3]}$ tais como: neurotransmissãa ${ }^{[4]}$, no processo normal de ereção do pênis ${ }^{[5]}$, no relaxamento da musculatura ${ }^{[6,7]}$ e no controle da pressão sangüínea ${ }^{[8]}$. A importância destas descobertas acerca do NO, aclamado como "a molécula do ano" em 1992, rendeu em 1998, o Prêmio Nobel em Fisiologia e Medicina a Louis J. Ignarro, Robert F. Furchgott e Ferid Murad. Sendo assim, na última década a possível atividade biológica da forma reduzida de um elétron do óxido nítrico, $\mathrm{NO}^{\circ}$, ganhou considerável destaque.

A química do óxido nítrico (NO) envolve espécies interrelacionadas em diferentes estados de oxidação $\left(\mathrm{NO}^{+}\right.$, $\mathrm{NO}$ ou $\left.\mathrm{NO}^{-}\right)$com propriedades e reatividades distintas $^{[1,9-11]}$. Algumas propriedades físicas que ilustram essas distinções estão resumidas na Tabela 1.1.

Tabela 1.1 - Propriedades de monóxidos de nitrogênio ${ }^{[11]}$

\begin{tabular}{|c|c|c|c|}
\hline Molécula & $\operatorname{Nox}(\mathrm{N})$ & Comprimento de ligação $(\AA)$ & $v \mathrm{~N}-\mathrm{O}\left(\mathrm{cm}^{-1}\right)$ \\
\hline Cátion nitrosônio $\left(\mathrm{NO}^{+}\right)$ & +3 & 0,95 & 2300 \\
\hline Óxido nítrico (NO) & +2 & 1,15 & 1840 \\
\hline Ânion nitroxil (NO) & +1 & 1,26 & 1290 \\
\hline
\end{tabular}


$\mathrm{O} \mathrm{NO}^{\bullet}$ tem apenas um elétron em seu orbital $2 p-\pi$ antiligante, como mostra o diagrama de orbitais moleculares (Figura 1.1 $)^{[12]}$. A presença desse elétron desemparelhado ocupando um orbital $\pi$ antiligante confere ao NO caráter radicalar, com uma ordem de ligação de 2,5, o qual não apresenta uma forte tendência para dimerização. A remoção desse elétron gera o $\mathrm{NO}^{+}$, cuja ordem de ligação é 3 , sendo isoeletrônico com $\mathrm{N}_{2}$ e CO. Da mesma forma, a adição de um elétron no orbital $\pi^{\star}$ forma o $\mathrm{NO}^{-}$, isoeletrônico com o dioxigênio, com uma ordem de ligação 2 e com a carga negativa localizada no átomo de nitrogênio (o par ácido é $\mathrm{HNO})^{[9]}$.

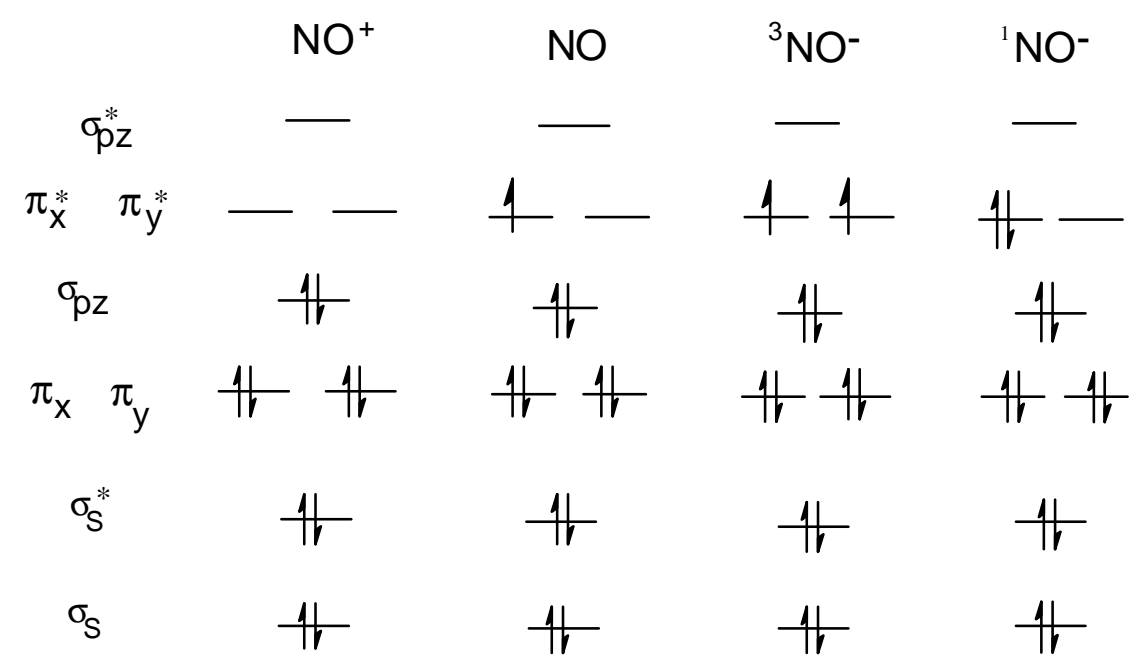

Figura 1.1 - Diagrama simplificado dos orbitais moleculares para o monóxido de nitrogênio, contendo o átomo de nitrogênio em diferentes estados de oxidação ${ }^{[12]}$.

Cada elétron adicionado (de $\mathrm{NO}^{+}$a $\mathrm{NO}^{-}$) diminui a ordem de ligação $\mathrm{N}-\mathrm{O}$, refletindo diretamente no aumento da distância de ligação e na diminuição da energia de estiramento $(\mathrm{vNO})$. A medida dessas propriedades fornece dados importantes para atribuir o caráter do grupo nitrosil em compostos contendo NO. O óxido nítrico forma facilmente complexos com íons de metais de transição. Muitos desses são complexos onde o $\mathrm{NO}$ está formalmente na forma de $\mathrm{NO}^{+}$. De acordo 
com a Figura 1.2, além da ligação $\sigma$ entre o óxido nítrico e o metal de transição, o íon $\mathrm{NO}^{+}$tem dois orbitais $\pi^{*}$ não preenchidos e degenerados $\left(\begin{array}{lll}\pi_{y}^{*} & \mathrm{e} & \pi_{z}^{*}\end{array}\right)$ simetricamente capazes de constituírem ligação $\pi$ com orbitais preenchidos $n d \pi$ de íons metálicos ${ }^{[13]}$.

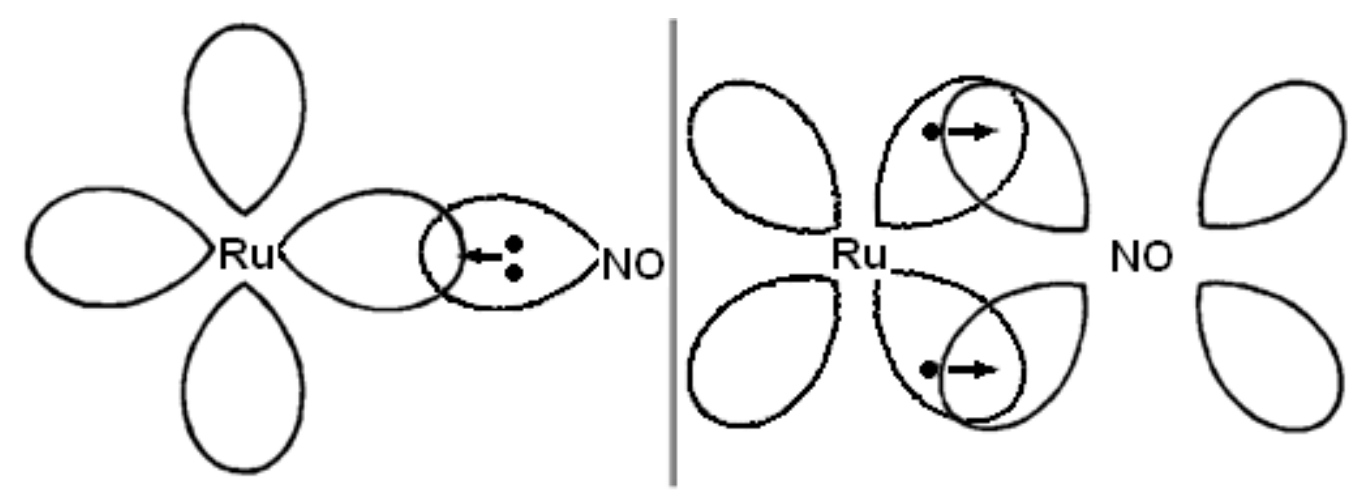

Figura 1.2 - Descrição simplificada da interação entre os orbitais da molécula de NO com os orbitais $\mathrm{d}_{\pi}$ do metal. Doação de um par de elétrons $\sigma$ do nitrogênio do NO para o metal, seguido de uma retrodoação do metal para o monóxido de nitrogênio ${ }^{[13]}$.

Por outro lado, a adição de mais um elétron no orbital $\pi^{*}$ da molécula de NO* leva ao enfraquecimento da ligação M-NO com o centro metálico e N-O, sendo que a freqüência de estiramento, $v_{N O}$, para nitroxilos metálicos dessa natureza estão geralmente na região de 1300 a $1500 \mathrm{~cm}^{-1[14-16]}$.

A afinidade eletrônica de $\mathrm{NO}^{\circ}$ irá depender se o produto $\mathrm{NO}^{-}$está no estado singleto ou tripleto, mas a redução do óxido nítrico ao íon nitroxil pode ser realizado por agentes redutores biológicos ${ }^{[17]}$. A Figura 1.3 ilustra as diferentes espécies redox de óxido de nitrogênio e o estado de oxidação do respectivo nitrogênio. 


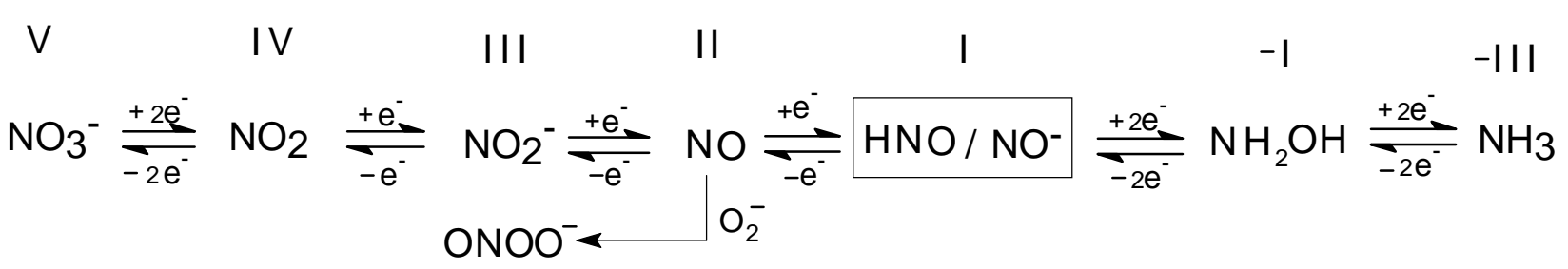

Figura 1.3 - Esquema redox para o óxido nítrico. Estados formais de oxidação dos átomos de nitrogênio são mostrados em números romanos ${ }^{[18]}$.

De todas as espécies de nitrogênio comumente estudadas $\left(\mathrm{NO}_{3}{ }^{-}, \mathrm{NO}_{2}{ }^{-}, \mathrm{NO}_{2}\right.$,

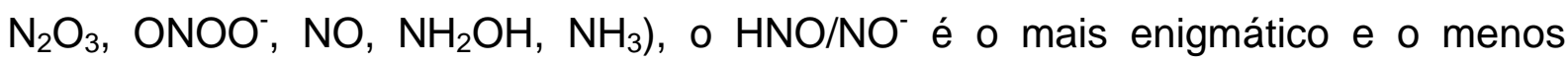
conhecido.

\section{1- Aspectos Gerais da Química do HNO}

Até alguns anos atrás, a espécie química HNO era de interesse exclusivamente acadêmico para químicos e microbiologistas e de pouco interesse para farmacologistas bioquímicos. $\mathrm{O}$ íon nitroxil, $\mathrm{NO}^{-}$, tornou-se farmacologicamente relevante quando revelaram a sua ação como inibidor da enzima aldeído deidrogenase e seu potencial para o tratamento antialcoolismo ${ }^{[19-20]}$.

Os nomes mais indicados para o HNO são hidreto de nitrosilo ou oxonitrato de hidrogênio (IUPAC), porém a maioria das literaturas utiliza os termos nitroxil para o HNO e ânion nitroxil para a espécie desprotonada NO', os quais serão utilizados neste trabalho.

Apesar de sua simplicidade estrutural, a detecção e a investigação da química do HNO, quando comparada a de outros óxidos de nitrogênio, são mais complicadas devido à sua elevada reatividade. Dentre as dificuldades para o estudo experimental do nitroxil em solução aquosa destaca-se a sua curta meia-vida, de 6-10 s (em pH 
fisiológico ou alcalino). Sua dimerização é rápida e espontânea, produzindo o ácido hiponitroso $\left(\mathrm{H}_{2} \mathrm{~N}_{2} \mathrm{O}_{2}\right)$, que se desidrata entre $\mathrm{pH} 2-11$, formando o óxido nitroso $\left(\mathrm{N}_{2} \mathrm{O} \text {, um agente anestésico comumente usado) e água (Equação } 1\right)^{[1,18]}$.

$$
2 \mathrm{HNO} \longrightarrow \underset{\mathrm{HO}}{\dot{N}} \dot{\mathrm{N}}=\mathrm{N}^{-\mathrm{OH}} \longrightarrow \mathrm{N}_{2} \mathrm{O}+\mathrm{H}_{2} \mathrm{O}
$$

A constante de velocidade específica de segunda ordem para a dimerização de HNO atualmente aceita é de $8 \times 10^{6} \mathrm{Lmol}^{-1} \mathrm{~s}^{-1[21]} \mathrm{sob}$ condições fisiológicas, a qual varia consideravelmente com a concentração de [NO]. Dessa forma, diferentemente das outras espécies de óxido de nitrogênio comumente estudadas, tais como, $\mathrm{NO}_{3}$, $\mathrm{NO}_{2}, \mathrm{NO}_{2}^{-}, \mathrm{NO}, \mathrm{ONOO}^{-}$e $\mathrm{NH}_{2} \mathrm{OH}$, o $\mathrm{HNO}$ não pode ser estocado ${ }^{[21]}$.

Devido à dimerização de HNO (Equação 1) dificultar o acesso direto desta espécie em sistemas químicos e biológicos, muitos dos estudos sobre a química e biologia do HNO utilizam moléculas doadoras de HNO, tais como nitrometano, $\mathrm{N}$ hidroxibenzenossulfonamida (Ácido de Piloty), ou o sal inorgânico $\mathrm{Na}_{2} \mathrm{~N}_{2} \mathrm{O}_{3}$ (Sal de Angeli, trioxodinitrato (N-N) (-2) (IUPAC), cujo ácido conjugado $\left(\mathrm{H}_{2} \mathrm{~N}_{2} \mathrm{O}_{3}\right)$ apresenta valores de $\mathrm{pK}_{\mathrm{a} 1 \text { e }} \mathrm{pK}_{\mathrm{a} 2}$ de 2,5 e 9,7, respectivamente ${ }^{[22-26]}$.

O sal de Angeli é o doador sintético mais comumente utilizado em estudos da química e efeitos farmacológicos do HNO em solução aquosa. O monoânion deste sal, $\mathrm{HN}_{2} \mathrm{O}_{3}{ }^{-}$, se decompõe entre pH 4-8 liberando espontaneamente HNO (Equação 2), no estado fundamental singleto, com uma meia vida de 2,1 min a $\mathrm{pH} 7,4$ e 37 ${ }^{\circ} C^{[27-28]}$.

$$
{ }_{-\mathrm{O}^{-}}^{\mathrm{H}} \mathrm{N}^{+}=\mathrm{N}_{-\mathrm{O}}^{-\mathrm{O}^{-}}=\mathrm{NO}^{-}+\mathrm{NO}_{2}^{-}+\mathrm{H}^{+}
$$


A velocidade das reações envolvendo o íon nitroxil normalmente é determinada pela velocidade de decomposição de suas espécies geradoras, sendo assim a concentração de íon nitroxil presente em solução sempre será incerta. Portanto, para uma melhor compreensão de HNO como um agente farmacológico, bem como para confirmar se as atividades biológicas observadas são realmente devido ao HNO, novos compostos liberadores de HNO necessitam ser desenvolvidos ${ }^{[29-31]}$ como alternativa ao sal de Angeli.

Mesmo o mais simples de todos os processos envolvendo o $\mathrm{HNO}$, a sua desprotonação, é relativamente complexo. A desprotonação de HNO produz a base conjugada $\mathrm{NO}^{-}$(Equação 3). Entretanto, o equilíbrio ácido-base do HNO não é típico devido ao par ácido-base conjugado ter diferentes estados de spin eletrônicos. 0 estado fundamental do $\mathrm{HNO}$ é o singleto, enquanto que o $\mathrm{NO}^{-}$tem a mesma configuração eletrônica do oxigênio molecular. Assim, possui um estado fundamental tripleto $\left({ }^{3} \mathrm{NO}^{-}\right)$e um estado excitado singleto $\left({ }^{1} \mathrm{NO}^{-}\right)$com uma energia de aproximadamente 17-20 kcal.mol ${ }^{-1}$ maior. Isso significa que a transferência de próton requer uma mudança no estado spin, a qual é proibida pela mecânica quântica ${ }^{[32-34]}$.

$$
{ }^{1} \mathrm{HNO}+\mathrm{H}_{2} \mathrm{O} \rightleftharpoons{ }^{3} \mathrm{NO}^{-}+\mathrm{H}_{3} \mathrm{O}^{+}
$$

Assim, a reação de protonação-desprotonação do nitroxil representa um processo proibido por spin e, por isso deve-se esperar uma baixa probabilidade de ocorrer, ou seja, a reação é cineticamente lenta comparada às reações normais de ácido-base (aquelas em que não ocorre a alteração de spin).

As propriedades do nitroxil aquoso ( $\mathrm{HNO}$ ) e seu ânion ( $\mathrm{NO}^{-}$) foram revisadas nos últimos anos demonstrando que o HNO é um ácido muito mais fraco $\left(\mathrm{p} K_{a}>\right.$ 
$11)^{[21]}$ do que se acreditavam $\left(\mathrm{p} K_{a}>4,7\right)^{[35]}$. Assim, considera-se atualmente que 0 ${ }^{1} \mathrm{HNO}$, e não ${ }^{3} \mathrm{NO}^{-}$ou ${ }^{1} \mathrm{NO}^{-}$, é a forma dominante de nitroxil em condições fisiológicas. Porém, o valor de $\mathrm{p} K_{\mathrm{a}}$ é pouco significativo para este sistema, que deve considerar a velocidade de desprotonação de $\mathrm{HNO}$ e de protonação de NO${ }^{-}$. Desde que ambas as espécies $\mathrm{HNO}$ e $\mathrm{NO}^{-}$são altamente reativas, todas as outras reações envolvendo essas espécies serão cineticamente favoráveis em relação à de transferência de próton. Portanto, uma vez formada, a espécie ${ }^{3} \mathrm{NO}^{-}$pode ter um tempo de vida significante (da ordem de milisegundos) antes da protonação, podendo ser capaz de participar de reações adversas ${ }^{[35]}$.

Desde que o HNO é o produto de redução de um elétron do NO, então é possível que a simples redução de NO possa resultar em sua formação ${ }^{[36-38]}$. Claramente, um fator importante na geração de HNO proveniente da redução de NO deve ser o potencial de redução monoeletrônica de NO recentemente determinado, situando-se na faixa de $-0,5$ a $-0,6 \vee(v s E N H)^{[17,21]}$ a $22 \stackrel{\circ}{\circ}$. Por outro lado, o potencial de redução para o par $\mathrm{NO}^{3} \mathrm{NO}^{-}$é mais desfavorável $(-0,8 \mathrm{~V} \text { vs } \mathrm{ENH})^{[17,21]} \mathrm{a}$ $22 \stackrel{\circ}{ } \mathrm{C}$. Assim, ao menos em princípio, propõem-se que a espécie HNO poderia ser formada pela redução direta de um elétron de NO em meio biológico, apesar da "proibição" de spin.

Além das espécies $\mathrm{HNO}$ e ${ }^{3} \mathrm{NO}$, existem outras espécies de nitroxil semelhantes em estrutura e estado spin. A protonação do ${ }^{3} \mathrm{NO}$ foi proposta para ocorrer no átomo de oxigênio (mais eletronegativo), formando o ${ }^{3} \mathrm{NOH}^{[1,21]}$. Porém, a única evidência experimental direta para a existência de ${ }^{3} \mathrm{NOH}$ foi obtida através da detecção de uma banda de IR em uma matriz de argônio sólido seguindo por uma descarga de microondas dentro de uma mistura $\mathrm{H}_{2} / \mathrm{NO} / \mathrm{Ar}$. Em contraste, a presença 
da espécie HNO foi observada espectroscopicamente na fase gasosa e em uma matriz de argônio 40 anos antes ${ }^{[38]}$. A Figura 1.4 ilustra as diferentes espécies de nitroxil ${ }^{[18]}$.

$$
{ }^{1} \mathrm{HNO} \stackrel{\mathrm{K}_{\mathrm{a} 1}}{\rightleftharpoons}{ }^{1} \mathrm{NO}^{-} \longrightarrow{ }^{3} \mathrm{NO}^{-} \stackrel{\mathrm{K}_{\mathrm{a} 2}}{\rightleftharpoons}{ }^{3} \mathrm{NOH} \longrightarrow{ }^{3} \mathrm{HNO} \longrightarrow{ }^{1} \mathrm{HNO}
$$

Figura 1.4 - Espécies de nitroxil

As espécies ${ }^{1} \mathrm{NO}^{-}$e ${ }^{3} \mathrm{NOH}$ não devem ser acessíveis biologicamente, visto que eles não podem ser gerados sob condições biológicas normais por processos térmicos. As energias relativas dessas espécies estão representadas na Figura $1.5^{[1]}$, mostrando que as espécies ${ }^{1} \mathrm{HNO}$ e ${ }^{3} \mathrm{NO}^{-}$são as mais estáveis em solução.

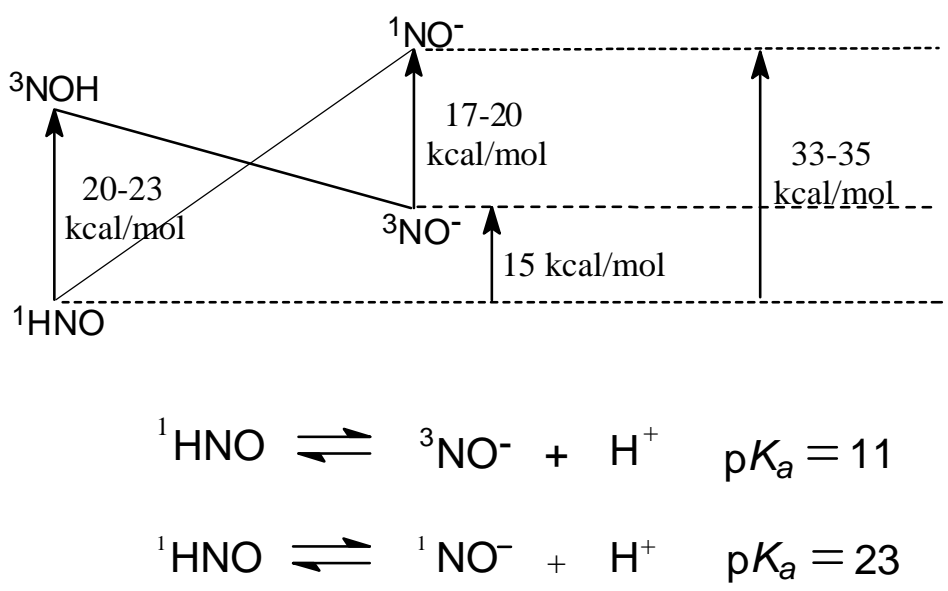

Figura 1.5 - Diagrama de energia das várias espécies de nitroxil em fase gasosa.

É estabelecido que o ânion nitroxil no estado fundamental tripleto, ${ }^{3} \mathrm{NO}$, pode reagir com $\mathrm{O}_{2}$ para formar o peroxinitrito, ${ }^{-} \mathrm{ONO}{ }^{[39-41]}$ (Equação 4), um oxidante forte, com uma constante de velocidade de segunda ordem de $2,7 \times 10^{9} \mathrm{~L} \cdot \mathrm{mol}^{-1} \cdot \mathrm{s}^{-1[27]}$ a $22 \stackrel{\circ}{\circ}$. 


$$
{ }^{3} \mathrm{NO}^{-}+{ }^{3} \mathrm{O}_{2} \longrightarrow \mathrm{ONOO}^{-}
$$

Porém, espera-se que baixas concentrações de $\mathrm{NO}^{-}$seja produzido por HNO em condições fisiológicas. Dessa forma, a reação de $\mathrm{HNO}$ com $\mathrm{O}_{2}$ apesar de relativamente lenta $\left(K_{a}=3 \times 10^{3} \mathrm{M}^{-1} \cdot \mathrm{s}^{-1}\right)^{[40]}$, é potencialmente mais relevante em sistemas biológicos, visto que esta espécie é a mais estável em meio fisiológico. A literatura sugere que a reação de $\mathrm{HNO}$ e $\mathrm{O}_{2}$ produz um potente oxidante de dois elétrons distinto do OONO${ }^{-[40,42]}$.

Os resultados de estudos das propriedades farmacológicas de doadores de HNO, como exemplo, o sal de Angeli ${ }^{[42]}$, indicam que o HNO quando administrado antes da isquemia atua como proteção para um subseqüente dano de reperfusão. $O$ dano de isquemia-reperfusão é um fenômeno pelo qual tecidos isquêmicos (ausentes de oxigênio) são altamente danificados quando o fornecimento de oxigênio é reestabelecido, possivelmente devido à formação de superóxido $\left(\mathrm{O}_{2}{ }^{-}\right)$e peróxido de hidrogênio $\left(\mathrm{H}_{2} \mathrm{O}_{2}\right)$. Neste caso, o óxido nítrico protege contra os danos de reperfusão, provavelmente por captação do superóxido. Entretanto, a administração de HNO durante a reperfusão agrava o dano de isquemiareperfusão ${ }^{[40,43-45]}$. Recentes descobertas de que o HNO possui a capacidade de aumentar a contração ventricular esquerda e, ao mesmo tempo, diminuir a sobrecarga cardíaca e a pressão diastólica sem aumentar a resistência arterial, faz com que o nitroxil seja um candidato ideal para o tratamento de ataque cardíaco, desde que aumente a contração cardíaca, enquanto diminui a resistência $\operatorname{vascular}^{[43]}$. 
Como o óxido nítrico, o nitroxil também tem sido ligado a processos de vasodilatação $^{[46]}$. Além disso, os estudos dos efeitos de HNO no sistema cardiovascular indicam que a sua ação é independente de NO e do monofosfato cíclico de guanosina (cGMP). Especificamente, o nitroxil estimula a liberação de peptídeos relacionados ao gene calcitonina (CGRP), a qual conduz a uma elevação de monofosfato cíclico de adenosina (MPAc) intracelular, enquanto que o óxido nítrico age através da ativação de guanilato ciclase solúvel (sCG) e elevações na concentração de $\mathrm{MPGc}^{[44]}$, como mostra a Figura 1.6.

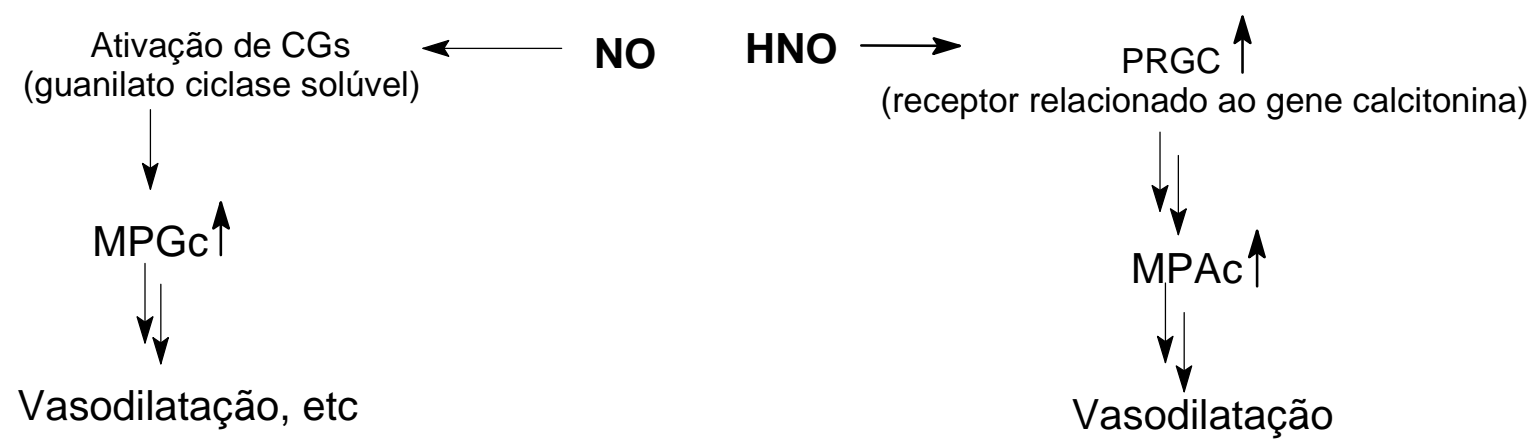

Figura 1.6 - Esquema das rotas de ação de $\mathrm{NO}$ e $\mathrm{HNO}^{[18]}$

Isso indica que o HNO deve agir (pelo menos em sistemas cardiovasculares) pela rota contendo monofosfato cíclico de adenosina (MPAc), a qual é fundamentalmente distinta da rota seguida pelo NO. Essa diferença fundamental entre as ações de HNO e NO têm sido descritas como "ortogonais", pois envolvem sistemas de mensageiros distintos, sugerindo que as ações de HNO não são simplesmente devido à sua conversão oxidativa a NO. Estes estudos indicam a capacidade do nitroxil atravessar a membrana celular e acessar o espaço intracelular $^{[47]}$.

Desde que a energia de ligação H-NO é somente de 48-50 kcal.mol ${ }^{-1}$, o HNO pode agir também como um bom doador de átomo de hidrogênio. Sendo assim, 
espera-se que o HNO possa ser um eficiente captador de radicais e/ou antioxidante através da doação do átomo de $\mathrm{H}$ e formação de $\mathrm{NO}^{[48]}$.

Como todos os agentes farmacológicos, o HNO também pode ter implicações toxicológicas associada com a sua administração. Pesquisadores revelaram que o HNO, derivado do sal de Angeli, é citotóxico para fibroblastos em concentrações milimolares do doador ${ }^{[1,49]}$, e causa danos aos sítios específicos de DNA, sendo este último independente de $\mathrm{O}_{2}$ (Equação 3), indicando que ONOO- não está envolvido neste processo ${ }^{[50]}$.

Por causa da natureza altamente reativa do nitroxil, sua detecção direta permanece difícil, sendo mais comumente identificado indiretamente por meio de seus produtos finais estáveis, por exemplo o $\mathrm{N}_{2} \mathrm{O}$. Por isso, a detecção de $\mathrm{N}_{2} \mathrm{O}$ tem sido usada como evidência da geração de HNO, devido à reação de dimerização (Equação 1). Entretanto, isso não é prova absoluta da intermediação de HNO, visto que $\mathrm{N}_{2} \mathrm{O}$ pode ser gerado por caminhos que não envolvem HNO livre, tais como via redução de $\mathrm{NO}^{[51]}$. Além disso, a formação de $\mathrm{N}_{2} \mathrm{O}$ é uma reação de segunda ordem e deve requerer altas concentrações de $\mathrm{HNO}$ para que a reação produza $\mathrm{N}_{2} \mathrm{O}$ em concentrações significativas.

Um dos primeiros detectores descritos para a identificação do nitroxil ocorre via reação com tetracianoniquelato, $\left[\mathrm{Ni}(\mathrm{CN})_{4}\right]^{2-}$, onde o íon $\mathrm{NO}^{-}$desloca o íon $\mathrm{CN}^{-}$no complexo citado, obtendo-se como produto a espécie níquel-nitroxil (Equação 5) ${ }^{[52]}$.

$$
\mathrm{Ni}(\mathrm{CN})_{4}{ }^{2-}+\mathrm{HNO}^{-\mathrm{NO}^{-}} \rightarrow \mathrm{NiNO}(\mathrm{CN})_{3}{ }^{2-}+\mathrm{HCN}^{-} \mathrm{CN}^{-}
$$

A formação do produto $\left[\mathrm{NiNO}(\mathrm{CN})_{3}\right]^{2-}$ é monitorado espectrofotometricamente a $\lambda=498 \mathrm{~nm}\left(\varepsilon=427 \mathrm{~L} \cdot \mathrm{mol}^{-1} \cdot \mathrm{cm}^{-1}\right)$. Entretanto, este processo não é eficiente, pois é 
dependente do $\mathrm{pH}$ e só ocorre em condições onde o pH está acima de 9,0, limitando-se com isso, a utilização de alguns nitrosilos complexos, que são instáveis em soluções de baixa concentração hidrogeniônicas ${ }^{[52]}$.

Baseado no potencial de redução para o $\mathrm{NO}$ (de $-0,5$ a $-0,8 \vee$ vs $\mathrm{ENH}$ ), o $\mathrm{HNO} /{ }^{3} \mathrm{NO}^{-}$pode agir como um poderoso redutor de um elétron. Por exemplo, a reação de HNO com o heme férrico resulta na geração do aduto nitrosil ferroso, em competição com a formação de $\mathrm{N}_{2} \mathrm{O}$, via nitrosilação redutiva (Equação 6) ${ }^{[44,53]} \mathrm{com}$ uma constante de velocidade de $8 \times 10^{5} \mathrm{M}^{-1} \cdot \mathrm{s}^{-1[53]}$ sob condições fisiológicas.

$$
\mathrm{Fe}^{\prime \prime \prime} \mathrm{Mb}+\mathrm{HNO} \longrightarrow \mathrm{Fe}^{\prime \prime}(\mathrm{NO}) \mathrm{Mb}+\mathrm{H}^{+}
$$

A formação de nitrosilmioglobina (MbNO) pode ser determinada pelo monitoramento espectrofotométrico do aumento de absorbância em 543 e 578 nm a

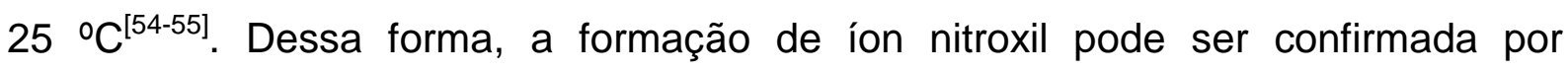
captação com metmioglobina ( $\mathrm{Fe}(\mathrm{III}))$, sendo este, portanto, o método que será utilizado neste trabalho. Outros métodos de detecção/captação de HNO têm sido estudados, tais como via reação com nitrosobenzeno ${ }^{[56-57]}$. Entretanto, não serão utilizados em nossos estudos.

\section{2- Compostos nitrosilos de rutênio}

Em nosso Grupo de pesquisa foram sintetizados complexos do tipo trans$\left[\mathrm{RuNO}\left(\mathrm{NH}_{3}\right)_{4} \mathrm{~L}\right]^{3+}$, onde $\mathrm{L}=$ isn, nic, py, 4-pic, L-Hist, imN, dentre outros ${ }^{[58]}$. Estes ligantes foram escolhidos considerando sua correspondente acidez e basicidade $\pi \mathrm{e}$ $\sigma$, a fim de modular em intensidades diferentes a interação Ru-NO ao longo do eixo L-Ru-NO. As vias de síntese estão bem definidas e os complexos apresentam características convenientes para sua aplicação como modelos de fármacos, pois 
são solúveis em água, estáveis em presença de oxigênio e apresentam moderada toxicidade. Além disso, como as amônias se comportam como ligantes inocentes é factível, em princípio, modelar as propriedades do ligante $\mathrm{NO}^{+}$em função do ligante L, situado em posição trans na esfera de coordenação do metal ${ }^{[59]}$.

O interesse farmacológico em se produzir substitutos para o nitroprussiato, composto utilizado como agente terapêutico devido à sua eficácia como vasodilatador, encoraja a síntese de compostos de coordenação que possam liberar ou captar o óxido nítrico de forma controlada. Esse interesse se deve ao fato de que o nitroprussiato de sódio libera íons cianeto, que é reconhecidamente tóxico, além de não permitir a modelagem de suas propriedades, por alteração em sua esfera de coordenação ${ }^{[60]}$. Dessa forma, a habilidade em liberar $\mathrm{NO}^{\bullet}$ por redução química, aliada à solubilidade dos compostos de rutênio sintetizados em nosso laboratório tornou claras as suas potencialidades como modelo de fármacos doadores de $\mathrm{NO}^{[61-}$ 62]. Assim sendo, a descoberta dos efeitos farmacológicos de HNO nos inspirou a investigar detalhadamente o potencial dos complexos de rutênio como liberadores de nitroxil.

Dentre os compostos, o complexo trans-[RuNO $\left.\left(\mathrm{NH}_{3}\right)_{4} \mathrm{P}(\mathrm{OEt})_{3}\right]\left(\mathrm{PF}_{6}\right)_{3}$ é o que se apresenta como candidato bastante promissor para o estudo de liberação de nitroxil, devido ao seu espectro eletroquímico, o qual indica claramente a existência de um segundo processo de redução após a formação da espécie trans$\left[\mathrm{RuNO}\left(\mathrm{NH}_{3}\right)_{4} \mathrm{P}(\mathrm{OEt})_{3}\right]^{2+}$. 


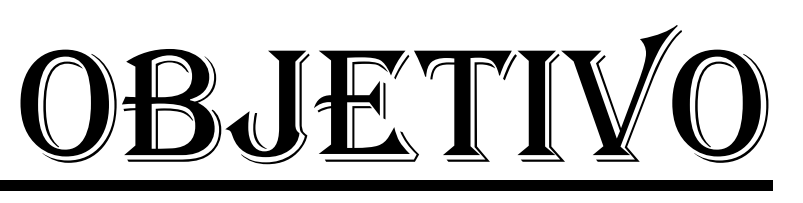




\section{OBJETIVOS}

Considerando o conhecimento acumulado em nossos estudos sobre nitrosilos, o presente visa estudar eletroquimicamente os íons complexos nitrosilos de rutênio sintetizados em nosso laboratório, tais como: trans$\left[\mathrm{RuNO}\left(\mathrm{NH}_{3}\right)_{4} \mathrm{~L}\right]^{3+}$, onde $\mathrm{L}=\mathrm{P}\left(\mathrm{OC}_{2} \mathrm{H}_{5}\right)_{3}$, piridina, imidazol, 4-picolina, nicotinamida, ou $[\mathrm{RuNO}(\text { cyclam })(\mathrm{Cl})]^{2+}$ e $[\mathrm{RuNO}($ Hedta $)]$, objetivando esclarecer o segundo processo de redução nos complexos supracitados. Com base nas características dos espectros voltamétricos, o composto trans$\left[\mathrm{RuNO}\left(\mathrm{NH}_{3}\right)_{4} \mathrm{P}\left(\mathrm{OC}_{2} \mathrm{H}_{5}\right)\right]\left(\mathrm{PF}_{6}\right)_{3}$ será escolhido para o estudo de liberação de HNO por possuir a segunda onda catódica mais bem definida e a potenciais menos negativos em relação aos demais complexos. Além disso, o efeito e influência trans do $\mathrm{P}\left(\mathrm{OC}_{2} \mathrm{H}_{5}\right)_{3}$ proporciona a rápida liberação do ligante $\mathrm{HNO} \mathrm{NO}^{-}$da esfera de coordenação da espécie gerada na segunda onda de redução. A investigação será conduzida através de técnicas eletroquímicas e espectroeletroquímicas.

A redução do complexo trans- $\left[\mathrm{RuNO}\left(\mathrm{NH}_{3}\right)_{4} \mathrm{P}\left(\mathrm{OC}_{2} \mathrm{H}_{5}\right)_{3}\right]^{3+}$ também será investigada utilizando-se um composto capaz de agir como um redutor ( $\alpha$ cetoglutarato), cujo potencial seja acessível à segunda onda de redução no complexo. Além disso, para avaliar a estabilidade da espécie contendo $\mathrm{HNO} \mathrm{NO}^{-}$coordenado ao metal no complexo trans-[RuNO$\left.\left(\mathrm{NH}_{3}\right)_{4} \mathrm{P}\left(\mathrm{OC}_{2} \mathrm{H}_{5}\right)_{3}\right]^{3+}$ será utilizado um composto capaz de reagir com o nitroxil liberado em solução. Para tanto, serão utilizadas técnicas eletroquímicas e espectroscópicas. 


\section{PARTE}

\section{EXPERIMENTAL}




\section{3- PARTE EXPERIMENTAL}

A água utilizada para a preparação das soluções foi previamente destilada e posteriormente deionizada por um sistema Milli-Q (Millipore), e todos os reagentes utilizados foram de pureza analítica (Aldrich, Sigma ou Merck). Quando necessário, realizou-se sua purificação conforme métodos descritos na literatura ${ }^{[61]}$.

\section{1- Reagentes e soluções}

- Argônio ${ }^{[64]}$

As preparações e os experimentos envolvendo complexos de rutênio foram sempre realizados sob atmosfera inerte, utilizando-se técnicas padrões para a manipulação de compostos sensíveis ao oxigênio. Assim sendo, utilizou-se argônio, de procedência White Martins, nestes experimentos. O fluxo de argônio utilizado nas operações de desaeração foi purificado para eliminar traços residuais de oxigênio, antes de chegar às soluções. Dessa forma, fazia-se o gás passar através de dois frascos lavadores contendo solução de $\mathrm{Cr}(\mathrm{II}) 0,3 \mathrm{molL}^{-1} \mathrm{em} \mathrm{CrCl}_{3}$ e $\mathrm{HCl} 0,5 \mathrm{molL}^{-1}$, previamente desaerada, com amálgama de zinco. A redução total dos íons $\operatorname{Cr}($ III) pelo amálgama de zinco e sob atmosfera de argônio foi efetivada após um período de 6 horas, constatada pela mudança da coloração verde para azul. Um terceiro frasco contendo ácido sulfúrico concentrado foi utilizado, a fim de eliminar a umidade presente no gás. Todos os compostos preparados foram estocados em dessecador, a vácuo, e na ausência de luz. 


\section{- Amálgama de zinco}

O amálgama de zinco foi preparado pela reação de uma solução saturada de cloreto de mercúrio (II) em $\mathrm{HClO}_{4} 0,05 \mathrm{molL}^{-1}$ com zinco metálico granulado, que foi previamente tratado com uma solução de $\mathrm{HClO}_{4} 4,0 \mathrm{molL}^{-1}$. Após 10 minutos, o amálgama foi separado da solução, lavado com água destilada, seco ao ar em papel de filtro e imediatamente utilizado após a sua preparação.

\section{- Solventes}

Éter etílico: Foi tratado com $\mathrm{CaCl}_{2}$ e sulfato ferroso amoniacal e destilado. Após a destilação foi adicionado, lentamente, fios de sódio metálico, permanecendo armazenado até cessar a evolução de bolhas de gás. Em seguida foi filtrado e novamente destilado.

Gás óxido nitroso: (99,9\% de pureza e de procedência White Martins) foi utilizado sem tratamento prévio.

Ácido trifluoroacético: $\left(\mathrm{CF}_{3} \mathrm{COOH} 99 \%\right.$ de pureza e de procedência Aldrich) foi usado na preparação de soluções com diversas finalidades: controle de $\mathrm{pH}$, sínteses e eletrólito de suporte.

Ligante trietilfosfito: $\left(\mathrm{P}(\mathrm{OEt})_{3}\right.$, de procedência Aldrich) foi destilado. O espectro de Ressonância Magnética Nuclear ${ }^{31} \mathrm{P}$ indicou ausência de fosfonados. $\mathrm{O}$ reagente foi então ampolado em frasco contendo $1 \mathrm{~mL}$ do ligante, ao abrigo da luz. Quando necessário, o ligante foi tratado com sódio metálico, seguido por destilação à pressão reduzida. Ao se observar uma forte banda em $1260 \mathrm{~cm}^{-1}$ por espectroscopia 
na região do infravermelho, a qual caracteriza uma ligação $\mathrm{P}=\mathrm{O}$, faz-se necessário tratar o ligante trietilfosfito com sódio metálico.

Composto tricloreto de rutênio: $\left(\mathrm{RuCl}_{3} \cdot \mathrm{xH}_{2} \mathrm{O}\right.$ de procedência Aldrich) foi empregado como reagente de partida na síntese do complexo cloreto de cloropentaaminrutênio (III) $\left(\left[\mathrm{Ru}\left(\mathrm{NH}_{3}\right)_{5} \mathrm{Cl}\right] \mathrm{Cl}_{2}\right)$.

Hexafluorofosfato de Amônio: $\left(\mathrm{NH}_{4} \mathrm{PF}_{6} 99 \%\right.$ de pureza e de procedência Aldrich), foi usado como contra íon nas sínteses dos complexos de rutênio.

Composto a-cetoglutarato: $\left(\mathrm{Na}_{2} \mathrm{C}_{5} \mathrm{H}_{4} \mathrm{O}_{5} 99,5 \%\right.$ de pureza e procedência Acros Organics) foi utilizado na reação com o complexo de rutênio, sem qualquer tratamento prévio.

Metmioglobina ${ }^{[65]}$ : foi preparada por oxidação de mioglobina de músculo de esqueleto do cavalo (95-100\%) em pH 4,2 e tampão acetato $0,1 \mathrm{molL}^{-1}$, com um excesso de ferricianeto de potássio ( $5 \%$ molar) no mesmo tampão. $O$ excesso de ferricianeto foi removido por filtração da solução em uma coluna cromatográfica por exclusão de tamanho Sephadex G-25, equilibrada em pH 4,2 em tampão acetato 0,1 $\mathrm{molL}^{-1}$. Depois de filtrada, alíquotas foram armazenadas na geladeira por três dias ao máximo, em ausência de luz.

\section{- Eletrólito de Suporte}

A força iônica das soluções foi mantida utilizando trifluoroacetato de sódio, $\mathrm{NaCF}_{3} \mathrm{COO}$. A solução deste sal foi preparada a partir do ácido trifluoracético (Aldrich), e de hidróxido de sódio (Merck). Os dois reagentes padronizados foram misturados em quantidades suficientes para se ter uma solução estoque com a 
concentração em $0,1 \mathrm{molL}^{-1}$. $\mathrm{O}$ valor do $\mathrm{pH}$ desejado em cada experimento foi ajustado pela adição de uma solução de hidróxido de sódio $1,0 \mathrm{molL}^{-1}$ e/ou ácido trifluoracético $1,0 \mathrm{molL}^{-1}$.

\section{- Formação de NO}

$\mathrm{O}$ gás $\mathrm{NO}$ foi produzido pela adição de $\mathrm{H}_{2} \mathrm{SO}_{4}$, proveniente de um funil de separação, em $\mathrm{NaNO}_{2}$ sólido, contido em um erlenmeyer. O gás formado foi forçado a passar através de um vaso lavador contendo $\mathrm{NaOH}$ concentrado para remover traços de $\mathrm{NO}_{2}$ e, em seguida, foi borbulhado através de um outro frasco contendo água destilada, a fim de remover a possível presença de $\mathrm{NaOH}$ carregado pelo gás.

\section{- Óxido de Deutério $\left(D_{2} O\right)$}

O óxido de deutério, 99,8 \% de pureza e de procedência Aldrich, foi utilizado como solvente nos experimentos de ressonância magnética nuclear de fósforo.

\section{2- Sínteses}

Os compostos trans-[RuNO(NH$\left.)_{4}(\mathrm{~L})\right]\left(\mathrm{BF}_{4}\right)_{3}$, onde $\mathrm{L}=\mathrm{imN}$, 4-pic, py e nic, já são conhecidos e foram sintetizados seguindo procedimentos descritos na literatura ${ }^{[58]}$, a partir dos compostos precursores $\left[\mathrm{Ru}\left(\mathrm{NH}_{3}\right)_{5} \mathrm{Cl}_{\mathrm{Cl}} \mathrm{Cl}_{2}^{[58]}\right.$, trans$\left[\mathrm{Ru}\left(\mathrm{NH}_{3}\right)_{4}\left(\mathrm{HSO}_{3}\right)_{2}\right]^{[66]}$, trans- $\left.\left[\mathrm{Ru}\left(\mathrm{NH}_{3}\right)_{4} \mathrm{SO}_{2} \mathrm{Cl}\right] \mathrm{Cl}\right|^{[66]}$ e trans-[Ru( $\left.\left(\mathrm{NH}_{3}\right)_{4}\left(\mathrm{SO}_{4}\right) \mathrm{L}\right]\left.\mathrm{Cl}\right|^{[58,67]}$.

O composto [RuNOHedta] foi sintetizado a partir dos precursores $\mathrm{K}_{2}\left[\mathrm{RuCl}_{5} \mathrm{H}_{2} \mathrm{O}\right] \mathrm{e}$ K[RuHedtaCl], de acordo com a literatura ${ }^{[68-69]}$. O composto $[\mathrm{Ru}(\mathrm{NO}) \mathrm{Cl}(\mathrm{cyclam})]\left(\mathrm{PF}_{6}\right)_{2}{ }^{[70,71]}$ foi gentilmente cedido pelo prof. Dr. Elia Tfouni Faculdade de Filosofia, Ciências e Letras de Ribeirão Preto, Universidade São Paulo. O composto trans- $\left[\mathrm{RuNO}\left(\mathrm{NH}_{3}\right)_{4} \mathrm{P}(\mathrm{OEt})_{3}\right]\left(\mathrm{PF}_{6}\right)_{3}$ foi sintetizado conforme descrito abaixo. 


\section{- $\left[\mathrm{Ru}\left(\mathrm{NH}_{3}\right)_{5} \mathrm{Cl}_{\mathrm{Cl}} \mathrm{Cl}_{2}^{[58]}\right.$}

2,0 g de $\mathrm{RuCl}_{3} \cdot \mathrm{xH}_{2} \mathrm{O}$ foram dissolvidos em $27,0 \mathrm{~mL}$ de água destilada. A seguir, adicionou-se cuidadosamente $26,0 \mathrm{~mL}$ de hidrato de hidrazina $\left(\mathrm{NH}_{2} \mathrm{NH}_{2} . \mathrm{xH}_{2} \mathrm{O}\right)$ sob agitação constante e em banho de gelo. A mistura permaneceu reagindo por 6 horas e, em seguida, adicionou-se $50,0 \mathrm{~mL}$ de $\mathrm{HCl}$ concentrado, sob banho de gelo e agitação. A solução foi refluxada por 2 horas, ocorrendo a formação de um precipitado amarelo. A mistura foi resfriada, o sólido filtrado e lavado por diversas vezes com $\mathrm{HCl} 1,5 \mathrm{moll}^{-1}$ gelado.

Recristalização: O sólido obtido foi dissolvido em 200,0 mL de $\mathrm{HCl}$ 0,1 $\mathrm{molL}^{-1}$ a quente $\left(50-60^{\circ} \mathrm{C}\right)$, e a solução resultante foi filtrada a quente após completa dissolução. $\mathrm{O}$ sólido foi reprecipitado pela adição de excesso de $\mathrm{HCl}$ concentrado à solução, ainda a quente, em banho de gelo. O sólido amarelo formado foi filtrado, seco à vácuo e estocado ao abrigo da luz.

\section{- $\left[\mathrm{Ru}\left(\mathrm{NH}_{3}\right)_{5} \mathrm{H}_{2} \mathrm{O}\right]\left(\mathrm{PF}_{6}\right)_{2}{ }^{[72]}$}

Adicionou-se 0,2 $\mathrm{g}$ de $\left[\mathrm{Ru}\left(\mathrm{NH}_{3}\right)_{5} \mathrm{Cl}_{3} \mathrm{Cl}_{2}\right.$ e algumas pastilhas de amálgama de zinco a 7,0 mL de uma solução aquosa, previamente desoxigenada, de $\mathrm{CF}_{3} \mathrm{COOH}$ 0,01 $\mathrm{molL}^{-1}$. Após 1 hora de reação, sob fluxo de argônio, o amálgama reduz o Ru (III) a Ru (II), sendo o íon cloreto substituído pela água rapidamente. A solução adquiriu uma coloração amarelo claro. A seguir, adicionou-se $1,0 \mathrm{~g}$ de $\mathrm{NH}_{4} \mathrm{PF}_{6} \mathrm{e}$ filtrou-se o precipitado amarelo em glove-bag. O sólido foi lavado com etanol e secado a vácuo durante 15-20 minutos e usado posteriormente. 


\section{- trans- $\left[\mathrm{Ru}\left(\mathrm{NH}_{3}\right)_{4}\left(\mathrm{P}\left(\mathrm{OEt}_{3}\right)_{2}\right]\left(\mathrm{PF}_{6}\right)_{2}{ }^{[72]}\right.$}

Em um frasco borbulhador, colocou-se $10,0 \mathrm{~mL}$ de acetona, previamente desoxigenada por 30 minutos, e adicionou-se $0,2 \mathrm{~g}$ de $\mathrm{t}-\left[\mathrm{Ru}\left(\mathrm{NH}_{3}\right)_{5} \mathrm{H}_{2} \mathrm{O}\right]\left(\mathrm{PF}_{6}\right)_{2}$, recentemente preparado, e 1,0 $\mathrm{mL}$ de trietilfosfito, $\left(\mathrm{P}(\mathrm{OEt})_{3}\right)$. A mistura permaneceu reagindo, sob fluxo de argônio, por aproximadamente 1 hora. $O$ excesso de acetona foi eliminado empregando-se o evaporador rotatório, formando o bifosfito complexo, trans- $\left[\mathrm{Ru}\left(\mathrm{NH}_{3}\right)_{4}\left(\mathrm{P}\left(\mathrm{OEt}_{3}\right)_{2}\right]^{2+}\right.$. O sólido amarelo claro foi precipitado com a adição de uma mistura éter-etanol 2:1. O sólido foi filtrado e lavado com uma mistura de éter/etanol, para a eliminação do excesso de ligante, secado e estocado a vácuo, ao abrigo da luz.

\section{- trans- $\left[\mathrm{RuNO}\left(\mathrm{NH}_{3}\right)_{4} \mathrm{P}(\mathrm{OEt})_{3}\right]\left(\mathrm{PF}_{6}\right)_{3}{ }^{[73]}$}

$200 \mathrm{~mL}$ de $\mathrm{CF}_{3} \mathrm{COOH}$ 0,001 mol. $\mathrm{L}^{-1}$ foram desoxigenados sob fluxo de argônio por aproximadamente 3 horas. Em seguida, adicionou-se $0,2 \mathrm{~g}$ de trans$\left[\mathrm{Ru}\left(\mathrm{NH}_{3}\right)_{4}\left(\mathrm{P}(\mathrm{OEt})_{3}\right)_{2}\right]\left(\mathrm{PF}_{6}\right)_{2}$. A mistura permaneceu em reação a $40{ }^{\circ} \mathrm{C}$ por 5 horas, sob fluxo de argônio. Sob estas condições forma-se 0 íon t$\left[\mathrm{Ru}\left(\mathrm{NH}_{3}\right)_{4}\left(\mathrm{P}\left(\mathrm{OEt}_{3}\right)_{2} \mathrm{H}_{2} \mathrm{O}\right]^{2+[58,74]}\right.$, cuja formação foi acompanhada por Espectroscopia na região do UV-Visível, através da formação da banda em $316 \mathrm{~nm}\left(\varepsilon=650 \mathrm{Lmol}^{-}\right.$ $\left.{ }^{1} \mathrm{~cm}^{-1}\right)^{[74]}$. Evaporou-se o excesso de solvente em evaporador rotatório, à aproximadamente $40^{\circ} \mathrm{C}$, até atingir o volume de aproximadamente $3,0 \mathrm{~mL}$. A esta mistura adicionou-se 2,0 mL de $\mathrm{CF}_{3} \mathrm{COOH}$ 2,0 molL $^{-1}$, para acidificar o meio. Sob constante fluxo de argônio, adicionou-se $0,2 \mathrm{~g}$ de $\mathrm{NaNO}_{2}$. A solução adquiriu imediatamente uma coloração rósea. Esta mistura permaneceu em reação por 30 minutos. Em seguida, adicionou-se $0,15 \mathrm{~g}$ de $\mathrm{NH}_{4} \mathrm{PF}_{6}$ e deixou-se no refrigerador até a formação de um sólido cristalino róseo. O precipitado foi filtrado, lavado com éter, 
previamente desoxigenado, seco e estocado a vácuo e ao abrigo da luz. O composto é solúvel em água e etanol, e insolúvel em éter etílico e clorofórmio.

Todos os compostos foram caracterizados por: espectroscopia na região do UV-Visível e do infravermelho, ressonância paramagnética de elétrons e técnicas voltamétricas.

\section{3- Metodologia Experimental}

- Espectroscopia Eletrônica nas Regiões do Ultravioleta e Visível

As medidas nas regiões do visível e ultravioleta foram realizadas em um espectrofotômetro Hittachi modelo 3501-U, utilizando-se células de quartzo com caminho óptico de $1,0 \mathrm{~cm}$ adaptadas com rolhas de borracha. As análises foram feitas sob atmosfera inerte, com as cubetas cujas extremidades superiores foram vedadas por uma rolha de borracha, a qual permitia a passagem de um tubo de teflon ("tygon"), para a transferência da solução. A temperatura foi mantida constante $(20,0 \pm 0,2)^{\complement} \mathrm{C}$ com o auxílio de um termostato da ma rca Superhom de fabricação nacional. As medidas foram realizadas pela leitura direta dos espectros utilizando-se como branco o respectivo solvente.

\section{- Espectroscopia Vibracional na Região do Infravermelho vs Potencial}

As medidas de espectro vibracional vs potencial foram realizadas no laboratório de Eletroquímica, do Instituto de Química de São Carlos, sob supervisão da prof ${ }^{a}$. Dra. Tereza Benita Iwasita, utilizando-se de um sistema Potentioscan Wenking, modelo POS 73 e um espectrofotômetro BOMEM FTIR modelo NEXUS 870 MB-102, equipado com um acessório de reflectância especular de ângulo variável e um detector. Os espectros foram obtidos a partir de amostras líquidas (solução aquosa 
de $\mathrm{NaCF}_{3} \mathrm{COO}$ ) em $\mathrm{pH}=3,0$ força iônica $0,1 \mathrm{molL}^{-1}$ e a temperatura ambiente. $\mathrm{A}$ solução foi desaerada com gás nitrogênio. Neste experimento foi utilizado um sistema composto por três eletrodos: eletrodo de carbono vítreo como eletrodo de trabalho, eletrodo de hidrogênio como referência e eletrodo de platina como auxiliar. O ângulo incidente foi ajustado para $27^{\circ}$. Um total de 50 varreduras interferométrica com resolução de $8 \mathrm{~cm}^{-1}$, que foram acumuladas para um espectro médio nos experimentos de FT-IR, a cada etapa de potencial. O espectro resultante foi normalizado como a Equação 7 sugere.

$$
\frac{\Delta R}{R}=\frac{\left[R\left(E_{s}\right)-R\left(E_{R}\right)\right.}{R\left(E_{R}\right)}
$$

Onde $E_{S}, E_{R}$ representam o potencial aplicado sob a amostra e o potencial de referência, e $R\left(E_{S}\right)$ e $R\left(E_{R}\right)$ representa o espectro de feixe simples obtido a $E_{S}$ e $E_{R}$, respectivamente. Pela subtração do espectro de reflexão ao potencial da amostra, $R\left(E_{S}\right)$, do espectro de reflexão ao potencial de referência, $R\left(E_{R}\right)$, o "background" devido à absorção do solvente é eliminado. Conseqüentemente, um sinal no sentido negativo e um no sentido positivo de bandas indicam o aumento e a diminuição em intensidade de transmissão das bandas a $E_{S}$, respectivamente ${ }^{[75-76]}$.

\section{- Espectroscopia de Ressonância Magnética Nuclear}

As medidas de ressonância magnética nuclear $\left(R M N{ }^{31} \mathrm{P}\right)$ foram realizadas obtidas empregando-se um espectrômetro Bruker, modelo AC 200, munido de magneto 4,7 T. Os espectros de $R M N{ }^{31} \mathrm{P}$ foram obtidos em solução de água deuterada e trifluoroacetato de sódio em $\mathrm{pH} 3,0$. Os experimentos foram realizados na Universidade Federal de São Carlos, pelo aluno Gustavo Von Poelhsitz. 
As soluções foram desaeradas por 30 minutos e transferidas via "tygon" para o interior do tubo de RMN, previamente desaerado.

\section{- Voltametria Cíclica e de Pulso Diferencial}

As técnicas de voltametria cíclica e de pulso diferencial foram empregadas para o estudo preliminar da segunda redução eletrônica dos complexos de rutênio sintetizados pelo nosso grupo de pesquisa. De início, os experimentos consistiram em testes com diferentes compostos, no intervalo de potencial adequado a cada um, com o intuito de avaliar a resposta voltamétrica. Nestes experimentos, os voltamogramas cíclicos foram registrados no intervalo de 1,0 a -1,2 V vs eletrodo de calomelano saturado (ECS), empregando-se o sistema eletroquímico EG\&G Princeton Applied Research - Modelo 264 A.

A célula eletroquímica, munida com camisa para circulação de água termostatizada, era constituída por três eletrodos: um eletrodo de calomelano saturado como referência, um fio de platina como auxiliar e um eletrodo de carbono vítreo como eletrodo de trabalho. Um tubo para entrada de argônio foi adaptado na tampa da célula de forma que, atingisse a solução antes das medidas, e na superfície da solução durante o registro dos voltamogramas cíclicos (Figura 3.1). Uma solução de $\mathrm{HCF}_{3} \mathrm{COO} / \mathrm{NaCF}_{3} \mathrm{COO} 0,1 \mathrm{molL}^{-1} \mathrm{em} \mathrm{pH}=3,0$ foi usada como eletrólito. Os voltamogramas foram registrados em um programa desenvolvido pela MICROQUÍMICA Ind. Com. e Rep. LTDA.

Os experimentos foram realizados a $(25,0 \pm 0,2){ }^{\circ} \mathrm{C}$ e a $(2,5 \pm 0,2){ }^{\circ} \mathrm{C}$, mantendo-se a temperatura constante com o auxílio de um banho termostatizado. 


\section{- Voltametria de Onda Quadrada}

As medidas de voltametria de onda quadrada foram realizadas no laboratório de Materiais Eletroquímicos e Métodos Eletroanalíticos do Instituto de Química de São Carlos, por Andréia Renata Malagutti. O experimento foi conduzido nas mesmas condições utilizadas para a realização das medidas de Voltametria Cíclica. Para isso foi utilizado o sistema Potenciostato/Galvanostato Autolab, modelo PGSTAT 12/30/302 acoplado ao programa GPES Manager - General Purpose, Electrochemical System version 4.9.

Um passo importante para a realização do experimento foi a otimização dos parâmetros que possam influenciar na resposta voltamétrica. Para isto foi realizado um teste dos parâmetros da voltametria de onda quadrada, como freqüência da onda quadrada $(f)$, amplitude da onda quadrada $\left(\Delta \mathrm{E}_{\mathrm{p}}\right)$ e incremento de varredura $\left(\Delta \mathrm{E}_{\mathrm{s}}\right)$, buscando, desta forma, o melhor sinal analítico.

\section{- Medidas de pH}

As medidas de $\mathrm{pH}$ foram realizadas utilizando-se de um pHmetro, ION ANALYSER modelo PHM250 Meter Lab - Radiometer Analitical - Copenhagem, equipado com eletrodo de vidro, combinado com um eletrodo de referência $\mathrm{Ag} / \mathrm{AgCl}$, em KCl $3 \mathrm{molL}^{-1}$. 


\section{- Decomposição Gaussiana}

Quando necessário, para uma melhor interpretação, os voltamogramas foram submetidos à decomposição gráfica empregando-se o programa do Microcal Origin 6.0. As deconvoluções foram realizadas mediante condição de retorno, assumindose formas gaussianas para as componentes individuais dos voltamogramas.

\section{4- Métodos e Cálculos}

\section{- Voltametria Cíclica ${ }^{[77-79]}$}

A voltametria é uma técnica eletroquímica onde as informações qualitativas e quantitativas de uma espécie química são obtidas a partir do registro de curvas corrente-potencial, feitas durante a eletrólise dessa espécie em uma cela eletroquímica constituída de pelo menos dois eletrodos, o eletrodo de trabalho e o eletrodo de referência. O potencial é aplicado entre os dois eletrodos em forma de varredura, isto é, variando-o a uma velocidade constante em função do tempo. O potencial e a corrente resultante são registrados simultaneamente. A curva corrente vs potencial obtida é denominada de voltamograma.

As técnicas voltamétricas permitem extrair vários parâmetros importantes para o estudo do comportamento de vários compostos inorgânicos, dentre eles o grau de reversibilidade da reação, a ocorrência ou não de processos adsortivos na superfície do eletrodo e o número de prótons e elétrons envolvidos na reação. Sendo assim, a técnica de voltametria cíclica foi utilizada neste estudo e os parâmetros eletroquímicos foram obtidos diretamente dos voltamogramas cíclicos, ou seja, das curvas de corrente (i) versus potencial (E). 


\section{- Voltametria de Onda Quadrada ${ }^{[79-82]}$}

Uma das técnicas eletroquímicas selecionadas para 0 estudo do comportamento eletroquímico do íon complexo trans-[Ru( $\left.\left(\mathrm{NH}_{3}\right)_{4} \mathrm{P}(\mathrm{OEt})_{3} \mathrm{NO}\right]^{3+}$ foi a voltametria de onda quadrada (VOQ). Na voltametria de onda quadrada, a forma do pico de corrente resultante é proveniente da aplicação de pulsos de potenciais de altura $\Delta \mathrm{E}_{\mathrm{p}}$ (amplitude de pulso), que variam de acordo com uma escada de potencial com largura $\Delta \mathrm{E}_{\mathrm{s}}$ (incremento de potencial).

As curvas de corrente-potencial apresentam perfil bem definido e são, geralmente, simétricas, porque as correntes elétricas são medidas somente no final de cada semiperíodo (final dos pulsos diretos e reversos). A diferença entre duas leituras sucessivas $\left(i=i_{1}-i_{2}\right)$, corrente resultante $(\Delta i)$, que é um sinal obtido diferencialmente, é registrado como uma função do potencial de cada período de meia onda. Isso faz com que a técnica apresente excelente sensibilidade e baixa influência das correntes capacitivas. Esta medida precede um tempo inicial $\left(\mathrm{t}_{\mathrm{i}}\right)$ que é onde o eletrodo de trabalho é polarizado a um potencial onde a reação redox não ocorre. As variações na altura e na largura do pulso de potencial são sempre constantes para um determinado intervalo de potenciais.

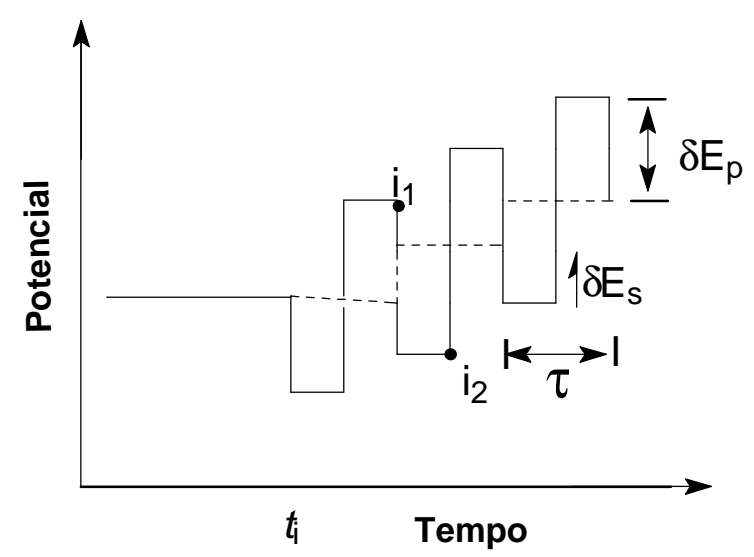

Figura 2.1 - Forma da onda tempo/potencial para a voltametria de onda quadrada, mostrando a escada de potencial, $E_{s}$, o potencial de pulso, $E_{p}$, e o tempo entre as escada aplicadas. 
$\mathrm{O}$ incremento de potencial $\left(\Delta \mathrm{E}_{\mathrm{s}}\right)$ é um dos responsáveis pela definição da velocidade de varredura de potenciais, visto que esta é dada pelo produto do incremento de potencial pela freqüência de aplicação dos pulsos de potencial.

A corrente de pico $\left(i_{p}\right)$ apresenta uma relação linear com a freqüência de aplicação do pulso de potencial $(f)$, se a reação for totalmente irreversível (Equação 8):

$$
\mathrm{i}_{\mathrm{p}}=K_{r} f
$$

Para os potenciais de pico em reações redox totalmente irreversíveis, existe uma relação linear entre $\left(E_{p}\right)$ e o logaritmo da freqüência, com uma inclinação de :

$$
\frac{\delta \mathrm{E}_{\mathrm{p}}}{\delta \log (f)}=\frac{-2,3 \mathrm{RT}}{\alpha \mathrm{nF}}
$$

onde $\mathrm{R}$ é a constante dos gases, $\mathrm{T}$ é a temperatura, $\alpha$ o coeficiente de transferência eletrônica, $n$ o número de elétrons envolvidos na transferência eletrônica e F a constante de Faraday.

Esta metodologia possibilita uma varredura completa do potencial em curto intervalo de tempo, se comparado a técnicas tradicionais como a voltametria de pulso diferencial, além de minimizar ao máximo os efeitos da corrente capacitiva. Além disso, observando-se o sinal de corrente obtidos nas varreduras direta e inversa é possível conseguir as mesmas informações da voltametria cíclica e, assim, analisar o mecanismo de redução eletroquímica trans- $\left[\mathrm{RuNO}\left(\mathrm{NH}_{3}\right)_{4} \mathrm{P}\left(\mathrm{OC}_{2} \mathrm{H}_{5}\right)_{3}\right]^{3+}$ pela variação dos parâmetros voltamétricos. 


\section{- Cálculos Teóricos}

Todos os cálculos teóricos das espécies trans-[Ru(NH$\left.\left.)_{3}\right)_{4} \mathrm{P}(\mathrm{OEt})_{3} \mathrm{~L}\right]^{\mathrm{n}}$, onde $\mathrm{L}=$ $\mathrm{NO}^{+}, \mathrm{NO}, \mathrm{NO}^{-}$e HNO foram realizadas no Instituto de Química de São Carlos, por Francisco das Chagas, usando o programa Gaussian $03^{[83]}$. Os cálculos teóricos foram realizados com o intuito de verificar o provável sítio de redução da espécie trans- $\left[\mathrm{Ru}\left(\mathrm{NH}_{3}\right)_{4} \mathrm{P}(\mathrm{OEt})_{3} \mathrm{NO}\right]^{2+}$. Inicialmente foram desenvolvidos cálculos da geometria no vácuo em nível de Teoria de Densidade Funcional (DFT) utilizando o funcional híbrido B3LYP com o conjunto de base LanL2DZ. Com as estruturas otimizadas no vácuo, realizaram-se cálculos levando em consideração o efeito do solvente. O modelo utilizado foi o modelo de polarização continua (Polarized Continuum Model - PCM ${ }^{[84-85]}$. Esse modelo define a cavidade como a união de uma serie de esferas atômicas entrelaçadas. O efeito da polarização do solvente é representado numericamente e computado por uma integração numérica. A água foi utilizada como solvente no presente trabalho. Os cálculos foram realizados sem imposição de simetria $C_{1}$ para todos os complexos. Os Cálculos de freqüência foram realizados para verificar o verdadeiro estado de mínimo das estruturas otimizadas. Os cálculos dos orbitais naturais de ligação foram realizados utilizando o programa NBO $3.0^{[86]}$, como está implementado o programa Gaussian 03. Os orbitais de fronteiras, HOMO e LUMO, foram representados pelo programa de visualização Gauss View, versão $3.09^{[87]}$. Os métodos que utilizam orbitais moleculares têm sido utilizados nos cálculos de diversos parâmetros de interesse químico. Dentre estes parâmetros dois são muito utilizados em estudos das relações estrutura-atividade: energia do HOMO ("Highest Occupied Molecular Orbital" - orbital molecular ocupado de mais alta energia) e energia do LUMO ("Lowest Unoccupied Molecular Orbital” orbital molecular desocupado de menor energia). 


\section{RESULTADOS E}

DISCUSS $\tilde{A} 0$ 


\section{4- RESULTADOS E DISCUSSÕES}

\section{1 - Perfil voltamétrico do íon complexo trans-[RuNO $\left.\left(\mathrm{NH}_{3}\right)_{4} \mathrm{P}\left(\mathrm{OC}_{2} \mathrm{H}_{5}\right)_{3}\right]^{3+}$}

A técnica de voltametria cíclica (VC) foi empregada para a avaliação preliminar da reação de redução dos complexos nitrosilos de rutênio, a fim de se familiarizar com os seus respectivos espectros voltamétricos. Em particular, o interesse inicial era de verificar quais dentre esses compostos possuem um segundo processo de redução acessível aos redutores biológicos. Os voltamogramas mostraram que o íon complexo trans-[RuNO $\left.\left(\mathrm{NH}_{3}\right)_{4} \mathrm{P}\left(\mathrm{OC}_{2} \mathrm{H}_{5}\right)_{3}\right]^{3+}$ apresenta uma segunda onda de redução bem definida e a potencial menos negativo em relação aos demais compostos.

A Figura 4.1 apresenta o perfil voltamétrico do íon complexo trans$\left[\mathrm{RuNO}\left(\mathrm{NH}_{3}\right)_{4} \mathrm{P}\left(\mathrm{OC}_{2} \mathrm{H}_{5}\right)_{3}\right]^{3+}$.

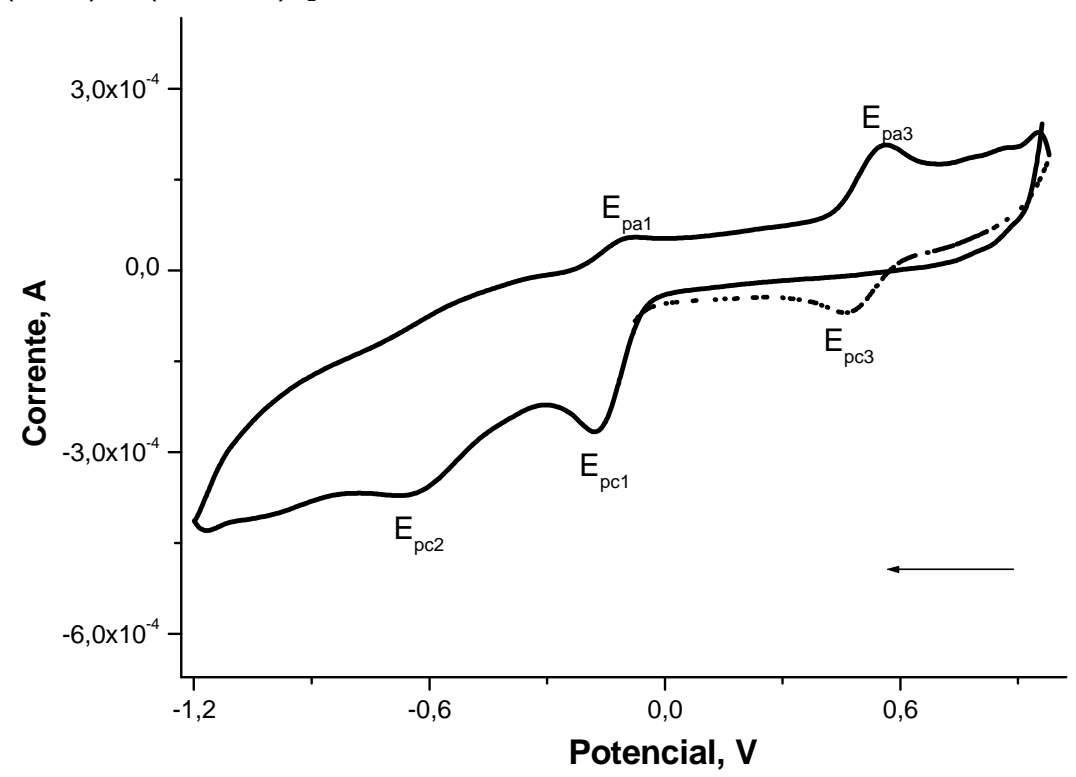

Figura 4.1 - Voltamograma cíclico do íon complexo trans-[RuNO $\left.\left(\mathrm{NH}_{3}\right)_{4} \mathrm{P}\left(\mathrm{OC}_{2} \mathrm{H}_{5}\right)_{3}\right]^{3+}$ em solução de $\mathrm{CF}_{3} \mathrm{COOH} / \mathrm{NaCF}_{3} \mathrm{COO}$, mostrando o perfil voltamétrico. (-) primeira varredura; (...) segunda varredura. Condições: $\mathrm{pH}=3,0 ; \mu=0,1 \mathrm{~mol} . \mathrm{L}^{-1} ; \mathrm{C}_{\mathrm{Ru}}=1,3 \times 10^{-3}$ mol. $\mathrm{L}^{-1}, \mathrm{v}=0,1 \mathrm{~V} . \mathrm{s}^{-1} ; \mathrm{T}=25^{\circ} \mathrm{C}$; eletrodo de trabalho: carbono vítreo. 
Pode-se observar neste voltamograma a existência de três processos no intervalo de potencial de 1,0 a -1,2 V em soluções cujo pH varia de 1,0 a 3,0: o pico catódico $E_{p c 1}$ em $-0,18$ V vs ECS, é atribuído à redução reversível da espécie $\left[\mathrm{RuNO}^{+}\right]^{3+}$ a $[\mathrm{RuNO}]^{2+} \mathrm{e}$ o pico catódico $E_{p a 1}$ à oxidação do processo inverso; o pico catódico $E_{p c 2}$ em -0,69 V vs ECS, não relatado na literatura, será tentativamente atribuído ao processo de redução $\left[\mathrm{RuNO}^{\circ}\right]^{2+}$ a [RuNO$]^{+}$no decorrer deste trabalho; e um terceiro pico anódico ( $\left.\mathrm{E}_{\mathrm{pa} 3}\right)$ em $0,55 \mathrm{~V}$ vs ECS que é referente à oxidação do par redox $\left[\mathrm{Ru}^{\text {Il }} \mathrm{H}_{2} \mathrm{O}\right]^{2+} /\left[\mathrm{Ru}^{\text {III }} \mathrm{H}_{2} \mathrm{O}\right]^{3+}$ formado, o qual pode-se observar em uma segunda varredura, o pico catódico do processo inverso, $\left[\mathrm{Ru}^{\prime \prime \prime} \mathrm{H}_{2} \mathrm{O}\right]^{3+} /\left[\mathrm{Ru}^{\prime \prime} \mathrm{H}_{2} \mathrm{O}\right]^{2+}$. A faixa de concentração hidrogeniônica em experimentos utilizando este complexo é limitada pelo fato de que o composto apresenta outros processos além dos assimilados à espécie aquo e nitrosilo complexo, quando a $\mathrm{C}_{\mathrm{H}^{+}}<10^{-4} \mathrm{~mol}^{-\mathrm{L}^{-1}}$. De acordo com estudos anteriores ${ }^{[88]}$, pode ocorrer uma reação de desproporcionamento no íon complexo trans-[Ru( $\left.\left(\mathrm{NH}_{3}\right)_{4}\left(\mathrm{H}_{2} \mathrm{O}\right) \mathrm{P}\left(\mathrm{OC}_{2} \mathrm{H}_{5}\right)_{3}\right]^{3+}$ formando o $\mathrm{Ru}(\mathrm{II})$ e $\mathrm{Ru}(\mathrm{VI})$ como produtos majoritários. Esta reação conduz a uma mudança no espectro voltamétrico em $\mathrm{C}_{\mathrm{H}^{+}}<10^{-4} \mathrm{~mol}^{-\mathrm{L}^{-1}}$, visto que o $\mathrm{Ru}$ (II) oxidado na superfície do eletrodo gerando o $\mathrm{Ru}(\mathrm{III})$, rapidamente se desproporciona formando o $\mathrm{Ru}(\mathrm{VI})$ e mais $\mathrm{Ru}(\mathrm{II})^{[74]}$. Portanto, um aumento na corrente de pico anódico $\left[\mathrm{Ru}^{\mathrm{ll}} \mathrm{H}_{2} \mathrm{O}\right]^{2+} /$ $\left[\mathrm{Ru}^{\mathrm{III}} \mathrm{H}_{2} \mathrm{O}\right]^{3+}$ será observado.

No voltamograma da Figura 4.1, observa-se que o processo $E_{p a 3}$ e $E_{p c 3}$, referentes ao complexo aquofosfito, é dependente do primeiro processo de redução do complexo nitrosilo de rutênio, $\left[\mathrm{RuNO}^{+}\right]^{3+} /\left[\mathrm{RuNO}^{\circ}\right]^{2+}$. Estudos anteriores ${ }^{[89]}$ indicam que os centros metálicos de rutênio possuem baixa afinidade por NO, sendo que o produto de redução monoeletrônica do íon complexo trans-[RuNO $\left.\left(\mathrm{NH}_{3}\right)_{4} \mathrm{P}\left(\mathrm{OC}_{2} \mathrm{H}_{5}\right)_{3}\right]^{3+}$ possui a mais elevada 
constante de velocidade específica para a liberação de NO dentre as tetraaminas sintetizadas por nosso grupo de pesquisa $\left(\mathrm{k}_{-\mathrm{NO}}=0,97 \mathrm{~s}^{-1} \text { a } 25^{\circ} \mathrm{C}\right)^{[88]}$. Assim, após a redução monoeletrônica sobre o fragmento $\left[\mathrm{Ru}^{\prime \prime} \mathrm{NO}^{+}\right]$, ocorre a dissociação de NO e a formação do respectivo aquo complexo ${ }^{[89]}$, que posteriormente sofre o processo de oxidação, de acordo com as Equações 8 e 9.

$$
\begin{gathered}
t-\left[\mathrm{Ru}^{\prime \prime}\left(\mathrm{NO}^{+}\right)\left(\mathrm{NH}_{3}\right)_{4} \mathrm{P}(\mathrm{OEt})_{3}\right]^{3+}+\mathrm{e}^{-} \stackrel{\text { Rápida }}{\longrightarrow} t-\left[\mathrm{Ru}^{\mathrm{Il}}\left(\mathrm{NO}^{0}\right)\left(\mathrm{NH}_{3}\right)_{4} \mathrm{P}(\mathrm{OEt})_{3}\right]^{2+} \\
t-\left[\mathrm{Ru}^{\mathrm{II}}\left(\mathrm{NO}^{0}\right)\left(\mathrm{NH}_{3}\right)_{4} \mathrm{P}(\mathrm{OEt})_{3}\right]^{2+}+\mathrm{H}_{2} \mathrm{O} \stackrel{\mathrm{k}_{-\mathrm{NO}}}{\mathrm{K}_{+} \mathrm{NO}} t-\left[\mathrm{Ru}^{\mathrm{Il}}\left(\mathrm{NH}_{3}\right)_{4}\left(\mathrm{H}_{2} \mathrm{O}\right) \mathrm{P}(\mathrm{OEt})_{3}\right]^{2+}+\mathrm{NO} \\
t-\left[\mathrm{Ru}\left(\mathrm{NH}_{3}\right)_{4}\left(\mathrm{H}_{2} \mathrm{O}\right) \mathrm{P}\left(\mathrm{OC}_{2} \mathrm{H}_{5}\right)_{3}\right]^{2+} \longrightarrow t-\left[\mathrm{Ru}\left(\mathrm{NH}_{3}\right)_{4}\left(\mathrm{H}_{2} \mathrm{O}\right) \mathrm{P}\left(\mathrm{OC}_{2} \mathrm{H}_{5}\right)_{3}\right]^{3+}+1 e^{-}
\end{gathered}
$$

Este processo de dissociação de NO pela espécie [Ru"NO*] é dependente da temperatura, aumentando com a mesma. Além disto, a velocidade de varredura tem efeito indireto nas correntes de pico de cada um desses processos, pois a baixas velocidades de varredura maior será o tempo de varredura, proporcionando um aumento na quantidade da espécie $\left[\mathrm{Ru}^{\mathrm{Il}} \mathrm{H}_{2} \mathrm{O}\right]^{2+}$. Isto foi observado em voltamogramas onde o potencial varia de $1,0 \mathrm{~V}$ a $-0,5 \mathrm{~V}$, considerando o primeiro processo de redução do trans-[RuNO $\left.\left(\mathrm{NH}_{3}\right)_{4} \mathrm{P}\left(\mathrm{OC}_{2} \mathrm{H}_{5}\right)_{3}\right]^{3+}$ e o processo referente ao complexo aquofosfito. Neste caso, com o aumento da temperatura observa-se a diminuição da corrente de pico anódica do par $\left[\mathrm{RuNO}^{\circ}\right]^{2+} /\left[\mathrm{RuNO}^{+}\right]^{3+}$ devido à dissociação de $\mathrm{NO}$ da espécie $\left[\mathrm{RuNO}^{\circ}\right]^{2+}$ e o aumento da corrente de pico referente à oxidação/redução do complexo aquofosfito, $i_{p a 3}$ e $i_{p c 3}$. Com a diminuição da temperatura acontece o contrário.

Da mesma maneira, para voltamogramas em que o potencial varia de 1,0 a $-1,2 \mathrm{~V}$, sendo considerado também o segundo processo de redução, $\left[\mathrm{RuNO}^{\circ}\right]^{2+} /\left[\mathrm{RuNO}^{-}\right]^{+}$, a 
diminuição da temperatura aumenta a concentração da espécie [RuNO $]^{2+}$ a ser oxidada a $\left[\mathrm{RuNO}^{+}\right]^{3+}$ na superfície do eletrodo, aumentando assim a corrente de pico anódica do $\operatorname{par}\left[\mathrm{RuNO}^{\circ}\right]^{2+} /\left[\mathrm{RuNO}^{+}\right]^{3+}$. O aumento da concentração de $[\mathrm{RuNO}]^{2+}$ conduz ao aumento da corrente de pico pertinente ao pico de redução da espécie $\left[\mathrm{RuNO}^{\circ}\right]^{2+}$ a $\left[\mathrm{RuNO}^{\circ}\right]^{+}$, o qual torna-se mais definido.

A aparente irreversibilidade da onda anódica a $-0,69$ V vs ECS poderia ser explicada em parte pela reação de dissociação de $\mathrm{NO}^{-}$coordenado ao centro metálico do rutênio (II). Entretanto, como veremos mais adiante, esta situação é mais complexa devido à alteração de spin. Por isso, a segunda onda catódica pode ser mais bem observada se a velocidade de varredura for aumentada e se a temperatura da solução for diminuída.

O perfil voltamétrico das ondas de redução do íon complexo trans$\left[\mathrm{RuNO}\left(\mathrm{NH}_{3}\right)_{4} \mathrm{P}\left(\mathrm{OC}_{2} \mathrm{H}_{5}\right)_{3}\right]^{3+}$ é mostrado na Figura 4.2, a qual enfatiza as duas ondas de redução a velocidades de varredura de 0,005 e $0,5 \mathrm{~V} \cdot \mathrm{s}^{-1}$.

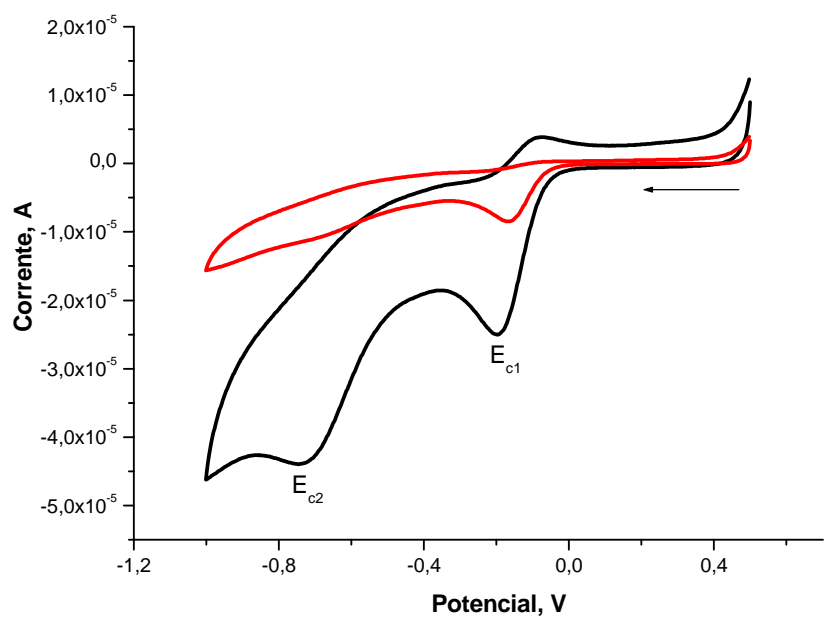

Figura 4.2 - Voltamograma cíclico do complexo trans- $\left[\mathrm{RuNO}\left(\mathrm{NH}_{3}\right)_{4} \mathrm{P}\left(\mathrm{OC}_{2} \mathrm{H}_{5}\right)_{3}\right]\left(\mathrm{PF}_{6}\right)_{3}$ $(-) \mathrm{v}=0,005 \mathrm{~V} . \mathrm{s}^{-1} ;(-) \mathrm{v}=0,5 \mathrm{~V} / \mathrm{s}$. Condições: $\mathrm{CF}_{3} \mathrm{COOH} / \mathrm{NaCF}{ }_{3} \mathrm{COO} \mathrm{pH}=3,0$; $\mu=0,1 \mathrm{molL}^{-1} ; \mathrm{T}=25{ }^{\circ} \mathrm{C} ; \mathrm{C}_{\mathrm{Ru}}=1,1 \times 10^{-3} \mathrm{molL}^{-1}$; eletrodo de trabalho: carbono vítreo; $\mathrm{E}_{\mathrm{i}}$ $=0,3 \mathrm{~V} ; \mathrm{E}_{\mathrm{f}}=-1,0 \mathrm{~V}$. 
A Figura 4.2 mostra claramente a não equivalência entre as correntes dos picos de redução e oxidação da mesma espécie. Conforme foi comentado, observa-se que os processos de redução do trans-[RuNO $\left.\left(\mathrm{NH}_{3}\right)_{4} \mathrm{P}\left(\mathrm{OC}_{2} \mathrm{H}_{5}\right)_{3}\right]^{3+}$ se tornam mais bem definidos à medida em que a velocidade de varredura aumenta.

Este segundo processo de redução foi observado para outros compostos sintetizados em nosso Laboratório ${ }^{(56)}$, tais como: trans-[RuNO$\left.\left(\mathrm{NH}_{3}\right)_{4}(\mathrm{~L})\right]^{3+}$, onde $\mathrm{L}=4$ pic, py, ImN, nic, trans-[Ru(NO)Cl(cyclam) $]^{2+}$. Voltamogramas cíclicos, assim como os voltamogramas de pulso diferencial, para as soluções desses compostos estão ilustrados no apêndice A. Para o complexo [RuNOHedta]. $\mathrm{H}_{2} \mathrm{O}$, não se observa uma segunda onda catódica em potenciais aplicados de 1,0 a -1,0 V. A Figura 4.3 apresenta o voltamograma cíclico de uma solução aquosa contendo o complexo trans[Ru(NO)(Hedta)], a $25^{\circ} \mathrm{C}$.

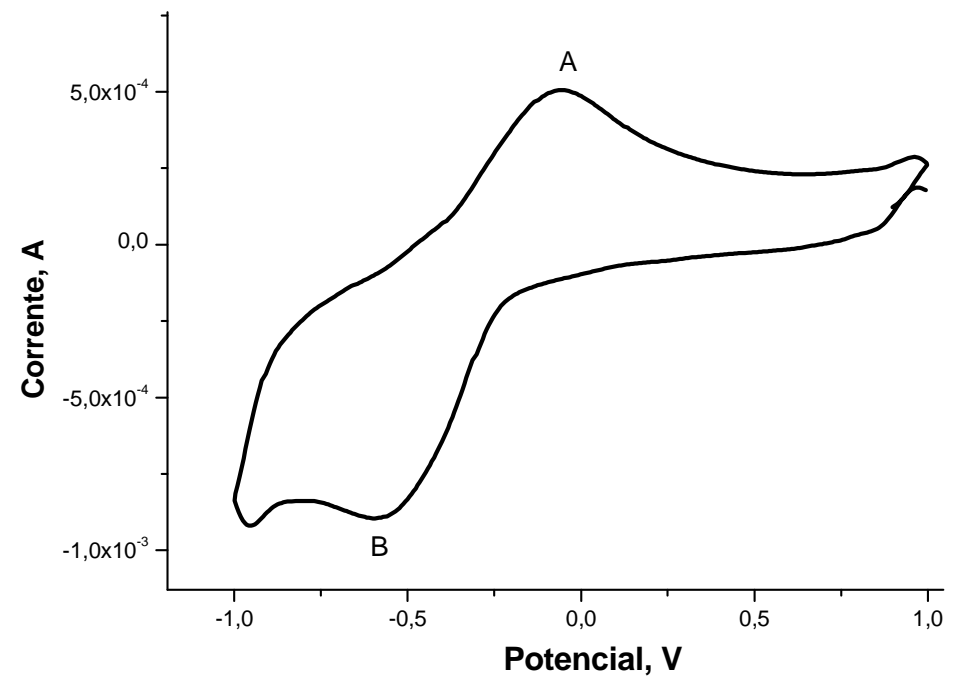

Figura 4.3 - Voltamograma cíclico do complexo [Ru(HEdta)NO]. $\mathrm{H}_{2} \mathrm{O}$. Condições: $\mathrm{CF}_{3} \mathrm{COOH} / \mathrm{NaCF}_{3} \mathrm{COO} \mu=0,1 \mathrm{molL}^{-1} ; \mathrm{pH}=5,4 ; \mathrm{C}_{\mathrm{Ru}}=5,9 \times 10^{-3} \mathrm{molL}^{-1} ; \mathrm{T}=25{ }^{\circ} \mathrm{C} ; \mathrm{v}=0,2$ V.s. ${ }^{-1}$.

Este complexo apresenta um processo reversível já bem caracterizado ${ }^{[68]}(A$ e $B)$, com um potencial de meia onda de $\mathrm{E}_{\mathrm{NO}+\mathrm{NO}}=-0,3 \mathrm{~V}$. Por outro lado, não se observa a 
segunda onda catódica no voltamograma do composto. Este comportamento da espécie [RuNOHedta]. $\mathrm{H}_{2} \mathrm{O}$ pode ser devido à segunda transferência eletrônica ocorrer a potenciais bem mais negativos, confundindo-se com processos devido ao eletrólito de suporte, nas condições de trabalho realizadas.

Em uma análise mais detalhada da segunda onda catódica procurou-se estimar o número aproximado de elétrons envolvido no processo. Para tanto, tentou-se aplicar o processo de deconvolução ao voltamograma e realizar experimentos usando a técnica de voltametria de onda quadrada.

Uma tentativa para se estimar o número de elétrons envolvidos no processo

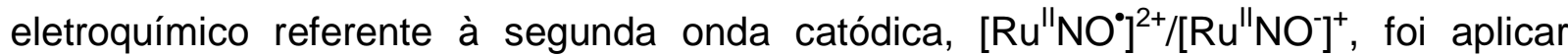
deconvolução das ondas de redução sob a faixa de 0,0 a -1,0 V.

Para se construir uma curva de calibração normalmente colocam-se os valores das correntes de pico (ou a área sob o pico) contra as concentrações da espécie eletroativa correspondentes a eles. Desta forma, a corrente de pico (altura ou área) será diretamente proporcional à concentração da espécie eletroativa ${ }^{[78]}$. Assim sendo, por comparação de duas ondas catódicas de um mesmo voltamograma, pode-se estimar o número de elétrons através dos valores de corrente de pico de ambas as ondas. Para tanto, a deconvolução foi efetuada descontando-se a linha de base, considerando a variação da mesma de forma linear.

No caso em questão foi verificado que ambas as ondas catódicas apresentaram áreas similares sugerindo uma possível redução de um elétron para a segunda onda catódica, visto que a primeira onda catódica é atribuída a uma redução monoeletrônica 
do par $\left[\mathrm{Ru}^{\prime \prime} \mathrm{NO}^{+}\right]^{3+} /\left[\mathrm{Ru}^{\prime \prime} \mathrm{NO}^{*}\right]^{2+}$. A Figura 4.4 mostra a deconvolução de um voltamograma, no sentido de redução, para o íon complexo trans$\left[\mathrm{Ru}\left(\mathrm{NH}_{3}\right)_{4} \mathrm{NOP}\left(\mathrm{OC}_{2} \mathrm{H}_{5}\right)_{3}\right]^{3+}$.

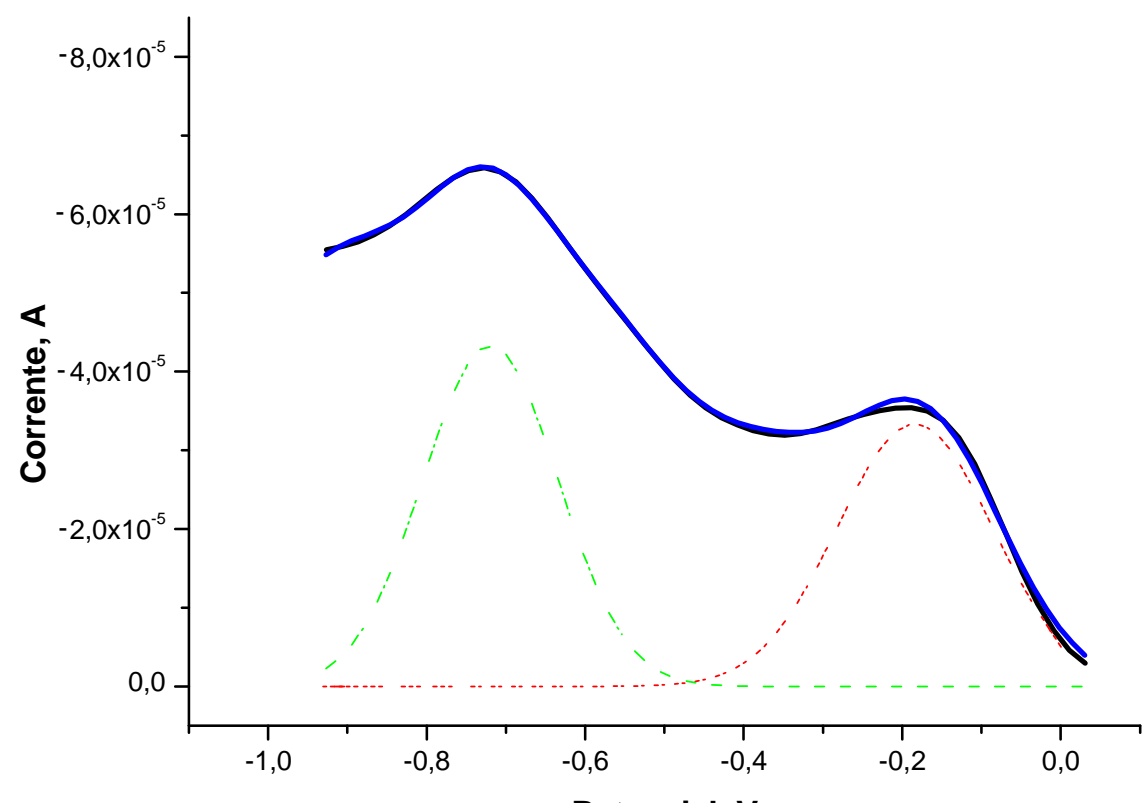

Potencial, $\mathbf{V}$

Figura 4.4 - Deconvolução do voltamograma do íon complexo $t$ $\left[\mathrm{Ru}\left(\mathrm{NH}_{3}\right)_{4} \mathrm{NOP}\left(\mathrm{OC}_{2} \mathrm{H}_{5}\right)_{3}\right]^{3+}$. Condições: $\mathrm{pH}=3,0 ; \mathrm{T}=2,5^{\circ} \mathrm{C} ; \mathrm{C}_{\mathrm{Ru}}=5,3 \times 10^{-3} \mathrm{molL}$;

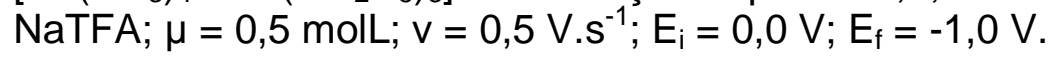

A Voltametria de onda quadrada foi utilizada para o estudo do comportamento eletroquímico do íon complexo trans- $\left[\mathrm{RuNO}\left(\mathrm{NH}_{3}\right)_{4} \mathrm{P}\left(\mathrm{OC}_{2} \mathrm{H}_{5}\right)_{3}\right]^{3+}$ por ser uma técnica voltamétrica de pulso mais rápida e sensível dentre todas, possibilitando assim, uma análise do tipo de processo redox envolvido ${ }^{[90]}$ e uma estimativa do número de elétrons utilizando os critérios de diagnósticos desenvolvidos por LOVRIC e OSTERYOUNG ${ }^{[91]}$.

Inicialmente foi necessário estabelecer as condições experimentais apropriadas para a análise, após tal, o incremento de varredura $\left(\Delta E_{s}\right)$ foi fixado em $2 \mathrm{mV}$ e a amplitude de pulso $\left(\Delta \mathrm{E}_{\mathrm{p}}\right)$ foi mantida em $50 \mathrm{mV}$, condições estas que demonstraram 
satisfatórias para as medidas realizadas, baseadas no perfil voltamétrico referente ao $E_{p c 2}$.

A freqüência de aplicação dos pulsos de potenciais $(f)$ é uma das variáveis mais importantes envolvidos na voltametria de onda quadrada, pois mantendo-se a concentração constante é ela quem determina a intensidade dos sinais, e conseqüentemente, a sensibilidade obtida nas análises, além de possibilitar uma observação do tipo de processo e o número de elétrons envolvidos na transferência eletrônica $^{[79]}$. Desta forma, uma avaliação da influência da variação da freqüência (f) de um pulso foi efetuado no intervalo entre 100 e $600 \mathrm{~Hz}$, utilizando-se uma solução contendo o íon trans-[RuNO $\left.\left(\mathrm{NH}_{3}\right)_{4} \mathrm{P}\left(\mathrm{OC}_{2} \mathrm{H}_{5}\right)_{3}\right]^{3+}$. As respostas voltamétricas para 0 segundo pico de redução $\left(E_{p}=-0,69 \mathrm{~V}\right)$ obtidas nestas condições, em função da variação da freqüência de aplicação dos pulsos de potenciais são mostradas na Figura 4.5 .

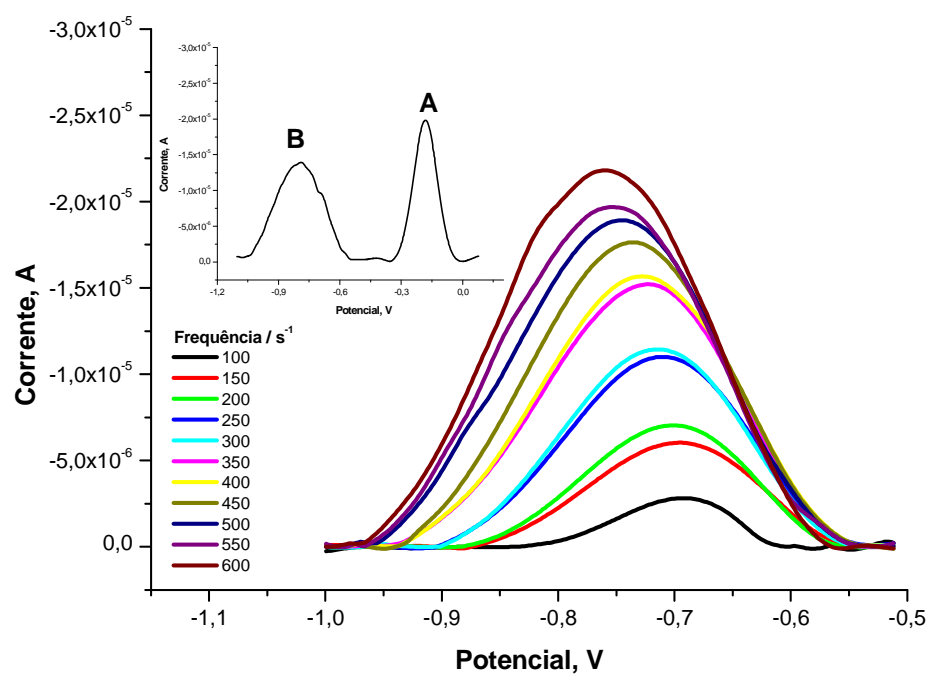

Figura 4.5 - Voltamogramas de onda quadrada mostrando a influência da variação da freqüência de aplicação dos pulsos de potenciais $(f)$ sobre o segundo pico de redução do íon complexo trans-[RuNO $\left.\left(\mathrm{NH}_{3}\right)_{4} \mathrm{P}\left(\mathrm{OC}_{2} \mathrm{H}_{5}\right)_{3}\right]^{3+}$. Condições: $\mathrm{C}_{\mathrm{Ru}}=1,4 \times 10^{-3} \mathrm{molL}^{-1} \mathrm{em}$ solução de $\mathrm{CF}_{3} \mathrm{COOH} / \mathrm{NaCF}_{3} \mathrm{COO} \mathrm{pH}=3,0 ; \mu=0,1 \mathrm{molL}^{-1} ; \mathrm{T}=25{ }^{\circ} \mathrm{C} ; \Delta \mathrm{E}_{\mathrm{p}}=50 \mathrm{mV}$; $\Delta \mathrm{E}_{\mathrm{s}}=2 \mathrm{mV}$. Inserção: Voltamograma de onda quadrada mostrando os picos de redução $E_{p c 1}$ e $E_{p c 2}$. 
Observa-se que o aumento no valor da freqüência de aplicação dos pulsos de potenciais promoveu um aumento da intensidade da corrente de pico $\left(I_{p c 2}\right)$, e os potenciais de pico $\left(E_{p c 2}\right)$ se deslocaram para regiões mais negativas. O gráfico inserido na Figura 4.5 mostra a separação dos picos de redução $E_{p c 1}$ e $E_{p c 2}$. No entanto, freqüências abaixo de $100 \mathrm{~s}^{-1}$ não influenciam de maneira significativa na intensidade do sinal, por este motivo a freqüência de trabalho escolhida foi acima de $100 \mathrm{~s}^{-1}$, onde se obtém um voltamograma bem definido, com maior corrente de pico. Os valores de correntes e potenciais de pico em função da variação da freqüência de aplicação dos pulsos de potenciais estão resumidos na Tabela 4.1.

Tabela 4.1 - Variação do potencial e corrente de pico em função da freqüência para o segundo pico de redução do íon trans-[RuNO $\left.\left(\mathrm{NH}_{3}\right)_{4} \mathrm{P}\left(\mathrm{OC}_{2} \mathrm{H}_{5}\right)_{3}\right]^{3+}$

\begin{tabular}{ccc}
\hline Freqüência $\left(\mathrm{s}^{-1}\right)$ & $\mathrm{E}_{\mathrm{p} 2}(\mathrm{mV})$ & $\mathrm{I}_{\mathrm{p} 2}(\mu \mathrm{A})$ \\
\hline 100 & -691 & $-2,81$ \\
150 & -695 & $-5,94$ \\
200 & -700 & $-7,09$ \\
250 & -714 & $-10,92$ \\
300 & -716 & $-11,40$ \\
350 & -723 & $-15,17$ \\
450 & -736 & $-17,58$ \\
500 & -750 & $-18,89$ \\
550 & -752 & $-19,67$ \\
600 & -759 & $-21,81$ \\
\hline
\end{tabular}

Condições: solução NaTFA, $\mu=0,1 \mathrm{molL}^{-1} ; \mathrm{pH} 3,0 ; \mathrm{T}=25^{\circ} \mathrm{C}$ 
De acordo com a teoria da voltametria de onda quadrada ${ }^{[80]}$, para processos controlados pela difusão das espécies, a intensidade de corrente de pico varia linearmente com a freqüência $(f)$ de aplicação dos pulsos. A Figura 4.6 mostra o comportamento da corrente de pico em função da variação da freqüência da onda quadrada para a transferência de elétrons ao íon complexo trans$\left[\mathrm{RuNO}\left(\mathrm{NH}_{3}\right)_{4} \mathrm{P}\left(\mathrm{OC}_{2} \mathrm{H}_{5}\right)_{3}\right]^{2+}$.

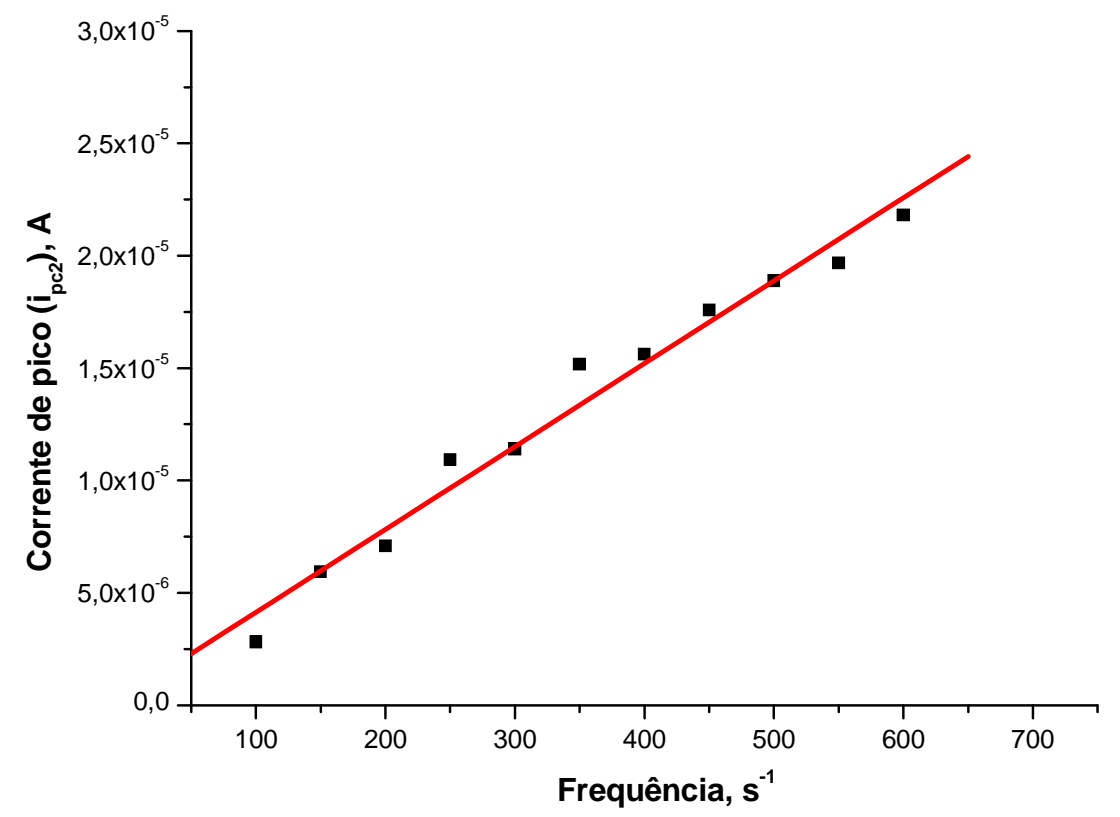

Figura 4.6 - Gráfico da variação da corrente de pico $\left(l_{p c 2}\right)$ em função da freqüência de onda quadrada $(f)$ para 0 segundo pico de redução do complexo trans[RuNO $\left.\left(\mathrm{NH}_{3}\right)_{4} \mathrm{P}\left(\mathrm{OC}_{2} \mathrm{H}_{5}\right)_{3}\right]^{3+}$. Condições: $\mathrm{CF}_{3} \mathrm{COOH} / \mathrm{NaCF}_{3} \mathrm{COO} \mathrm{pH}=3,0 ; \mu=0,1 \mathrm{molL}^{-1}$; $\mathrm{T}=25^{\circ} \mathrm{C} ; \mathrm{C}_{\mathrm{Ru}}=1,4 \times 10^{-3} \mathrm{molL}^{-1} ; \Delta \mathrm{E}_{\mathrm{s}}=50 \mathrm{mV} ; \Delta \mathrm{E}_{\mathrm{p}}=2 \mathrm{mV} ;(\mathrm{R}=0,98775)$.

Observa-se que a intensidade de corrente de pico varia linearmente com a freqüência da onda quadrada, mostrando que o processo da segunda onda de redução do complexo trans-[RuNO $\left.\left(\mathrm{NH}_{3}\right)_{4} \mathrm{P}\left(\mathrm{OC}_{2} \mathrm{H}_{5}\right)_{3}\right]^{3+}$ sobre o eletrodo de carbono vítreo apresenta-se como irreversível. 
Para sistemas redox totalmente irreversíveis, onde não ocorre adsorção e a corrente é controlada por difusão, também existirá uma relação linear entre a corrente de pico e a raiz quadrada da freqüência $\left(f^{1 / 2}\right)$. Este comportamento foi observado para a redução da espécie [Ru"NO'], como mostra a Figura 4.7.

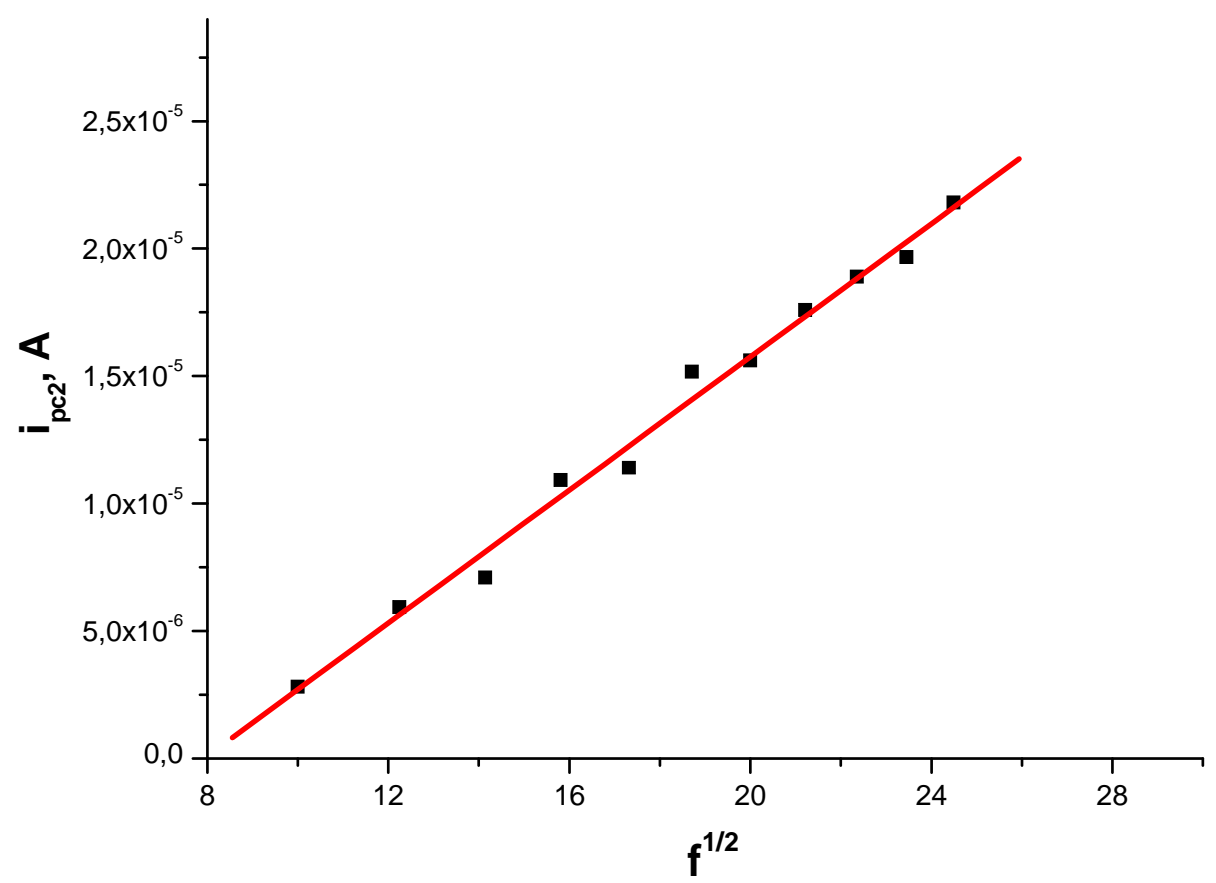

Figura 4.7 - Gráfico da variação da corrente de pico $\left(I_{p c 2}\right)$ em função da raiz quadrada da freqüência de onda quadrada $\left(\mathrm{f}^{1 / 2}\right)$ para o segundo pico de redução do complexo trans-[RuNO $\left.\left(\mathrm{NH}_{3}\right)_{4} \mathrm{P}\left(\mathrm{OC}_{2} \mathrm{H}_{5}\right)_{3}\right]^{3+}$. Condições: $\mathrm{CF}_{3} \mathrm{COOH} / \mathrm{NaCF}_{3} \mathrm{COO} \mathrm{pH}=3,0 ; \mu=0,10$ $\mathrm{molL}^{-1} ; \mathrm{T}=25{ }^{\circ} \mathrm{C} ; \mathrm{C}_{\mathrm{Ru}}=1,4 \times 10^{-3} \mathrm{molL}^{-1} ; \Delta \mathrm{E}_{\mathrm{s}}=50 \mathrm{mV} ; \Delta \mathrm{E}_{\mathrm{p}}=2 \mathrm{mV}(\mathrm{R}=0,99483)$.

De acordo com os critérios de diagnósticos da voltametria de onda quadrada, a dependência dos potenciais de pico sobre o logaritmo da freqüência para reações totalmente irreversíveis é linear, e apresenta uma inclinação de acordo com a Equação de Lovric ${ }^{[91]}$ :

$$
\frac{\delta \mathrm{E}_{\mathrm{p}}}{\delta \log (f)}=\frac{-2,3 \mathrm{RT}}{\alpha \mathrm{nF}}
$$


Construindo-se um gráfico de potencial de pico $\left(E_{\mathrm{pc} 2}\right)$ vs log $(f)$ é possível calcular o valor de an, aproximando-se o valor de a para $0,5^{[92]}$. Para a determinação do valor de an, foram realizados experimentos, onde as variações de freqüência foram conduzidas a temperaturas de $2,5^{\circ} \mathrm{C}$ e $25,0^{\circ} \mathrm{C}$. Com os valores dos potenciais de pico $\left(\mathrm{E}_{\mathrm{pc} 2}\right)$ para cada variação de freqüência foram obtidos gráficos de $E_{p}$ em função do log(f). Assim, a partir das inclinações das retas obtidas foi possível determinar os valores de $a \mathrm{n}$. $\mathrm{Na}$ Figura 4.8 está apresentado o comportamento do potencial de pico em função do logaritmo da freqüência, para o segundo processo de redução do íon trans$\left[\mathrm{RuNO}\left(\mathrm{NH}_{3}\right)_{4} \mathrm{P}\left(\mathrm{OC}_{2} \mathrm{H}_{5}\right)_{3}\right]^{3+}$.

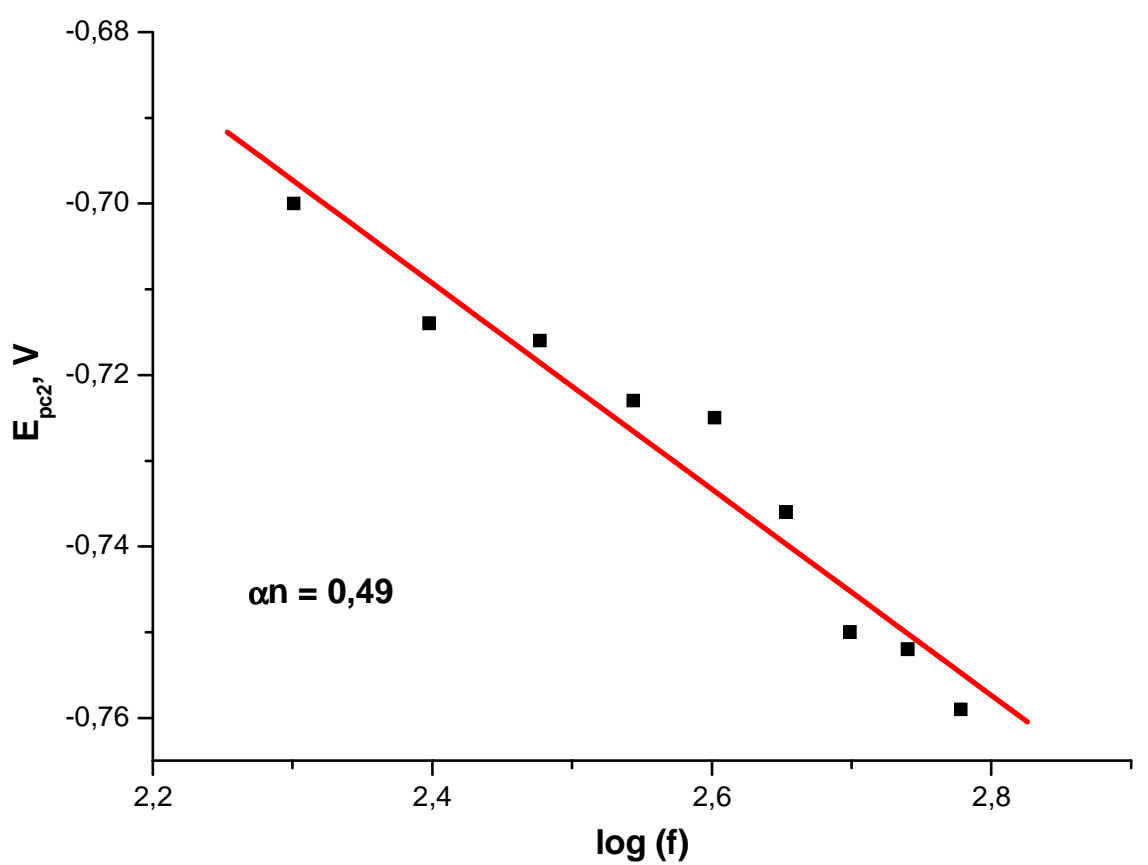

Figura 4.8 - Gráfico da variação da corrente de pico $\left(l_{\mathrm{pc} 2}\right)$ em função do logaritmo da freqüência de onda quadrada $(\log (f))$ para o pico de redução do íon complexo trans$\left[\mathrm{RuNO}\left(\mathrm{NH}_{3}\right)_{4} \mathrm{P}\left(\mathrm{OC}_{2} \mathrm{H}_{5}\right)_{3}\right]^{2+}$. Condições: $\mathrm{CF}_{3} \mathrm{COOH} / \mathrm{NaCF}_{3} \mathrm{COO} \mathrm{pH}=3,0 ; \mu=0,10 \mathrm{molL}^{-}$ 1; $\mathrm{T}=25{ }^{\circ} \mathrm{C} ; \mathrm{C}_{\mathrm{Ru}}=1,4 \times 10^{-3} \mathrm{molL}^{-1} ; \Delta \mathrm{E}_{\mathrm{s}}=50 \mathrm{mV} ; \Delta \mathrm{E}_{\mathrm{p}}=2 \mathrm{mV}$ (R=0,97092)-(Dados extraídos da Tabela 4.1). 
Considerando o processo como irreversível, em primeira aproximação, a correlação dos potenciais de pico em relação ao aumento da freqüência de aplicação dos pulsos de potenciais possibilitou uma estimativa do número de elétrons envolvidos neste processo redox. Observa-se um comportamento linear com inclinação para $\delta E_{p} /$ $\delta \log (f)$ de -0,12. Aplicando-se este valor na Equação 10 , tem-se que $\alpha \mathrm{n}=0,49$, o que corresponderia a um valor de $\mathrm{n}$ de 0,98 ( $\approx 1$ elétron). Este valor de $\mathrm{n}$ é compatível com a redução da espécie $\left[\mathrm{RuNO}^{\circ}\right]^{2+}$ a $\left[\mathrm{RuNO}^{-}\right]^{+}$.

\section{2 - Espectroscopia vibracional vs Potencial}

Espectros FT-IR in situ de uma solução contendo o íon complexo trans$\left[\mathrm{RuNO}\left(\mathrm{NH}_{3}\right)_{4} \mathrm{P}\left(\mathrm{OC}_{2} \mathrm{H}_{5}\right)_{3}\right]^{3+}$, registrados no intervalo de número de onda de 2200-1700 $\mathrm{cm}^{-1}$, considerando o processo de redução para a faixa de potencial de $-0,02 \vee$ a $-0,82$ V vs ECS, são mostrados na Figura 4.9.

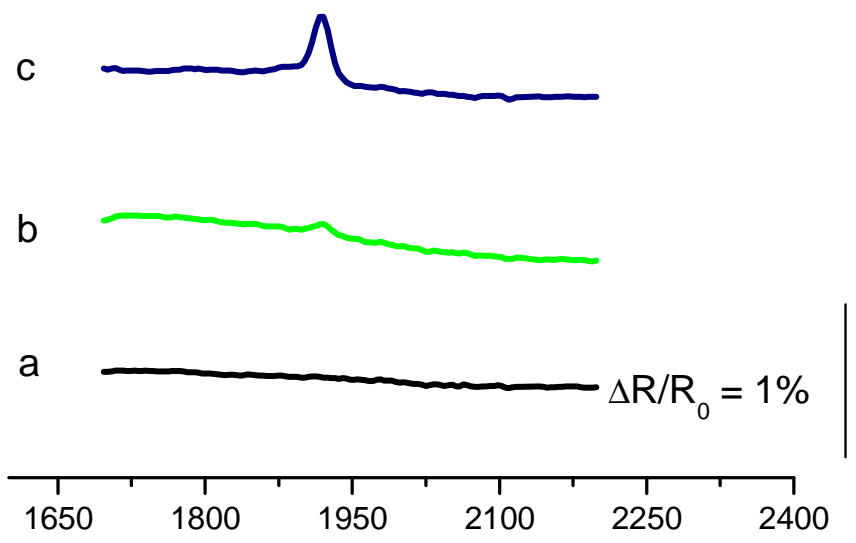

Número de onda, $\mathrm{cm}^{-1}$

Figura 4.9 - Espectro eletrônico na região do IR vs potencial para o complexo trans[RuNO(NH$\left.)_{4} \mathrm{P}\left(\mathrm{OC}_{2} \mathrm{H}_{5}\right)_{3}\right]^{3+}$; a) $\mathrm{E}_{\mathrm{S}}=-0,02 \mathrm{~V}$; b) $\mathrm{E}_{\mathrm{S}}=-0,22 \mathrm{~V}$; c) $\mathrm{E}_{\mathrm{S}}=-0,82 \mathrm{~V}$. Condições: $\mathrm{CF}_{3} \mathrm{COOH} / \mathrm{NaCF}_{3} \mathrm{COO} \mathrm{pH}=3,0 ; \mu=0,1 \mathrm{~mol} . \mathrm{L}^{-1} ; \mathrm{C}_{\mathrm{Ru}}=1,4 \times 10^{-3} \mathrm{~mol} . \mathrm{L}^{-1} ; \mathrm{T}=25,0{ }^{\circ} \mathrm{C} ; \mathrm{E}_{\mathrm{R}}$ $=0,5 \mathrm{~V}$. Luz s-polarizada, eletrodo de trabalho: carbono vítreo. 
Neste processo, para o potencial fixado em $-0,02$ V, não se observou uma mudança significativa no espectro, visto que neste caso ainda não foi atingido o potencial de redução do par redox $\left[\mathrm{Ru}^{\prime \prime} \mathrm{NO}^{+}\right]^{3+} /\left[\mathrm{Ru}^{\prime \prime} \mathrm{NO} \mathrm{O}^{2+}(-0,18 \vee v s \mathrm{ECS})\right.$. Em geral a freqüência de estiramento do monóxido de nitrogênio, $v_{N}$, coordenado em complexos do tipo $\left[\mathrm{Ru}(\mathrm{NO})\left(\mathrm{NH}_{3}\right)_{4} \mathrm{~L}\right]^{3+}\left(\mathrm{L}=\mathrm{P}(\mathrm{OEt})_{3}\right)$, nic, py $\operatorname{ImN}$, L-Hist, pz, isn) é intensa e apresenta-se na região de $1911-1970 \mathrm{~cm}^{-1[56]}$. Ajustando-se o potencial para $-0,22 \mathrm{~V}$, um sinal positivo em $1918 \mathrm{~cm}^{-1}$ começa a se definir, indicando o desaparecimento da espécie $\left[\mathrm{Ru}^{\prime \prime} \mathrm{NO}^{+}\right]^{3+}$ por redução, já que neste ponto se atinge o potencial de redução do par $\left[\mathrm{Ru}^{\prime \prime} \mathrm{NO}^{+}\right]^{3+} /\left[\mathrm{Ru}^{\prime \prime} \mathrm{NO}^{+}\right]^{2+}$. Além disso, quando o potencial aplicado é de $-0,82 \vee \mathrm{um}$ aumento desta variação de sinal é observado, visto que neste potencial uma maior quantidade de $\left[\mathrm{Ru}^{\mathrm{II}} \mathrm{NO}^{+}\right]^{3+}$ é reduzida, levando a um consumo maior dessa espécie. Deste modo, a variação de sinal em $1918 \mathrm{~cm}^{-1}$, conforme antecipado, é devido ao $v_{\mathrm{NO}}$.

O mesmo experimento foi realizado com o íon complexo trans-[RuNO $\left.\left(\mathrm{NH}_{3}\right)_{4} n i c\right]^{3+}$ obtendo-se o espectro apresentado na Figura 4.10.

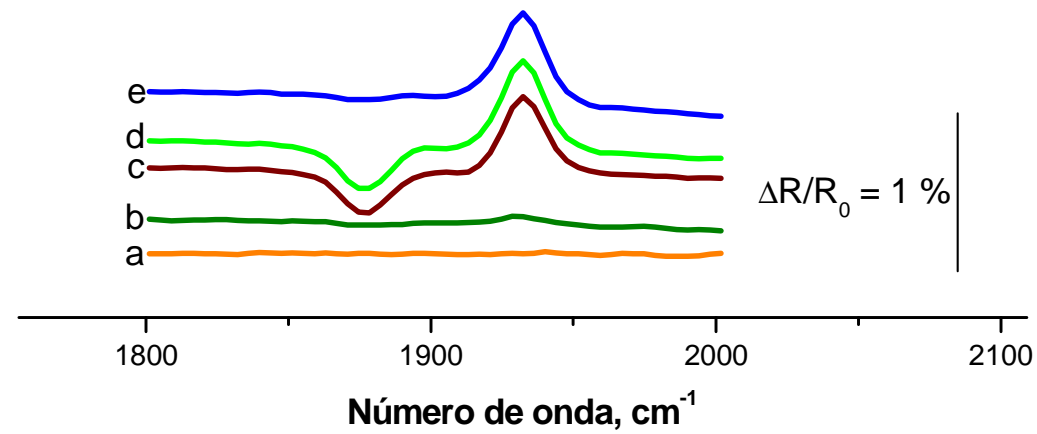

Figura 4.10 - Espectro eletrônico na região do IR vs potencial de pico para o complexo trans-[RuNO( $\left(\mathrm{NH}_{3}\right)_{4}$ nic $]^{3+}$; a) $E_{S}=0,05 \mathrm{~V}$; b) $E_{S}=-0,25 \mathrm{~V}$; c) $E_{S}=-0,35 \mathrm{~V}$; d) $E_{S}=-0,55$ $\mathrm{V}$; e) $\mathrm{E}_{\mathrm{S}}=-0,65 \mathrm{~V}$; Condições: $\mathrm{CF}_{3} \mathrm{COOH} / \mathrm{NaCF}_{3} \mathrm{COO} \mathrm{pH}=3,0 ; \mu=0,1 \mathrm{~mol} \cdot \mathrm{L}^{-1} ; \mathrm{C}_{\mathrm{Ru}}=$ $3,0 \times 10^{-3} \mathrm{~mol}^{-1} \mathrm{~L}^{-1} \mathrm{~T}=25,0^{\circ} \mathrm{C} ; \mathrm{E}_{\mathrm{R}}=0,5 \mathrm{~V}$. Eletrodo de trabalho: carbono vítreo. (região IR $\left.2000-1800 \mathrm{~cm}^{-1}\right)$. Luz s-polarizada. 
Neste caso, ao se atingir o potencial de redução da espécie $\left[\mathrm{Ru}^{\prime \prime} \mathrm{NO}^{+} n i c\right]^{3+}\left(\mathrm{E}_{\mathrm{NO}+/}\right.$ $\mathrm{NO}^{\bullet}=-0,26 \mathrm{~V}$ vs ECS) uma variação de sinal no sentido positivo em $1933 \mathrm{~cm}^{-1}$ começa a se definir, como mostra o espectro b da Figura 4.11. Neste potencial ocorre o desaparecimento da espécie $\left[\mathrm{Ru}^{\prime \prime} \mathrm{NO}^{+} \mathrm{nic}\right]^{3+}$, devido à redução para $\left[\mathrm{Ru} \mathbf{u N O}^{\prime \prime} \mathrm{nic}\right]^{2+}$, e deste modo este sinal foi atribuído ao $v_{\text {NO }}$ na espécie $\left[\mathrm{Ru}^{\prime \prime} \mathrm{NO}^{+} \text {nic }\right]^{3+}$. À medida que este potencial é alterado para $-0,35 \vee v s$ ECS (espectro c) e $-0,55 \vee v s$ ECS (espectro d) uma variação de sinal em $1875 \mathrm{~cm}^{-1}$ é evidenciada. Esta variação é indicativa da formação da espécie $\left[R u^{\prime \prime} \mathrm{NO}^{n} \text { nic }\right]^{2+}$, sendo portanto, atribuída ao $v_{\mathrm{NO}}$ nesta espécie. Esta observação foi possível, pois a constante de liberação de NO no íon complexo trans-[RuNO $\left.\left(\mathrm{NH}_{3}\right)_{4} n i c\right]^{2+}$ é favorável, $\mathrm{k}_{-\mathrm{NO}}=0,025 \mathrm{~s}^{-1[89]}$ e assim, a espécie reduzida mantém a sua integridade o tempo suficiente para ser detectada. Quando o potencial é elevado a -0,65 V vs ECS este sinal não é mais observado devido ao início do segundo processo de redução, que envolve o consumo da espécie trans-[RuNO $\left.\left(\mathrm{NH}_{3}\right)_{4} n i c\right]^{2+}$.

Quando este experimento foi realizado com o íon complexo trans$\left[\mathrm{RuNO}\left(\mathrm{NH}_{3}\right)_{4} \mathrm{P}\left(\mathrm{OC}_{2} \mathrm{H}_{5}\right)_{3}\right]^{3+}$ não foi possível observar a banda $v_{\mathrm{NO}}$ referente ao produto

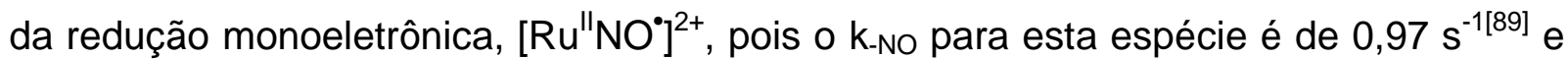
refletindo a baixa afinidade do centro de rutênio (II) pelo óxido nítrico, esta se dissocia com meia vida da ordem de 0,7 segundos. Assim, o tempo de obtenção da média dos espectros, em torno de $20 \mathrm{~s}$, é significantemente elevado para permitir a detecção da espécie trans-[RuNO $\left.\left(\mathrm{NH}_{3}\right)_{4} \mathrm{P}\left(\mathrm{OC}_{2} \mathrm{H}_{5}\right)_{3}\right]^{2+}$ sob as condições de temperatura em que 0 experimento foi conduzido $\left(T=25^{\circ} \mathrm{C}\right)$. 


\section{3 - Cálculos de DFT para os complexos trans-[Ru( $\left.\left(\mathrm{NH}_{3}\right)_{4} \mathrm{P}(\mathrm{OEt})_{3} \mathrm{~L}^{\mathrm{n}}\right]^{\mathrm{n}+2}$, onde $\mathrm{L}=\mathrm{NO}^{+}, \mathrm{NO}, \mathrm{NO}^{-}$e HNO}

Cálculos Quânticos, realizados anteriormente, permitiram interpretar os espectros eletrônicos de uma série de compostos do tipo trans-[Ru( $\left.\left(\mathrm{NH}_{3}\right)_{4} \mathrm{LNO}\right]^{3+}$, bem como verificar que a adição de um elétron aos compostos acima conduz à espécie trans$\left[\mathrm{Ru}\left(\mathrm{NH}_{3}\right)_{4} \mathrm{LNO}\right]^{2+}$ com densidade eletrônica correspondente ao elétron adicionado, situado principalmente sobre os orbitais do ligante NO. Para uma melhor compreensão da estabilidade do ligante NO coordenado ao metal no complexo em estudo, em seus diferentes estados de oxidação ( $\mathrm{NO}^{+}, \mathrm{NO}, \mathrm{NO}^{-}$e HNO) (Figura 4.2), bem como dos sítios de redução referente à espécie $\left[\mathrm{Ru}^{\mathrm{II}} \mathrm{NO} \mathrm{O}^{2+}\right.$, foram realizados cálculos quânticos para cada uma das espécies acima.

Para a validação da base de cálculo e da metodologia, foram calculados os parâmetros para a espécie complexo trans- $\left[\mathrm{Ru}\left(\mathrm{NH}_{3}\right)_{4} \mathrm{P}\left(\mathrm{OC}_{2} \mathrm{H}_{5}\right)_{3} \mathrm{NO}\right]\left(\mathrm{CF}_{3} \mathrm{COO}\right)_{3}$ e foi feito uma comparação com dados experimentais obtidos por difração de raios- $X^{[73]}$ para o mesmo complexo. As distâncias e os ângulos de ligação selecionados da otimização dessa molécula estão apresentados na Tabela 4.2. 
Tabela 4.2 - Distâncias de ligação e ângulos de ligação do Complexo trans$\left[\mathrm{Ru}\left(\mathrm{NH}_{3}\right)_{4} \mathrm{P}\left(\mathrm{OC}_{2} \mathrm{H}_{5}\right)_{3} \mathrm{~L}\right]^{\mathrm{n}+}\left(\mathrm{L}=\mathrm{NO}, \mathrm{NO}^{+}, \mathrm{NO}^{-}\right.$e $\left.\mathrm{HNO}\right)$ em água e a sua comparação com dados cristalográficos ${ }^{[49]}$ para o complexo.

\begin{tabular}{lccc}
\hline & $\mathbf{R u}-\mathbf{N}(\mathbf{N O})(\AA)$ & $\mathbf{N}-\mathbf{O}(\AA)$ & $\mathbf{R u - N ( N O ) - O}(\mathbf{g r a u})$ \\
\hline (NO $\left.^{+}\right)_{\exp }$ & 1,766 & 1,124 & 174,9 \\
(NO $\left.^{+}\right)$ & 1,815 & 1,170 & 177,9 \\
(NO) $^{-}$ & 1,915 & 1,213 & 141,6 \\
(NO) $^{-}$ & 1,926 & 1,282 & 116,9 \\
(HNO) & 1,938 & 1,282 & 122,7 \\
\hline
\end{tabular}

Pela análise da Tabela 4.2 observa-se que os resultados dos dados cristalográficos e os obtidos por cálculo teórico para o complexo trans$\left[\mathrm{Ru}\left(\mathrm{NH}_{3}\right)_{4} \mathrm{P}\left(\mathrm{OC}_{2} \mathrm{H}_{5}\right)_{3} \mathrm{NO}\right]\left(\mathrm{PF}_{6}\right)_{3}$, estão muito próximos, atestando a auto consistência do método de cálculo.

Assim a distância interatômica calculada para $\mathrm{Ru}-\mathrm{N}(\mathrm{O})$ é de $1,81 \pm 0,02 \AA$, sendo este valor próximo ao de $1,766 \AA$ obtido por difração de raios-X para o composto nitrosilo. Esta distância aumenta com a redução e a protonação do nitroxil atingindo o valor de 1,94 $\pm 0,02 \AA$. A distância N-O de 1,17 $\pm 0,02 \AA$ para o complexo nitrosilo também aumenta com a redução e a protonação do nitroxilo. Estas alterações estão também relacionadas à variação da ordem de ligação entre os átomos de $\mathrm{N}$ e $\mathrm{O}$, que diminui à medida que ocorre a população dos orbitais antiligantes do monóxido de nitrogênio, levando a um enfraquecimento da ligação $\mathrm{N}-\mathrm{O}$ e aumentando assim, a distância entre os dois átomos. 
A distância calculada para o fragmento Ru-NO será a soma das distâncias do Ru$\mathrm{N}(\mathrm{O})$ e $\mathrm{N}-\mathrm{O}$, que varia de 2,99 $\AA$ (nitrosilo complexo) a 3,22 $\AA$ (composto nitroxil protonado). Essa diferença na distância do fragmento Ru-NO com a redução do nitrosilo, é um reflexo do modelo de ligação, que considera a existência no complexo de nitrosilo de uma extensa retrodoação na ligação $\mathrm{Ru} \rightarrow \mathrm{NO}$. Este tipo de ligação diminui a distância metal-ligante. Por outro lado, a diminuição do efeito $\pi$-receptor do NO com a redução do nitrosilo leva ao enfraquecimento da ligação, e conseqüentemente, aumenta a distância metal-ligante ${ }^{[59]}$.

Foram também obtidas informações sobre a composição dos orbitais moleculares (HOMO e LUMO) do complexo onde a espécie NO se encontra em diferentes estados formais de oxidação $\left(\mathrm{NO}^{+}, \mathrm{NO}, \mathrm{NO}^{-}\right.$e $\left.\mathrm{HNO}\right)$. Esses orbitais moleculares (HOMO e LUMO) têm sido muito utilizados em estudos de reatividade química, pois indicam os possíveis sítios reativos em reações de oxidação e redução. Os orbitais moleculares HOMO fornecem indícios sobre a tendência de um composto em formar cátion, pois é deste orbital que o elétron seria retirado em uma reação de oxidação. Já o orbital LUMO fornece resultados sobre os sítios de redução de uma molécula, pois este orbital é o responsável pela entrada de elétron na molécula ${ }^{[93]}$.

Como neste trabalho a reação envolvendo o complexo é uma reação de redução, somente o orbital LUMO (orbital molecular onde entrará o elétron referente à redução do complexo) da espécie $\left[\mathrm{Ru}^{\mathrm{II}} \mathrm{NO} \mathrm{O}^{2+}\right.$ será analisado.

Para o complexo reduzido $\left[\mathrm{Ru}^{\prime \prime} \mathrm{NO}^{\circ}\right]^{2+}$ o LUMO e o LUMO +1 possuem 80 e $85 \%$ de caráter $\pi^{*}$ do $\mathrm{NO}$, respectivamente. Assim, pode-se considerar que a segunda 
redução ocorre com a população dos orbitais $\pi^{*}$ do NO. O LUMO +1 possui um aumento de energia de $0,30 \mathrm{eV}$ comparado à energia do LUMO. Como a diferença de energia entre o LUMO e o LUMO +1 é muito pequena, os dois estados podem ser considerados degenerados. A composição do LUMO para esta espécie é de $80 \% \pi$ (NO) e $16 \% d_{x^{2}}$ - y2 $(R u)$ e para o HOMO é de $100 \% d_{x y}(R u)$. A composição dos LUMOs e HOMOs para os demais sistemas, calculados por DFT, se encontram tabelados no Apêndice A.

Com o intuito de confirmar as evidências constatadas da análise do LUMO, foi efetuado o cálculo das cargas atômicas derivadas do potencial eletrostático, com o complexo contendo o $\mathrm{NO}$ em diferentes estados de oxidação. Este cálculo permitiu avaliar a mudança de densidade eletrônica do complexo antes e após as sucessivas reduções. Os valores das cargas atômicas calculadas estão indicados na Tabela 4.3.

Tabela 4.3 - Cálculo das cargas atômicas derivadas do potencial eletrostático para o complexo contendo o monóxido de nitrogênio em diferentes estados formais de oxidação

\begin{tabular}{ccccc}
\hline Átomos & $\mathrm{NO}^{+}$ & $\mathrm{NO}$ & $\mathrm{NO}^{-}$ & $\mathrm{HNO}$ \\
\hline $\mathrm{Ru}$ & 0,55 & 0,43 & 0,35 & 0,45 \\
$\mathrm{~N}(\mathrm{NO})$ & 0,30 & 0,13 & $-0,04$ & $-0,10$ \\
$\mathrm{O}(\mathrm{NO})$ & 0,05 & $-0,14$ & $-0,42$ & $-0,30$ \\
$\mathrm{P}$ & 1,86 & 1,79 & 1,69 & 1,78 \\
\hline
\end{tabular}


Ao analisar a Tabela 4.3, verifica-se que a adição de elétrons no orbital molecular do complexo leva a mudanças na densidade de carga eletrônica da molécula, porém a variação mais significativa ocorre nos átomos de $\mathrm{N}$ e O, comprovando novamente que o ligante $\mathrm{NO}$ é o principal sítio de redução dos pares $\left[\mathrm{Ru}^{\mathrm{Il}} \mathrm{NO}^{+}\right]^{3+} /\left[\mathrm{Ru}^{\mathrm{II}} \mathrm{NO}\right]^{2+}$ e $\left[\mathrm{Ru}^{\prime \prime} \mathrm{NO}^{*}\right]^{2+} /\left[\mathrm{Ru}^{\prime \prime} \mathrm{NO}^{-}\right]^{+}$.

Verificou-se também que o estiramento vibracional $\mathrm{NO}$, em termos de $\mathrm{cm}^{-1}$, do sistema trans-[RuL $\left.\left(\mathrm{NH}_{3}\right)_{4} \mathrm{P}\left(\mathrm{OC}_{2} \mathrm{H}_{5}\right)_{3}\right]^{3+}$, baseado nos cálculos quânticos, diminui com a redução das espécies: $L=N^{+}\left(1812 \mathrm{~cm}^{-1}\right), \mathrm{NO}\left(1588 \mathrm{~cm}^{-1}\right), \mathrm{NO}^{-}\left(1309 \mathrm{~cm}^{-1}\right), \mathrm{HNO}$ $\left(1297 \mathrm{~cm}^{-1}\right)$. Os valores teóricos de 1309 e $1297 \mathrm{~cm}^{-1}$ para o $v_{\mathrm{NO}}$ dos complexos $\left[\mathrm{Ru}^{\mathrm{IINO}}\right]^{+}$e $\left[\mathrm{Ru} \mathrm{IHNO}^{2+}\right.$, respectivamente, se encontram dentro da faixa dos valores de $v_{\mathrm{NO}}$ de $1300-1500 \mathrm{~cm}^{-1}$ para complexos de nitroxilos metálicos, contendo o ferro, ósmio, rênio e rutênio como centros metálicos ${ }^{[14-16,20]}$, relatados na literatura.

Os valores calculados para a energia de solvatação sugerem que a espécie $\left[\mathrm{Ru}^{\prime \prime} \mathrm{HNO}\right]^{2+}$ é mais estável que a espécie $\left[\mathrm{Ru}^{\prime \prime} \mathrm{NO}^{-}\right]^{+}$com uma diferença de energia de $104,4 \mathrm{kcal} . \mathrm{mol}^{-1}$. Além disso, a espécie $\left[\mathrm{Ru}^{1} \mathrm{NO}^{-}\right]^{+}$, onde o grupo NO se encontra no estado singlete, é mais estável que a espécie $\left[\mathrm{Ru}^{3} \mathrm{NO}^{-}\right]^{+}$, em que o grupo NO está no estado triplete, com uma diferença de 11,2 kcal.mol ${ }^{-1}$. Assim, é bastante razoável supor que o produto da redução de dois elétrons do íon trans-[Ru(NO) $\left.\left(\mathrm{NH}_{3}\right)_{4} \mathrm{P}\left(\mathrm{OC}_{2} \mathrm{H}_{5}\right)_{3}\right]^{3+}$ é provavelmente a espécie trans- $\left[\mathrm{Ru}\left(\mathrm{NH}_{3}\right)_{4} \mathrm{P}\left(\mathrm{OC}_{2} \mathrm{H}_{5}\right)_{3}{ }_{3} \mathrm{NO}\right]^{+}$, onde o $\mathrm{NO}$ se encontra na forma reduzida triplete, ${ }^{3} \mathrm{NO}^{-}$, a qual se isomeriza originando a espécie singleto trans$\left[\mathrm{Ru}\left(\mathrm{NH}_{3}\right)_{4} \mathrm{P}\left(\mathrm{OC}_{2} \mathrm{H}_{5}\right)_{3}{ }^{1} \mathrm{NO}\right]^{+}$mais estável. 


\section{4 - Redução química por reação com o $\alpha$-Cetoglutarato}

Para estudar a redução química do ligante $\mathrm{NO}^{+}$a $\mathrm{NO}^{-}$no íon complexo trans$\left[\mathrm{RuNO}\left(\mathrm{NH}_{3}\right)_{4} \mathrm{P}\left(\mathrm{OC}_{2} \mathrm{H}_{5}\right)_{3}\right]^{3+}$, escolheu-se um redutor de dois elétrons com potencial de redução adequado à segunda onda de redução, considerando-se $E_{p c 2}=-0,69 V v s$ ECS. Desta maneira, optou-se para este propósito, a utilização do a-cetoglutarato, um importante composto biológico e um intermediário fundamental no ciclo de Krebs.

Sabe-se que o $\alpha$-cetoglutarato ( $\alpha-C G$ ) pode sofrer uma aminação redutiva ${ }^{[95-96]}$, porém este composto também possui uma função importante em reações de oxirredução. O a-CG sofre uma descarboxilação formando o succinato semialdeído e $\mathrm{CO}_{2}{ }^{[97-98]}$, liberando com o processo dois elétrons ${ }^{[99]}$, conforme a Equação 6.

$$
\mathrm{C}_{5} \mathrm{H}_{6} \mathrm{O}_{5} \longrightarrow \mathrm{C}_{4} \mathrm{H}_{6} \mathrm{O}_{3}+\mathrm{CO}_{2}+2 \mathrm{e}^{-}
$$

O potencial de redução da reação é de $-0,90 \vee v s$ ECS $^{[99-100]}$, ou seja, possui um potencial acessível para atuar como redutor para o complexo em estudo. Por outro lado, a reação do complexo com o $\alpha-C G$ é relativamente lenta (cerca de alguns minutos), devido provavelmente à interconversão deste composto em outras formas inativas $^{[101-102]}$, como mostra a Figura 4.11. 

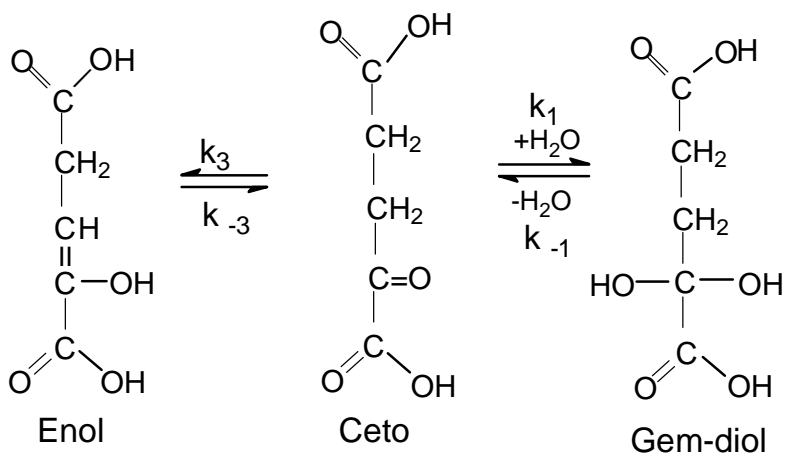

$$
\text { Cíclica }
$$

Figura 4.11 - Esquema de algumas formas do ácido a-cetoglutárico em solução ${ }^{[103]}$.

As evidências sugerem que a interconversão das formas cíclica $\leftrightarrows$ ceto é extremamente rápida, e que a concentração da forma gem-diol é elevada com a diminuição do pH, sendo que em pH 1,0 uma solução de $\alpha-C G$ contém $35 \%$ da forma gem-diol, $35 \%$ ceto e $30 \%$ da forma cíclica, e em pH neutro a forma gem-diol diminui para apenas $6 \%$, prevalecendo a forma ceto ${ }^{[99]}$, que é a forma ativa. Assim sendo, sob as condições experimentais $(\mathrm{pH} \approx 3,0) \circ \alpha-C G$ não se encontra totalmente em sua forma ativa (ceto).

Neste trabalho foi utilizado o composto a-cetoglutarato como redutor de dois elétrons para reduzir 0 íon complexo trans- $\left[\mathrm{RuNO}\left(\mathrm{NH}_{3}\right)_{4} \mathrm{P}\left(\mathrm{OC}_{2} \mathrm{H}_{5}\right)_{3}\right]^{3+}$ a trans$\left[\mathrm{Ru}\left(\mathrm{NH}_{3}\right)_{4} \mathrm{P}\left(\mathrm{OC}_{2} \mathrm{H}_{5}\right)_{3} \mathrm{NO}\right]^{+}$. 
O acompanhamento da reação de redução do íon complexo trans$\left[\mathrm{Ru}\left(\mathrm{NH}_{3}\right)_{4} \mathrm{NOP}\left(\mathrm{OC}_{2} \mathrm{H}_{5}\right)_{3}\right]^{3+}$ com o $\alpha-\mathrm{CG}$, foi efetuado utilizando-se a voltametria cíclica (Figura 4.12).

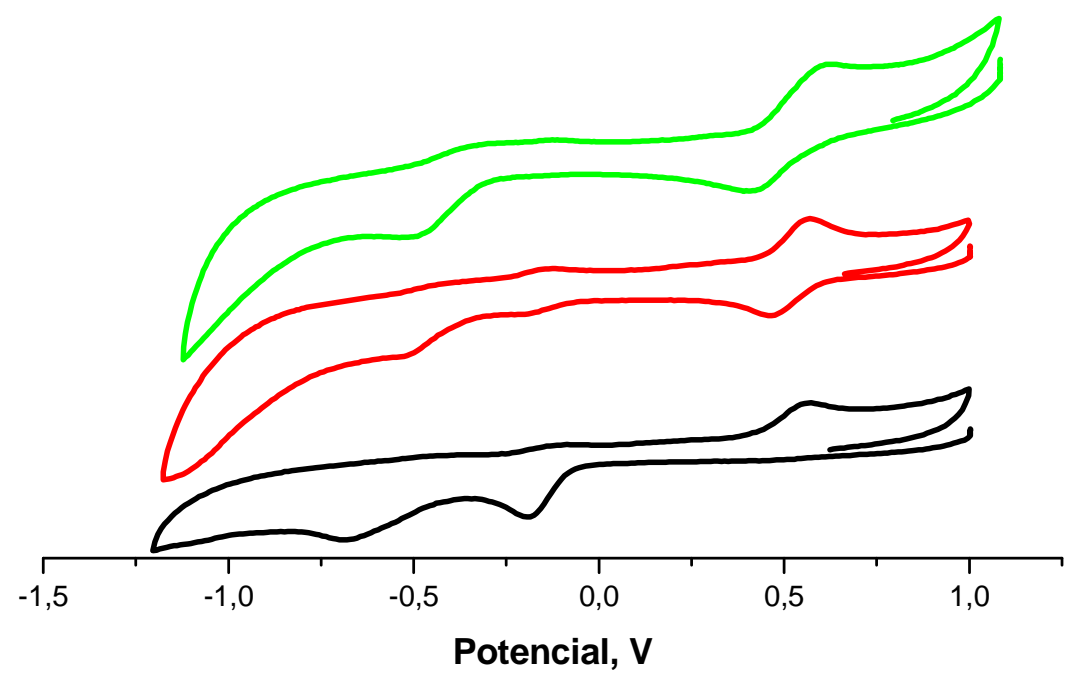

Figura 4.12 - Voltamograma cíclico $(-)$ do íon complexo $t$ - $\left[\mathrm{Ru}\left(\mathrm{NH}_{3}\right){ }_{4} \mathrm{NOP}\left(\mathrm{OC}_{2} \mathrm{H}_{5}\right)\right]^{3+}$; (-) após 45 min de reação do complexo com o a-Cetoglutarato; (-) Após 90 min de reação. Condições: NaTFA; $\mu=0,1 \mathrm{~mol} \cdot \mathrm{L}^{-1} ; \mathrm{pH}=2,9 ; \mathrm{T}=25^{\circ} \mathrm{C} ; \mathrm{C} \mathrm{Ru}=1,2 \times 10^{-3} \mathrm{~mol} \cdot \mathrm{L}^{-1}$; $\mathrm{C}_{\mathrm{a}-\mathrm{CG}}=1,1 \times 10^{-1} \mathrm{~mol} \cdot \mathrm{L}^{-1} ; \mathrm{v}=0,5 \mathrm{~V} \cdot \mathrm{s}^{-1}$.

Observa-se na Figura 4.12 o desaparecimento dos picos de redução em -0,18 e $0,69 \mathrm{~V}$, referindo-se às etapas $\left[\mathrm{Ru}^{\prime \prime} \mathrm{NO}\right]^{3+} \rightarrow\left[\mathrm{Ru}{ }^{\prime \prime} \mathrm{NO}\right]^{2+}$ e $\left[\mathrm{Ru}{ }^{\mathrm{II}} \mathrm{NO}\right]^{2+} \rightarrow\left[\mathrm{Ru}{ }^{\mathrm{II}} \mathrm{NO}\right]^{+}$, respectivamente, e o aparecimento de um pico em -0,50 V. A formação desse pico pode estar relacionado à liberação de óxido nitroso (produto da reação de dimerização do HNO) em solução ou do óxido nítrico, liberado pela dissociação de NO no complexo. Experimentos em soluções aquosas indicam que o óxido nitroso é reduzido utilizando um eletrodo de platina, provavelmente a gás nitrogênio ${ }^{[103]}$, de acordo com Equação 12:

$$
\mathrm{N}_{2} \mathrm{O}+\mathrm{H}_{2} \mathrm{O}+2 \mathrm{e}^{-} \longrightarrow \mathrm{N}_{2}+2 \mathrm{OH}^{-}
$$


Outra possibilidade seria a redução do óxido nítrico liberado no meio, formando o $\mathrm{HNO}^{[17,21]}$ (Equação 13):

$$
\mathrm{NO}+\mathrm{e}^{-} \longrightarrow \mathrm{HNO}
$$

Sendo assim, para verificar se a formação do pico em $-0,5 \mathrm{~V}$ referia-se a uma dessas reações de redução, em experimentos paralelos, borbulhou-se o óxido nitroso (solubilidade em água de aproximadamente $2 \times 10^{-2} \mathrm{molL}^{-1}$ a $\left.1 \mathrm{~atm}\right)^{[103]}$ e o óxido nítrico por cerca de $2 \mathrm{~h}$ em soluções contendo o eletrólito NaTFA $\mu=0,1 \mathrm{molL}$ e pH 3 . Voltamogramas cíclicos foram registrados em condições comparáveis aos experimentos realizados entre o a-CG e o complexo, para ambos os casos, como mostram as Figuras 4.13 e 4.14 .

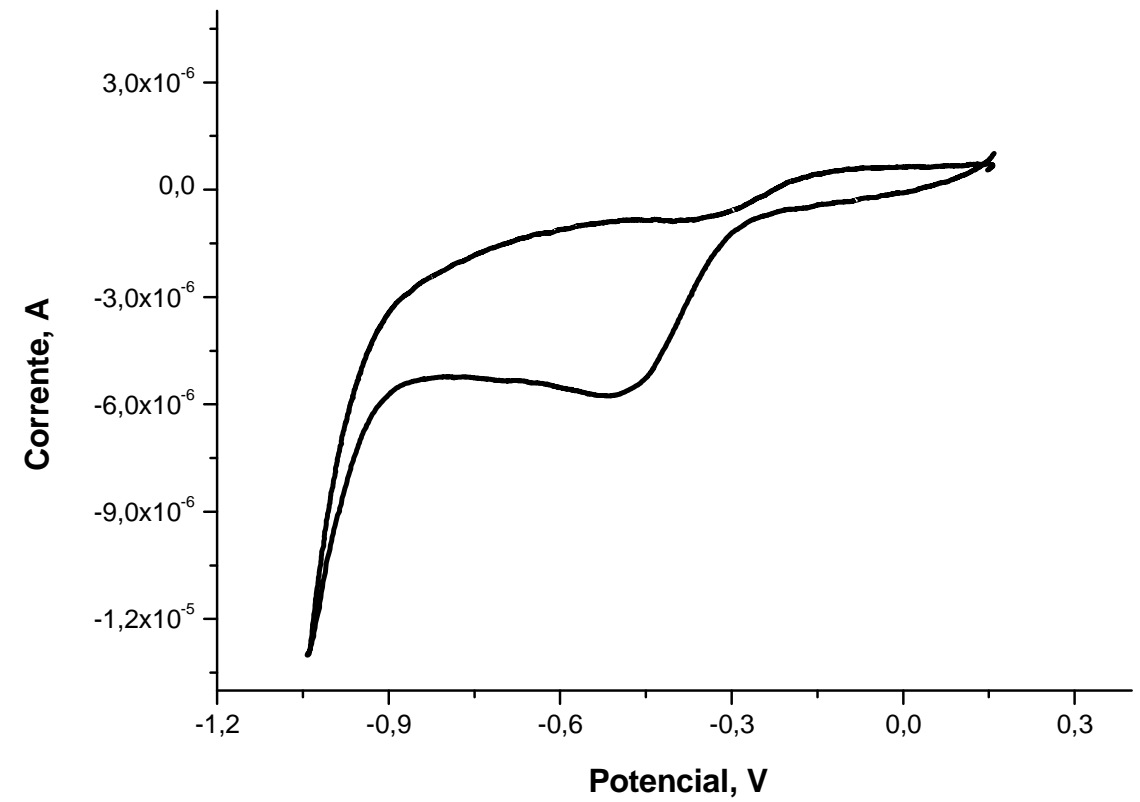

Figura 4.13 - Voltamograma cíclico de uma solução de NaTFA saturada com o gás $\mathrm{N}_{2} \mathrm{O}$. Condições: $\mu=0,1 \mathrm{molL}^{-1} ; \mathrm{pH}=3,1 ; \mathrm{v}=0,1 \mathrm{~V} \cdot \mathrm{s}^{-1} ; \mathrm{T}=25^{\circ} \mathrm{C}$. 


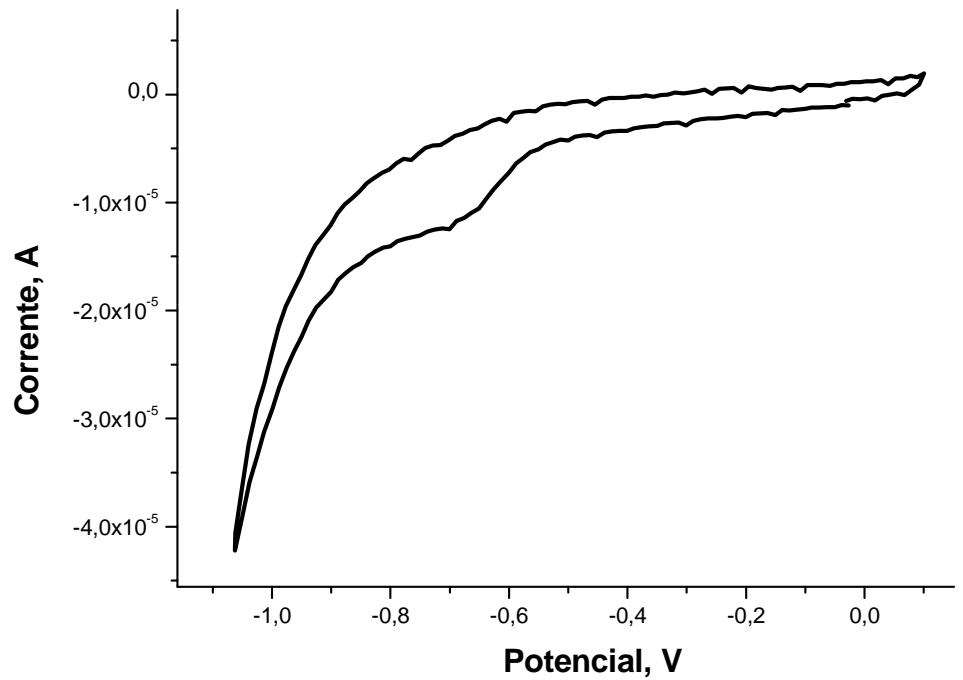

Figura 4.14 - Voltamograma cíclico de uma solução de NaTFA saturada com NO.

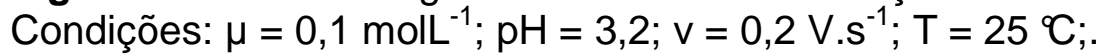

Pela análise dos voltamogramas cíclicos, observou-se que a redução da molécula NO ocorre a potencial mais negativo $(-0,7$ vs ECS) do que aquele observado para o produto formado pela reação do complexo e a-CG (-0,5 vs ECS). Entretanto, as soluções saturadas de óxido nitroso apresentaram pico de redução próximo ao observado para a reação. Deste modo, o aparecimento do pico a $-0,5 \mathrm{~V}$ vs ECS observado para as soluções de trans-[RuNO $\left.\left(\mathrm{NH}_{3}\right)_{4} \mathrm{P}\left(\mathrm{OC}_{2} \mathrm{H}_{5}\right)\right]^{3+}$, após a reação com o $\alpha$ cetoglutarato foi tentativamente atribuído à presença em solução da espécie eletroativa $\mathrm{N}_{2} \mathrm{O}$, o qual seria gerado pela reação de dimerização.

Foi realizado o monitoramento da reação por espectrofotometria na região do ultravioleta e visível (Figura 4.15). O espectro de absorção UV-vis do a-CG apresenta uma banda de absorção fraca em $320 \mathrm{~nm}\left(\varepsilon=29,1 \mathrm{~mol}^{-1} \mathrm{~L}^{-1} \mathrm{~cm}^{-1}\right)$ para a forma ceto $^{[102,104]}$, sendo que as formas gem-diol e cíclica não absorvem na faixa de 
comprimento de onda estudada. Além disso, o ácido succínico, um dos produtos da reação, apresenta uma banda em $215 \mathrm{~nm}^{[105]}$, ou seja, não interfere na análise do espectro.

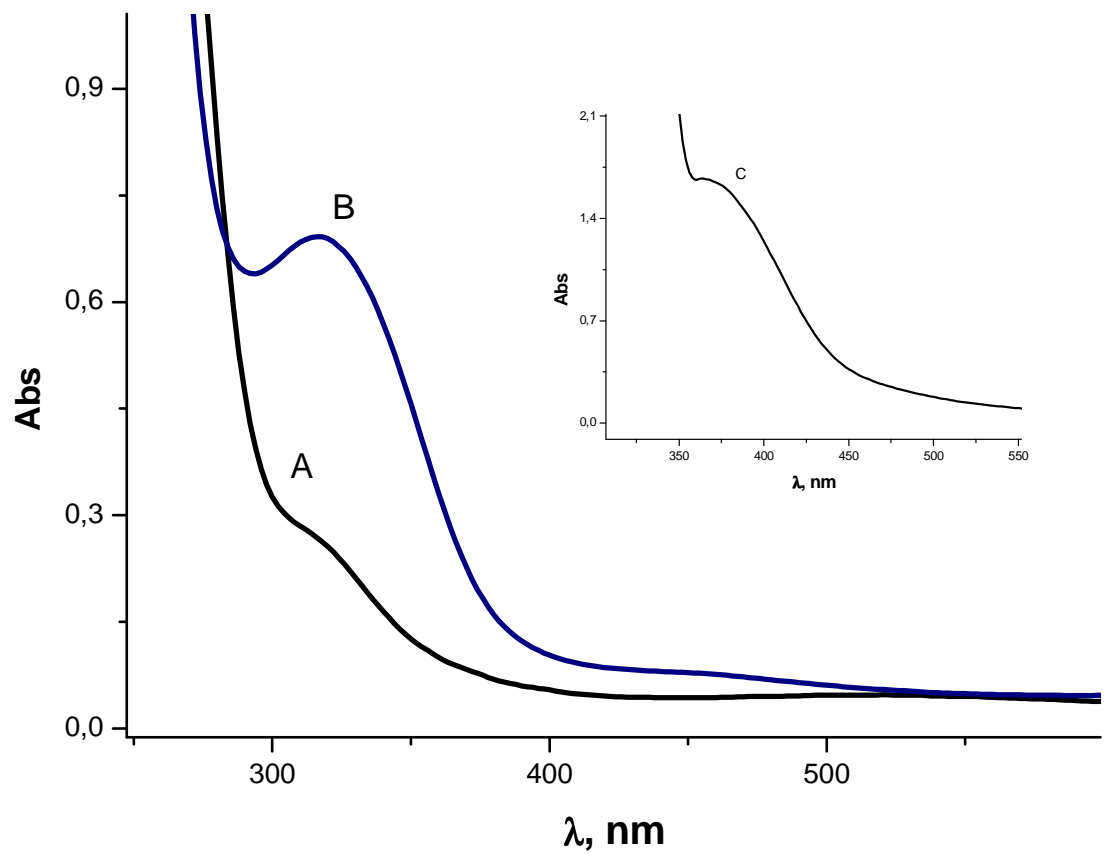

Figura 4.15 - Monitoramento espectrofotométrico da reação do complexo trans$\left[\mathrm{RuNO}\left(\mathrm{NH}_{3}\right)_{4} \mathrm{P}\left(\mathrm{OCH}_{2} \mathrm{CH}_{3}\right)\right]^{3+}$ e $\alpha-\mathrm{CG}$. Condições: $\mathrm{C}_{\mathrm{Ru}}=1,3 \times 10^{-3} \mathrm{~mol}^{-L^{-1}} ; \mathrm{C}_{\alpha-\mathrm{CG}}=9,6 \times 10^{-}$ ${ }^{2}$ mol. $L^{-1}$; NaTFA; $\mathrm{pH}=2,9 ; \mu=0,1 \mathrm{M} ; \mathrm{T}=25^{\circ} \mathrm{C}$.

Conforme indicado na Figura 4.16, a variação do espectro na região de 300 a 400 nm foi utilizada para monitorar a reação. Neste caso foi observado o aumento da banda em $316 \mathrm{~nm}$, que é onde os íons complexos trans-[Ru(NO) $\left.\left(\mathrm{NH}_{3}\right)_{4} \mathrm{P}\left(\mathrm{OCH}_{2} \mathrm{CH}_{3}\right)\right]^{3+}(\varepsilon=216$ $\left.\mathrm{mol}^{-1} \cdot \mathrm{L}^{-1} \cdot \mathrm{cm}^{-1}\right)$ e trans- $\left[\mathrm{Ru}\left(\mathrm{NH}_{3}\right)_{4}\left(\mathrm{H}_{2} \mathrm{O}\right) \mathrm{P}\left(\mathrm{OCH}_{2} \mathrm{CH}_{3}\right)\right]^{2+} \quad\left(\varepsilon=650 \mathrm{~mol}{ }^{-1} \cdot \mathrm{L}^{-1} \cdot \mathrm{cm}^{-1}\right)^{[33]}$ absorvem. Como o composto de partida é o nitrosilo complexo (espectro A) e, visto que a absortividade deste composto é menor que o do aquocomplexo, nota-se que a variação do espectro é consistente com a reação do nitrosilo complexo e $\alpha$-CG 
originando 0 íon complexo trans- $\left[\mathrm{Ru}\left(\mathrm{NH}_{3}\right)_{4}\left(\mathrm{H}_{2} \mathrm{O}\right) \mathrm{P}\left(\mathrm{OC}_{2} \mathrm{H}_{5}\right)\right]^{2+}$. Este fato pode ser comprovado pela reação do produto formado com pirazina (pz). Sabe-se que o íon complexo trans- $\left[\mathrm{Ru}\left(\mathrm{NH}_{3}\right)_{4}\left(\mathrm{H}_{2} \mathrm{O}\right) \mathrm{P}\left(\mathrm{OC}_{2} \mathrm{H}_{5}\right)\right]^{2+}$ reage rapidamente com pirazina para formar a espécie trans-[Ru( $\left.\left(\mathrm{NH}_{3}\right)_{4} \mathrm{P}\left(\mathrm{OC}_{2} \mathrm{H}_{5}\right)_{3}(\mathrm{pz})\right]^{2+}$. Este íon complexo possui uma banda de absorção em $366 \mathrm{~nm}\left(\varepsilon=4,2 \times 10^{3} \mathrm{~mol}^{-1} \cdot \mathrm{L}^{-1} \cdot \mathrm{cm}^{-1}\right)^{[106]}$, a qual pode ser observada no espectro registrado após a adição de excesso de pirazina no meio reacional no final da reação (espectro inserido na Figura 4.16).

A reação também foi monitorada por ressonância magnética nuclear. A Figura 4.16 apresenta o espectro de $\mathrm{RMN}{ }^{31} \mathrm{P}$ do produto final da reação do complexo trans$\left[\mathrm{Ru}\left(\mathrm{NH}_{3}\right)_{4} \mathrm{NOP}\left(\mathrm{OCH}_{2} \mathrm{CH}_{3}\right)\right]\left(\mathrm{PF}_{6}\right)_{3}$ e $\alpha$-cetoglutarato na proporção 1:100.

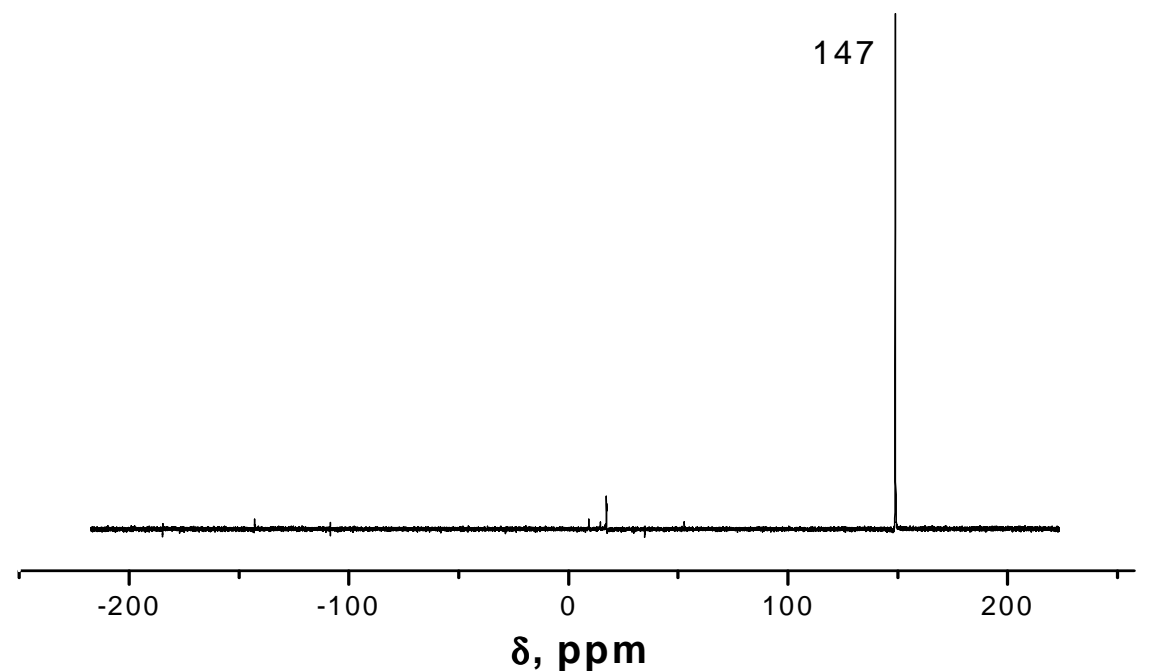

Figura 4.16 - RMN ${ }^{31} \mathrm{P}$ do produto final da reação do íon complexo trans[Ru(NO) $\left.\left(\mathrm{NH}_{3}\right)_{4} \mathrm{P}\left(\mathrm{OCH}_{2} \mathrm{CH}_{3}\right)\right]^{3+}$ e $\alpha-\mathrm{CG}$ (em água deuterada e NaTFA). Condições: $\mathrm{C}_{\mathrm{Ru}}=$ $5,4 \times 10^{-3}$ mol. $L^{-1} ; C_{\alpha-K G}=7,4 \times 10^{-1} \mathrm{~mol}^{-L^{-1}} ; \mu=0,1 \mathrm{~mol} . \mathrm{L}^{-1} ; \mathrm{pH}=3,2 ; \mathrm{T}=25^{\circ} \mathrm{C}$; tempo de reação $=2 \mathrm{~h}$.

Observa-se na Figura 4.16 o desaparecimento do singleto em 80 ppm, referente ao núcleo de fósforo do ligante trietilfosfito, $\mathrm{P}\left(\mathrm{OC}_{2} \mathrm{H}_{5}\right)$ no complexo nitrosilo de rutênio e 
o aparecimento de um singleto em $147 \mathrm{ppm}$, que é referente ao $\mathrm{P}\left(\mathrm{OC}_{2} \mathrm{H}_{5}\right)$ no complexo trans- $\left[\mathrm{Ru}\left(\mathrm{NH}_{3}\right)_{4}\left(\mathrm{H}_{2} \mathrm{O}\right) \mathrm{P}\left(\mathrm{OCH}_{2} \mathrm{CH}_{3}\right)\right]^{2+}$ formado. O desaparecimento do sinal em 80 ppm, confirma que o complexo contendo o íon nitrosilo foi totalmente convertido na espécie aquofosfito após o período de 2 horas. A reação foi realizada a temperatura ambiente e sob fluxo de argônio. A análise da reação por espectroscopia $\mathrm{RMN}{ }^{31} \mathrm{P}$ e por UV-vis mostra, portanto, o íon complexo trans- $\left[\mathrm{Ru}\left(\mathrm{NH}_{3}\right)_{4}\left(\mathrm{H}_{2} \mathrm{O}\right) \mathrm{P}\left(\mathrm{OCH}_{2} \mathrm{CH}_{3}\right)\right]^{2+}$ como um produto da reação, estando de acordo com o pressuposto.

\section{5- REAÇÃO COM A METMIOGLOBINA}

A metmioglobina e methemoglobina são convertidas em nitrosilmioglobina e nitrosilhemoglobina, respectivamente, por reação com doadores de $\mathrm{HNO} / \mathrm{NO}^{-[29]}$. Assim, tais proteínas são capazes de agir como captadores altamente seletivos para as espécies nitroxil. Essas reações são comumente denominadas de nitrosilação redutiva, visto que o Fe da hemoproteína está em seu estado oxidado (III) e após a reação o Fe será reduzido a (II).

Dessa forma, para verificar se há a liberação de NO’, o complexo foi reduzido com a-cetoglutarato em uma solução contendo a metmioglobina, sob atmosfera de argônio. A reação realizada em tampão ácido acético/acetato $\left(0,1 \mathrm{molL}^{-1}\right)$ e $\mathrm{pH}=4,2$, foi acompanhada espectroscopicamente na região do ultravioleta e visível (Figura 4.17). 


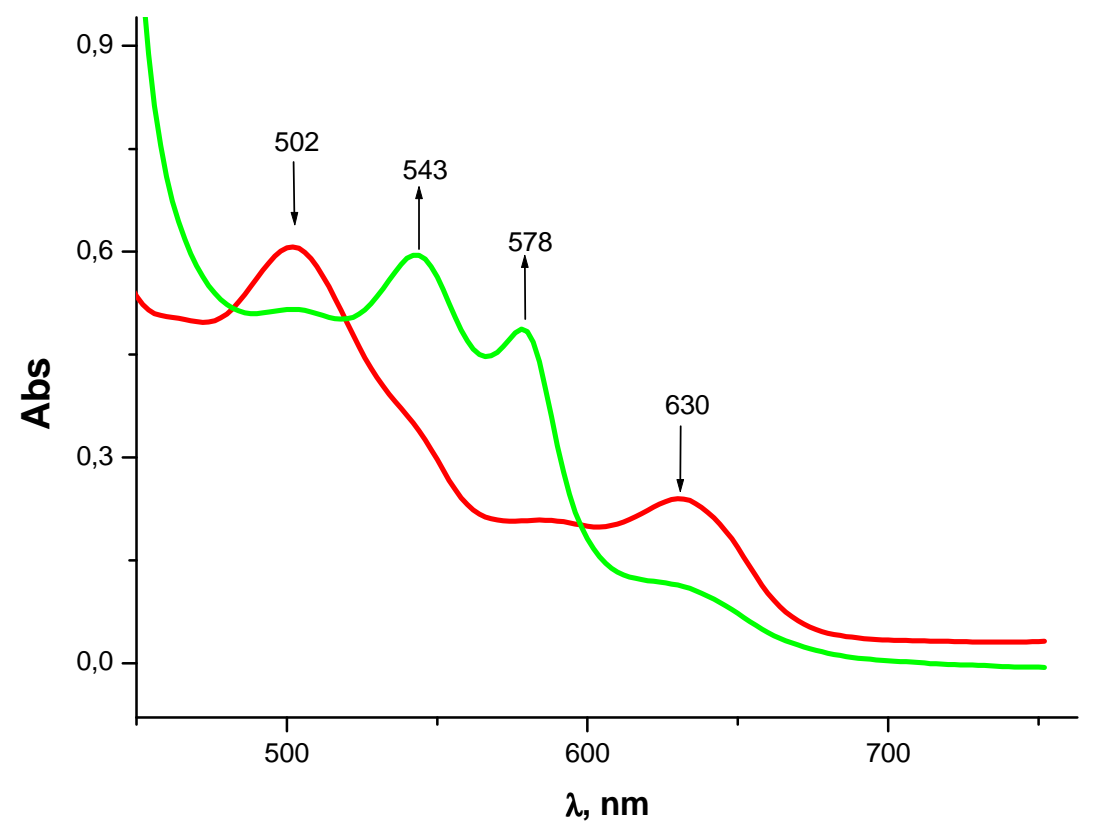

Figura 4.17 - Monitoramento espectrofotométrico da reação do complexo trans$\left[\mathrm{Ru}(\mathrm{NO})\left(\mathrm{NH}_{3}\right)_{4} \mathrm{P}\left(\mathrm{OCH}_{2} \mathrm{CH}_{3}\right)\right]^{3+}$, $\alpha-\mathrm{CG}$ e metMb. Condições: $\mathrm{C}_{\mathrm{Ru}}=5,4 \times 10^{-4} \mathrm{~mol}^{-\mathrm{L}^{-1}} ; \mathrm{C}_{\alpha-\mathrm{KG}}$ $=5,4 \times 10^{-2}$ mol. $L^{-1} ; C_{\text {metMb }}=5,9 \times 10^{-5} \mathrm{molL}^{-1} \mathrm{NaTFA} ; \mathrm{pH}=4,2 ; \mu=0,1 \mathrm{molL} ; \mathrm{T}=25 \mathrm{C}$. (A) espectro da metMb - $502 \mathrm{~nm}\left(\varepsilon=10,2 \times 10^{3} \mathrm{M}^{-1} . \mathrm{cm}^{-1}\right)$ e $630 \mathrm{~nm}\left(\varepsilon=3,9 \times 10^{3} \mathrm{M}^{-1} . \mathrm{cm}^{-1}\right)$; (B) Produto da reação $-543 \mathrm{~nm}$ e $576 \mathrm{~nm}$; tempo de reação $=1 \mathrm{~h}$.

A bem definida mudança no espectro UV-visível observada durante a redução do complexo, leva a identificação do produto como sendo o aduto nitrosilo ferroso, caracterizado pelo aparecimento das bandas de absorção em $543 \mathrm{~nm}\left(\varepsilon=11,6 \times 10^{3} \mathrm{~mol}^{-}\right.$ $\left.{ }^{1} \cdot \mathrm{L}^{-1} \cdot \mathrm{cm}^{-1}\right)$ e $578 \mathrm{~nm}\left(\varepsilon=10,5 \times 10^{3} \mathrm{~mol}^{-1} \cdot \mathrm{L}^{-1} \cdot \mathrm{cm}^{-1}\right)$. Assim, esses resultados fornecem fortes evidências para a produção de $\mathrm{HNO} \mathrm{NO}^{-}$durante a reação, visto que o espectro eletrônico da metmioglobina não mostrou nenhuma alteração ao se adicionado a uma solução contendo $\alpha$-cetoglutarato. A presença das bandas de absorções em $502 \mathrm{~nm}(\varepsilon$ $\left.=10,2 \times 10^{3} \mathrm{~mol}^{-1} \cdot \mathrm{L}^{-1} \cdot \mathrm{cm}^{-1}\right)$ e $630 \mathrm{~nm}\left(\varepsilon=3,9 \times 10^{3} \mathrm{~mol}^{-1} \cdot \mathrm{L}^{-1} \cdot \mathrm{cm}^{-1}\right)$ no espectro final, indicam a presença de metmioglobina não reativa. $\mathrm{O}$ produto formado mostrou-se 
instável quando exposto ao ar, revertendo-se a metMb em 30 minutos aproximadamente.

Um ponto de interesse no espectro da Figura 4.18 é a investigação da origem da formação do aduto MbFe-NO. Para confirmar se realmente é a espécie NO que reage com a mioglobina, foram realizados experimentos borbulhando o óxido nítrico por $1 \mathrm{~h}$ em uma solução de tampão acetato, $\mathrm{pH}=4,2, \mu=0,1 \mathrm{molL}^{-1}$, contendo a mioglobina, seguido por fluxo de argônio por alguns minutos para remover o NO que não reagiu, e em seguida foram registrados espectros na região do ultravioleta-visível (Figura 4.18).

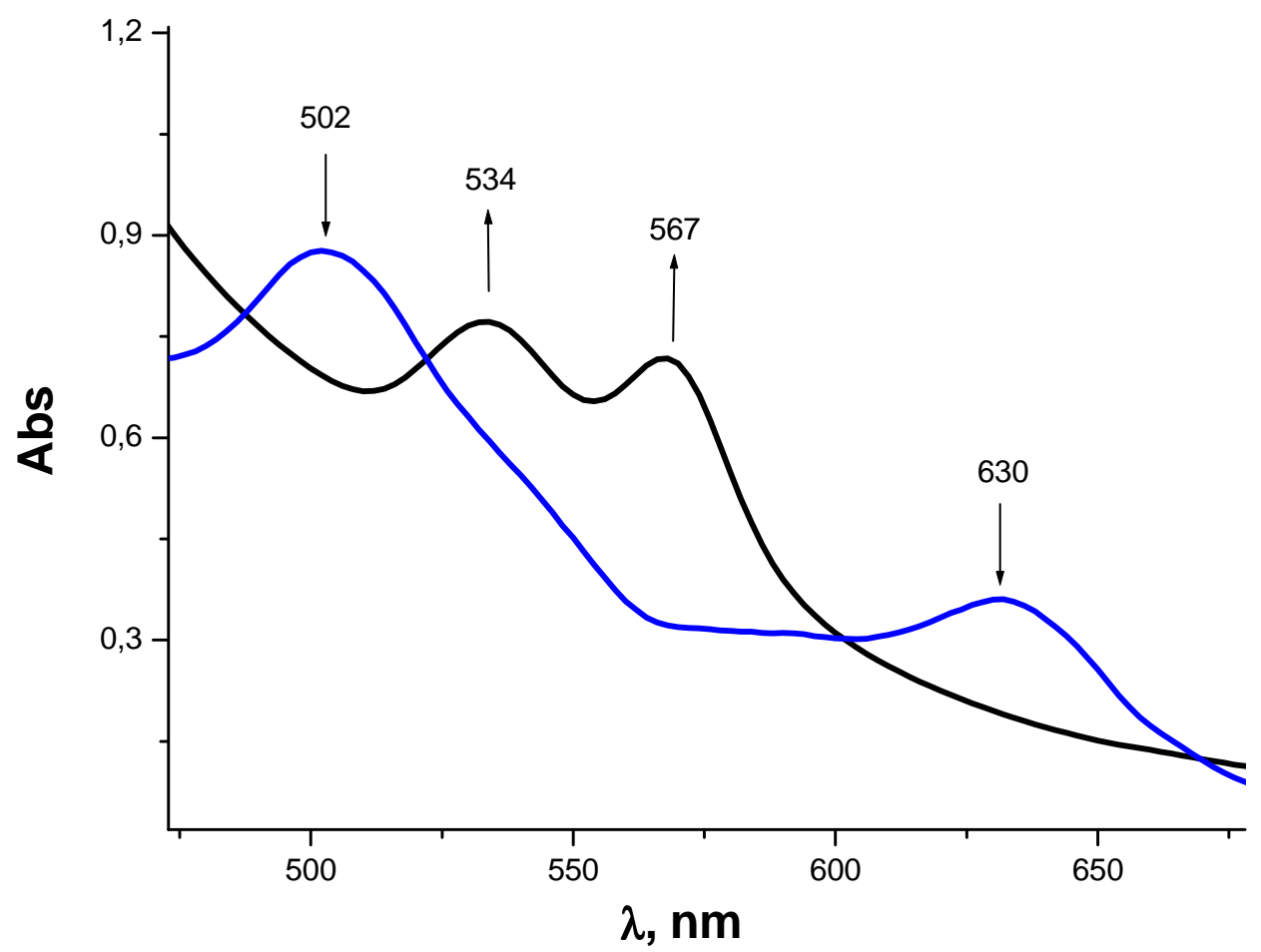

Figura 4.18 - Espectro eletrônico do produto da reação da metmioglobina e NO (一) metMb - 502 e $630 \mathrm{~nm}$ e (-) produto da reação - 534 e $567 \mathrm{~nm}$. Condições: $\mathrm{C}_{\text {metMb }}=$ $8,0 \times 10^{-4} \mathrm{molL}^{-1}$ tampão acetato $\mathrm{pH}=4,2 ; \mu=0,1 \mathrm{molL}^{-1} ; \mathrm{T}=25^{\circ} \mathrm{C}$. 
Neste caso, foram observados uma diminuição nas bandas características da metmioglobina (502 e $630 \mathrm{~nm}$ ) e um aumento das bandas em 534 e 567 nm. Essas bandas são atribuídas à formação do aduto $\mathrm{Mb}-\mathrm{Fe} e^{\mathrm{III}} \mathrm{NO} / \mathrm{Fe}^{\|} \mathrm{NO}^{+}$, formado a partir da reação de metMb e NO. Observa-se uma ligeira diferença entre os espectros formados pela reação de metMb e óxido nítrico (Figura 4.18) e pela reação de metMb com o produto da redução química do complexo nitrosilo de rutênio (Figura 4.17). Essa diferença entre as bandas indica que a reação entre a metMb e o produto liberado durante a redução química de trans-[RuNO $\left.\left(\mathrm{NH}_{3}\right)_{4} \mathrm{P}\left(\mathrm{OC}_{2} \mathrm{H}_{5}\right)_{3}\right]^{3+}$ e $\alpha-\mathrm{CG}$ não ocorre via óxido nítrico, confirmando as fortes evidências anteriores de liberação de nitroxil em solução.

A Figura 4.19 mostra o voltamograma cíclico de uma solução contendo o complexo, $\alpha-C G$ e a metMb (adicionada antes do complexo).

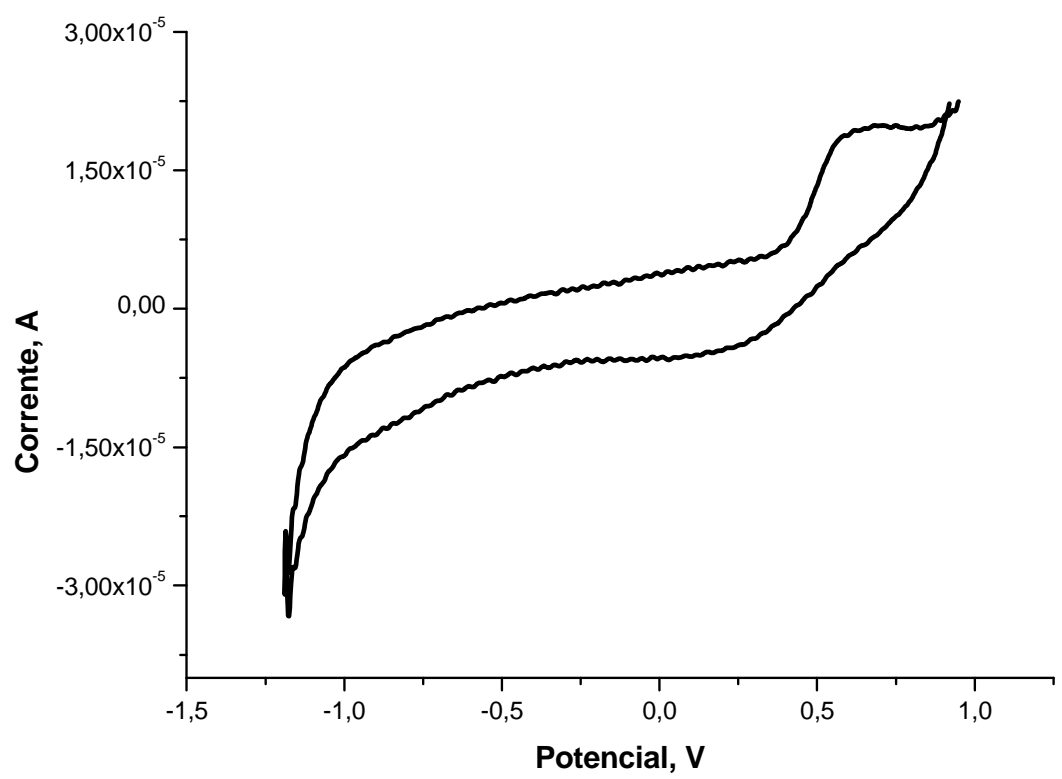

Figura 4.19 - Voltamograma cíclico de uma solução contendo íons trans[Ru(NO) $\left.\left(\mathrm{NH}_{3}\right)_{4} \mathrm{P}\left(\mathrm{OCH}_{2} \mathrm{CH}_{3}\right)\right]^{3+}$, a-CG e metmioglobina. Condições: eletrólito: Tampão acetato $0,1 \mathrm{~mol} . \mathrm{L}^{-1} ; \mathrm{pH}=4,2 ; \mathrm{v}=200 \mathrm{mV} . \mathrm{s}^{-1} ; \mathrm{C}_{\mathrm{Ru}}=1,0 \times 10^{-3} \mathrm{~mol}^{-\mathrm{L}^{-1}} ; \mathrm{C}_{\alpha-K G}=7,2 \times 10^{-1}$ mol. $L^{-1} ; C_{M b}=20 \mu$ mol. $L^{-1} ; T=25{ }^{\circ}$; tempo de reação $=1 \mathrm{~h}$. 
Nota-se nesta figura o desaparecimento do pico de redução em $-0,5 \mathrm{~V}$. Levando em consideração que este pico seja referente à redução do óxido nitroso, a adição de metMb, que age como captador do nitroxil, pode reduzir a concentração da espécie de nitroxil presente no meio reacional. Isso seria coerente com a hipótese de que o pico em $-0,5 \mathrm{~V}$ seja referente à presença de óxido nitroso, proveniente da dimerização do nitroxil. O pico de oxidação próximo a 0,6 V se refere ao aquocomplexo.

Com base nos resultados aqui obtidos, as Equações 14-17 propõem uma seqüência de reações que poderiam explicar o sistema em estudo.

$$
\begin{aligned}
& t \cdot\left[\mathrm{Ru}^{\prime \prime}\left(\mathrm{NO}^{+}\right)\left(\mathrm{NH}_{3}\right)_{4} \mathrm{P}(\mathrm{OEt})_{3}\right]^{3+}+1 \mathrm{e}^{-} \stackrel{\mathrm{E}=-0.18 \mathrm{~V}}{\longrightarrow} t-\left[\mathrm{Ru}^{\prime \prime}\left(\mathrm{NH}_{3}\right)_{4}(\mathrm{NO}) \mathrm{P}(\mathrm{OEt})_{3}\right]^{2+} \\
& t-\left[\mathrm{Ru}^{\prime \prime}\left(\mathrm{NH}_{3}\right)_{4}(\mathrm{NO}) \mathrm{P}(\mathrm{OEt})_{3}\right]^{2+}+1 \mathrm{e}^{-} \stackrel{\mathrm{E}=-0,69 \mathrm{~V}}{\longrightarrow} t-\left[\mathrm{Ru}\left(\mathrm{NH}_{3}\right)_{4} \mathrm{P}\left(\mathrm{OC}_{2} \mathrm{H}_{5}\right)_{3}\left({ }^{3} \mathrm{NO}\right)\right]^{+} \\
& \left.t-\left[\mathrm{Ru}\left(\mathrm{NH}_{3}\right)_{4} \mathrm{P}\left(\mathrm{OC}_{2} \mathrm{H}_{5}\right)_{3}\left({ }^{3} \mathrm{NO}-\right)\right]^{+} \longrightarrow t-\left[\mathrm{Ru}\left(\mathrm{NH}_{3}\right)_{4} \mathrm{P}\left(\mathrm{OC}_{2} \mathrm{H}_{5}\right)_{3}{ }^{1} \mathrm{NO}^{-}\right)\right]^{+} \\
& t \cdot\left[\mathrm{Ru}\left(\mathrm{NH}_{3}\right)_{4} \mathrm{P}\left(\mathrm{OC}_{2} \mathrm{H}_{5}\right)_{3}\left(\mathrm{NO}^{-}\right)\right]^{+}+2 \mathrm{H}_{2} \mathrm{O} \rightleftharpoons t-\left[\mathrm{Ru}\left(\mathrm{NH}_{3}\right)_{4}\left(\mathrm{H}_{2} \mathrm{O}\right) \mathrm{P}\left(\mathrm{OC}_{2} \mathrm{H}_{5}\right)_{3}\right]^{2+}+\mathrm{HNO}^{-\mathrm{OH}^{-}}
\end{aligned}
$$

Neste conjunto de reação o composto trans-[Ru(NO) $\left.\left(\mathrm{NH}_{3}\right)_{4} \mathrm{P}\left(\mathrm{OC}_{2} \mathrm{H}_{5}\right)\right]^{3+}$ é reduzido eletroquimicamente via 1 elétron formando a espécie [Ru"NO* ${ }^{2+}$ (Equação 9), que pode ser novamente reduzido monoeletronicamente (Equação 10). Deste processo de redução seria liberado a espécie nitroxil em solução. Por redução química o composto trans-[Ru(NO)($\left.\left(\mathrm{NH}_{3}\right)_{4} \mathrm{P}\left(\mathrm{OC}_{2} \mathrm{H}_{5}\right)\right]^{3+}$ pode ser reduzido via 2 elétrons formando provavelmente a espécie $\left[\mathrm{Ru}^{\prime \prime} \mathrm{NO}\right]^{+}$(Equação 11), que deve se dissociar liberando a espécie nitroxil e gerando o complexo trans$\left[\mathrm{Ru}\left(\mathrm{NH}_{3}\right)_{4}\left(\mathrm{H}_{2} \mathrm{O}\right) \mathrm{P}\left(\mathrm{OC}_{2} \mathrm{H}_{5}\right)\right]^{2+}$ (Equação 17). 


\section{CONSIDERAÇÕES}

FINAIS 


\section{5- CONSIDERAÇÕES FINAIS}

Este trabalho propõe uma seqüência de reações para explicar a redução de dois elétrons para o complexo trans-[Ru' $\left.\left(\mathrm{NO}^{+}\right)\left(\mathrm{NH}_{3}\right)_{4}\left(\mathrm{P}(\mathrm{OEt})_{3}\right)\right]^{3+}$ em solução aquosa. No espectro voltamétrico foi possível verificar que o complexo apresenta duas ondas (ou picos) de redução em -0,18 V e -0,69 V. A primeira onda de redução em $-0,18 \mathrm{~V}$ se refere à redução $\left[\mathrm{Ru}^{\prime \prime} \mathrm{NO}^{+}\right]^{3+} /\left[\mathrm{Ru}^{\prime \prime} \mathrm{NO}^{\circ}\right]^{2+}$.O estudo voltamétrico da segunda onda de redução no íon complexo trans-[Ru" $\left.\left(\mathrm{NO}^{+}\right)\left(\mathrm{NH}_{3}\right)_{4}\left(\mathrm{P}(\mathrm{OEt})_{3}\right)\right]^{3+}$ mostrou que o composto se reduz irreversivelmente com a transferência de 1 elétron, sendo a reação controlada por difusão. Portanto, a segunda onda de redução foi atribuída neste trabalho à redução da espécie $\left[\mathrm{Ru}^{\prime \prime} \mathrm{NO}{ }^{2}\right]^{2+}$ a $\left[\mathrm{Ru} \mathrm{U}^{\prime \prime} \mathrm{NO}\right]^{+}$.

Esse potencial de redução de $-0,69 \vee$ é acessível para redução química pelo composto a-cetoglutarato, capaz de agir como um redutor sobre o complexo. Nesta reação foi observada a formação do íon complexo trans-[Ru" $\left.\left(\mathrm{NH}_{3}\right)_{4}\left(\mathrm{H}_{2} \mathrm{O}\right)\left(\mathrm{P}(\mathrm{OEt})_{3}\right)\right]^{2+}$ e nitroxil como produtos da reação. Isso foi confirmado por medidas de $R M N{ }^{31} \mathrm{P}$, observando o aparecimento de um sinal em $147 \mathrm{ppm}$, referente ao grupo fosfito no trans-[Ru" $\left.\left(\mathrm{NH}_{3}\right)_{4}\left(\mathrm{H}_{2} \mathrm{O}\right)\left(\mathrm{P}(\mathrm{OEt})_{3}\right)\right]^{2+}$ e por espectrofotometria UV-Vis, por adição de pirazina após a reação, observando o aparecimento da banda em $366 \mathrm{~nm}$ devido à formação do complexo trans-[Ru"ll($\left.\left(\mathrm{NH}_{3}\right)_{4}\left(\mathrm{P}(\mathrm{OEt})_{3}\right) \mathrm{pz}\right]^{2+}$.

Os cálculos quânticos (DFT) indicam que o sítio de redução da espécie trans$\left[\mathrm{Ru}^{\prime \prime}\left(\mathrm{NH}_{3}\right)_{4}(\mathrm{NO})\left(\mathrm{P}(\mathrm{OEt})_{3}\right)\right]^{2+}$ se encontra quase que exclusivamente sobre os orbitais $\pi$ antiligantes do NO. A forma reduzida de dois elétrons do complexo trans$\left[\mathrm{Ru}^{\prime \prime}\left(\mathrm{NO}^{+}\right)\left(\mathrm{NH}_{3}\right)_{4}\left(\mathrm{P}(\mathrm{OEt})_{3}\right)\right]^{3+}$ apresenta uma rápida liberação do ligante nitroxil, 
devido à baixa afinidade que o rutênio (II) possui por esta molécula, em função do efeito e da influência trans do ligante $\mathrm{P}(\mathrm{OEt})_{3}$.

A liberação de nitroxil, pela redução de 2 elétrons no íon complexo trans$\left[\mathrm{Ru}^{\prime \prime}\left(\mathrm{NO}^{+}\right)\left(\mathrm{NH}_{3}\right)_{4}\left(\mathrm{P}(\mathrm{OEt})_{3}\right)\right]^{3+}$, foi verificado pela adição da metmioglobina, visto que o nitroxil liberado reage com heme férrico, gerando o heme nitrosilo ferroso, agindo como captador de nitroxil. Este composto foi escolhido devido à sua especificidade em relação à espécie nitroxil e a possibilidade de ser utilizado nas condições experimentais. Pode-se observar, por espectroscopia na região do UV-Vis, que o captador não reagiu preferencialmente com o óxido nítrico, visto que as bandas referentes ao aduto heme $\mathrm{MbFe}(\mathrm{III}) \mathrm{NO} / \mathrm{MbFe}(\mathrm{II}) \mathrm{NO}^{+}$não foram observadas. $\mathrm{O}$ aparecimento das bandas em 243 e 276 nm, característica do aduto nitrosilo reduzido, sugere que a espécie HNO se encontra predominantemente em solução. Desta forma, a provável seqüência de reações para a redução do complexo trans$\left[\mathrm{Ru}\left(\mathrm{NH}_{3}\right)_{4} \mathrm{NOP}\left(\mathrm{OCH}_{2} \mathrm{CH}_{3}\right)\right]\left(\mathrm{PF}_{6}\right)_{3}$ foi sugerido de acordo com os resultados eletroquímicos, químicos e os cálculos quânticos.

O estudo detalhado do mecanismo de redução de dois elétrons deve ir além desse complexo. Trabalhos envolvendo a redução de complexos nitrosilos de rutênio por outros agentes redutores biológicos estão sendo investigados em nosso laboratório. 


\section{REFERENNCIAS}

BIBLIOGRÁFICAS 


\section{REFERÊNCIAS BIBLIOGRÁFICAS}

[1] MIRANDA, K. M. The chemistry of nitroxyl (HNO) and implications in biology. Coordination Chemistry Reviews, v. 249, p. 433-455, 2005.

[2] MONCADA, S.; HIGGS, E. A. The discovery of nitric oxide and its role in vascular biology. British Journal of Pharmacology, v. 147, p.193-201, 2006.

[3] WINK, D. A.; MITCHELL, J. B. Chemical biology of nitric oxide: insights into regulatory, cytotoxic, and cytoprotective mechanisms of nitric oxide. Free Radical Biology and Medicine, v. 25, p. 434-456, 1998.

[4] STERN, J. E.; LI, Y; ZHANG, W. Nitric oxide: A local signaling molecule controlling the activity of pre-autonomic neurons in the paraventricular nucleus of the hypothalamus. Acta Physiologica Scandinavica, v. 177, p. 37-42, 2003.

[5] MAAS, R.; SCHWEDHELM, E; ALBSMEIER, J.; BOGER, R. H. The pathophysiology of erectile dysfunction related to endothelial dysfunction and mediators of vascular function. Vascular Medicine, v. 7, p. 213-225, 2002.

[6] IGNARRO, L. J. Nitric oxide. A novel signal transduction mechanism for transcellular communication. Hypertension, v. 16, p. 477-483, 1990.

[7] CARTER, T. D.; BETTACHE, N.; OGDEN, D. Potency and kinetics of nitric oxidemediated vascular smooth muscle relaxation determined with flash photolysis of ruthenium nitrosyl chlorides. British Journal of Pharmacology, v. 122, p. 971-973, 1997.

[8] BONAVENTURA, D.; OLIVEIRA, F. S.; SILVA, R. S.; BENDHACK, L. M. Decreased vasodilation induced by a new nitric oxide donor in two kidney, one clip hypertensive rats is due to impaired $\mathrm{K}^{+}$channel activation. Clinical and Experimental Pharmacology and Physiology, v. 32, p. 478-481, 2005.

[9] HUGHES, M. N. Relationships between nitric oxide, nitroxil ion, nitrosonium cation and peroxynitrito. Biochimica et Biophysica Acta, v. 141, p. 263-272, 1999.

[10] MARAJ, S. R.; KHAN, S.; CUI, X. Y.; CAMMACK, R.; JOANNOU, C. L.; HUGHES, M. N. Interactions of nitric oxide and redox-related species with biological targets. Analyst, v. 120, p. 699-703, 1995.

[11] STAMLER, J. S.; SINGEL, D. J.; LOSCALZO, J. Biochemistry of nitric oxide and its redox-activated forms. Science, v. 258, p. 1898-1902, 1992.

[12] AKHMETOV, N. Inorganic Chemistry. Editora MIR, 1973.

[13] BASOLO, F.; JOHNSON, R. Química de los compuestos de coordinación. Editorial Reverté, S. A., 1980. 
[14] CHEN, Y.; LIN, F. T.; SHEPHERD, R. E. ${ }^{15} \mathrm{~N}$ NMR and electrochemical studies of $\left[\mathrm{Ru}^{\prime \prime} \text { (hedta) }\right]^{-}$complexes of $\mathrm{NO}, \mathrm{NO}^{+}, \mathrm{NO}_{2}^{-}$and $\mathrm{NO}^{-}$. Inorganic Chemistry, v. 38, p. 973-983, 1999.

[15] SOUTHERN, J. S; GREEN, M. T.; HILLHOUSE, G. L.; GUZEI, I. A.; RHEINGOLD, A. L.; Chemistry of coordinated nitroxyl. Reagent-specific protonations of trans- $\mathrm{Re}(\mathrm{CO})_{2}(\mathrm{NO})\left(\mathrm{PR}_{3}\right)_{2}(\mathrm{R}=\mathrm{Ph}, \mathrm{Cy})$ that give the neutral nitroxyl complexes cis, trans- $\mathrm{ReCl}(\mathrm{CO})_{2}(\mathrm{NH}=\mathrm{O})\left(\mathrm{PR}_{3}\right)_{2}$ or the cationic hydride complex [trans, trans-

$\left.\mathrm{ReH}(\mathrm{CO})_{2}(\mathrm{NO})\left(\mathrm{PPh}_{3}\right)_{2}{ }^{+}\right]\left[\mathrm{SO}_{3} \mathrm{CF}_{3}{ }^{-}\right]$. Inorganic Chemistry, v. 40, p. 6039-6046, 2001.

[16] MARHENKE, J.; JOSEPH, C. A.; CORLISS, M. Z.; DUNN, T. J.; FORD, P. C. Thermal and photochemical reactivity of $\left[\mathrm{Os}(\mathrm{HNO})(\mathrm{CO}) \mathrm{Cl}_{2}\right]\left(\mathrm{PPh}_{3}\right)_{2}$. Evidence for photochemical HNO generation. Polyhedron, v. 26, p. 4638-4644, 2007.

[17] BARTBERGER, M. D.; LIU, W.; FORD, E.; MIRANDA, K. M.; SWITZER, C.; FUKUTO, J. M.; FARMER, P. J.; WINK, D. A.; HOUK, K. N. The reduction potential of nitric oxide (NO) and its importance to NO biochemistry. Proceedings of the National Academy of Sciences, v. 99, p. 10958-10963, 2002.

[18] FUKUTO, J. M.; BARTBERGER, M. D.; DUTTON, A. S.; PAOLOCCI, N.; WINK, D. A.; HOUK, K. N. The physiological chemistry and biological activity of nitroxil (HNO): the neglected, misunderstood, and enigmatic nitrogen oxide. Chemical Research in Toxicology (Review), v. 18, p. 790-801, 2005.

[19] NAGASAWA, H. T.; DEMASTER, E. G.; REDFERN, B.; SHIROTA, F. N.; GOON, D. J. W. Evidence for nitroxyl in the catalase-mediated bioactivation of the alcohol deterrent agent cyanamide. Journal of Medicinal Chemistry, v. 33, p. 31203122, 1990.

[20] LEE, M. J. C.; NAGASAWA, H. T.; ELBERLING, J. A.; DEMASTER, E. G. Prodrugs of nitroxyl as inhibitors of aldehyde dehydrogenase. Journal of Medicinal Chemistry, v. 35, p. 3648-3652, 1992.

[21] SHAFIROVICH, V.; LYMAR, S. V. Nitroxyl and its anion in aqueous solutions: Spin states, protic equilibria, and reactivities toward oxygen and nitric oxide, Proceedings of the National Academy of Sciences, v. 99, p. 7340-7345, 2002.

[22] DOYLE, M. P.; MAHAPATRO, S. N. Nitric oxide dissociation from trioxodinitrate (II) in aqueous solution. Journal of the American Chemistry Society, v. 106, p. 3678-3679, 1984.

[23] DONALD, C. E.; HUGHES, M. N.; THOMPSON, J. M.; BONNER, F. T. Photolysis of the $\mathrm{N}=\mathrm{N}$ bond in trioxodinitrate: reaction between triplet $\mathrm{NO}^{-}$and $\mathrm{O}_{2}$ to form peroxonitrite. Inorganic Chemistry, v. 25, p. 2676-2677, 1986.

[24] MIRANDA, K. M.; DUTTON, A. S.; RIDNOUR, L. A.; FOREMAN, C. A.; FORD, E.; PAOLOCCI, N.; KATORI, T.; TOCCHETTI, C. G.; MANDARDI, D.; THOMAS, D. D.; ESPEY, M. G.; HOUK, K. N.; FUKUTO, J. M.; WINK, D. A. Mechanism of aerobic decomposition of Angeli's salt (sodium trioxodinitrate) at physiological $\mathrm{pH}$. Journal of the American Chemistry Society, v. 127, p. 722-731, 2005. 
[25] BONNER, F. T.; RAVID, B. Thermal decomposition of oxyhyponitrite (sodium trioxodinitrate (II)) in aqueous solution. Inorganic Chemistry, v. 14, p. 558-563, 1975.

[26] BAZYLINSKI, D. A.; HOLLOCHER, T. C. Evidence from the reaction between trioxodinitrate (II) and ${ }^{15} \mathrm{NO}$ that trioxodinitrate (II) decomposes into nitrosyl hydride and nitrite in neutral aqueous solution. Inorganic Chemistry, v. 24, p. 4285-4288, 1985.

[27] FUKUTO, J. M.; SWITZER, C. H.; MIRANDA, K. M.; WINK, D. A. Nitroxyl (HNO): chemistry, biochemistry, and pharmacology. Annual Review Pharmacology and Toxicology, v. 45, p. 335-355, 2005.

[28] LIOCHEV, S. I.; FRIDOVICH, I. The mode of decomposition of Angeli's salt $\left(\mathrm{Na}_{2} \mathrm{~S}_{2} \mathrm{O}_{3}\right)$ and the effects thereon of oxygen, nitrite, superoxide dismutase, and glutathione. Free Radical Biology and Medicine, v. 34, p. 1399-1404, 2003.

[29] OENNINGTON, R. L.; SHA, X.; KING, B. N-Hydroxy sulfonimidamides as new nitroxyl (HNO) donors. Bioorganic and Medicinal Chemistry Letters, v. 15, p. 2331-2334, 2005.

[30] ZENG, B. B.; HUANG, J.; WRIGHT, M. W.; KING, S. B. Nitroxyl (HNO) release from new functionalized $N$-hydroxyurea-derived acyl nitroso-9,10-dimethylanthracene cycloadducts. Bioorganic and Medicinal Chemistry Letters, v. 14, p. 5565-5568, 2004.

[31] SHA, X.; ISBELL, T. S.; PATEL, R. P.; DAY, C. S.; KING, S. B. Hydrolysis of acyloxy nitroso compounds yields nitroxil (HNO). Journal of the American Chemistry Society, v. 128, p. 9687-9692, 2006.

[32] SHAFIROVICH, V.; LYMAR, S. V. Spin-forbidden deprotonation of aqueous nitroxil (HNO). Journal of the American Chemical Society, v. 125, p. 6547-6552, 2003.

[33] PAOLOCCI, N.; JACKSON, M. I.; LOPEZ, B. E.; MIRANDA, K.; TOCCHETTI, C. G.; WINK, D. A.; HOBBS, A. J.; FUKUTO, J. M. The pharmacology of nitroxyl (HNO) and its therapeutic potential: Not just the janus face of NO. Pharmacology and Therapeutics. V. 113, p. 442-458, 2007.

[34] JANAWAY, G. A.; BRAUMAN, J. I. Direct observation of spin forbidden protontransfer reactions: ${ }^{3} \mathrm{NO}^{-}+\mathrm{HA} \rightarrow{ }^{1} \mathrm{HNO}+\mathrm{A}^{-}$. The Journal of Physical Chemistry $\mathbf{A}$, v. 104, p. 1795-1798, 2000.

[35] GRATZEL, M.; TANIGUCHI, S.; HENGLEIN, A. A pulse radiolytic study of shortlived byproducts on nitric oxide reduction in aqueous solution. Ber Bunsenges Physical Chemistry, v. 74, p. 1003-1010, 1970.

[36] STOJANOVIĆ, S.; STANIĆ, D.; NIKOLIĆ, M.; SPASIĆ, M.; NIKETIĆ, V. Iron catalized conversion of $\mathrm{NO}$ into nitrosonium $\left(\mathrm{NO}^{+}\right)$and nitroxyl (HNO/NO') species. Nitric Oxide, v. 11, p. 256-262, 2004. 
[37] LYMAR, S. V.; SHAFIROVICH, V.; POSKREBYSHEV, G. A. One-reduction of aqueous nitric oxide: a mechanistic revision. Inorganic Chemistry, v. 44, p. 52125221, 2005.

[38] BROWN, H. W.; PIMENTEL, G. C. Photolysis of nitromethane and of methyl nitrite in an argon matrix; infrared detection of nitroxyl, HNO. The Journal of Chemical Physics, v. 29, p. 883-888, 1958.

[39] KIRSCH, M.; GROOT, H. Formation of peroxynitrite from reaction of nitroxyl anion with molecular oxygen. The of Biological Chemistry, v. 277, p. 13379-13388, 2002.

[40] FUKUTO, J. M.; DUTTON, A. S.; HOUK, K. N. The chemistry and biology of nitroxyl (HNO): A chemically unique species with novel and important biological activity. ChemBioChem, v. 6, 612-619, 2005.

[41] MIRANDA, K. M.; ESPEY, M. G.; YAMADA, K.; KRISHNA, M.; LUDWICK, N.; KIM, S. M.; JOURD'HEUIL, D.; GRISHAM, M. B.; FEELISCH, M.; FUKUTO, J. M.; WINK, D. A. Unique oxidative mechanisms for the reactive nitrogen oxide species, nitroxyl anion. The Journal Of Biological Chemistry, v. 276, p. 1720-1727, 2001.

[42] MIRANDA, K. M.; YAMADA, K.; ESPEY, M. G.; THOMAS, D. D.; DEGRAFF, W.; MITCHELL, J. B.; KRISHNA, M. C.; COLTON, C. A.; WINK, D. A. Further evidence for distinct reactive intermediates from nitroxil and peroxynitrite: effects of buffer composition on the chemistry of Angeli's salt and synthetic peroxynitrite. Archives of Biochemistry and Biophysica, v. 401, p. 134-144, 2002.

[43] PAGLIARO, P.; MANCARDI, D.; RASTALDO, R.; PENNA, C.; GATTULLO, D.; MIRANDA, K. M.; FEELISCH, M.; WINK, D. A.; KASS, D. A.; PAOLOCCI, N. Nitroxyl affords thiol-sensitive myocardial protective effects akin to early preconditioning. Free Radical Biology and Medicine, v. 34, p. 33-43, 2003.

[44] WINK, D. A.; MIRANDA, K. M.; KATORI, T.; MANCARDI, D.; THOMAS, D. D.; RIDNOUR, L.; ESPEY, M. G.; FEELISCH, M.; COLTON, C. A.; FUKUTO, J. M.; PAGLIARO, P.; KASS, D. A.; PAOLOCCI, N. Vascular signaling by free radicals orthogonal properties of the redox siblings nitroxyl and nitric oxide in the cardiovascular system: a novel redox paradigm. American Journal Physiology Heart and Circulatory Physiology, v. 285, p. 2264-2276, 2003.

[45] MA, X. L.; GAO, F.; LIU, G. L.; LOPEZ, B. L.; CHRISTOPHER, T. A.; FUKUTO, J. M.; WINK, D. A. Opposite effects of nitric oxide and nitroxyl on postischemic myocardial injury. Proceedings of the National Academy of Sciences, v. 96, p. 14617-14622, 1999.

[46] FUKUTO, J. M.; CHIANG, K.; HSZIEH, R.; WONG, P.; CHAUDHURI, G. The pharmacological activity of nitroxyl: a potent vasodilator with activity similar to nitric oxide and/or endothelium-derived relaxing factor. The Journal of Pharmacology and Experimental Therapeutics, v. 263, p. 546-551, 1992. 
[47] MIRANDA, K. M.; PAOLOCCI, N.; KATORI, T.; THOMAS, D. D.; FORD, E.; BARTBERGER, M. D.; ESPEY, M. G.; KASS, D. A.; FEELISCH, M.; FUKUTO, J. M.; WINK, D. A. A biochemical rationale for the discrete behavior of nitroxyl and nitric oxide in the cardiovascular system. Proceedings of the National Academy of Sciences, v. 100, p. 9196-9201, 2003.

[48] LOPEZ, B. E.; SHINYASHIKI, M.; HAN, T. H.; FUKUTO, J. M. Antioxidant actions of nitroxyl (HNO). Free Radical Biology and Medicine, v. 42, p. 482-491, 2007.

[49] WINK, D. A.; FEELISH,M.; FUKUTO, J.; CHISTODOULOU, D.; JOURD'HEUIL, D.; GRISHAM, M. B.; VODOVOTZ, J.; COOK, J. A.; KRISHNA, M.; DEGRAFF, W. G.; KIM, S.; GAMSON, J.; MITCHELL, J. B. The citotoxicity of nitroxyl: possible implications for the pathophysiological role of NO. Archives of Biochemistry and Biophysics, v. 351, p. 66-74, 1998.

[50] CHAZOTTE-AUBERT, L.; OIKAWA, S.; GILIBERT, I.; BIANCHINI, F.; KAWANISHI, S.; OHSHIMA, H. Cytotoxicity and site-specific DNA damage induced by nitroxyl anion (NO) in the presence of hydrogen peroxide. The Journal of Biological Chemistry, v. 274, p. 20909-20915, 1999.

[51] RINDEN, E.; MARICQ, M. M.; GRABOWSKI, J. J. Gas-phase ion-molecule reactions of the nitric oxide anion. Journal of the American Chemistry Society, $v$. 111, p. 1203-1210, 1989.

[52] BONNER, F. T.; AKHTAR, M. J. Formation of nitrosyltricyanonickelate $\left(\mathrm{NiNO}(\mathrm{CN})_{3}{ }^{2-}\right)$ in a direct $\mathrm{NO}^{-}$displacement reaction. Inorganic Chemistry, v. 20 , 3155-3160, 1981.

[53] DOYLE, M. P.; MAHAPATRO, S. N.; BROENE, R. D.; GUY, J. K. Oxidation and reduction of hemoproteins by trioxodinitrate (II). The role of nitrosyl hydride and nitrite. Journal of the American Chemistry Society, v. 110, p. 593-599, 1988.

[54] BAZYLINSKI, D. A.; HOLLOCHER, T. C. Metmyoglobin and methemoglobin as efficient traps for nitrosyl hydride (nitroxyl) in neutral aqueous solution. Journal of the American Chemistry Society, v. 107, p. 7982-7986, 1985.

[55] TIRAVANTI, E.; SMOUILOV, A.; ZWEIER, J. L. Nitrosyl-heme complexes are formed in the ischemic heart. The Journal of Biological Chemistry, v. 279, p. 11065-11073, 2004.

[56] SHOEMAN, D. W.; NAGASAWA, H. T. The reaction of nitroxyl (HNO) with nitrobenzene gives cupferron (N-Nitrophenylhydroxylamine), Nitric Oxide: Biology and Chemistry, v. 2, p. 66-72, 1998.

[57] BARI, S. E.; MARTI, M. A.; AMOREBIETA, V. T.; ESTRIN, D. A.; DOCTOROVICH, F. Fast nitroxyl trapping by ferric porphyrins. Journal of the American Chemistry Society, v. 125, p. 15272-15273, 2003. 
[58] BORGES, S. S. S.; DAVANZO, C. U.; CASTELLANO, E. E.; Z-SCHPECTOR, J.; SILVA, S. C.; FRANCO, D. W. Ruthenium nitrosyl complexes with N-heterocyclic ligands. Inorganic Chemistry, v. 37, p. 2670-2677, 1998.

[59] TOLEDO, J. C.; LIMA-NETO, B. S.; FRANCO, D. W. Mutual effects in the chemical properties of the ruthenium metal Center and ancillary ligands upon coordination. Coordination Chemistry Reviews, v. 249, p. 419-431, 2005.

[60] SWINEHART, J. H. The nitroprusside ion. Coordination Chemistry Reviews, v. 2, p. 385-402, 1967.

[61] BARROS, B. F.; TOLEDO JR, J. C.; FRANCO, D. W.; TFOUNI, E.; KRIEGER, M. H. A new inorganic vasodilator, trans-[Ru(NO) $\left(\mathrm{NH}_{3}\right)_{4} \mathrm{P}\left(\mathrm{OEt}_{3}\right]\left(\mathrm{PF}_{6}\right)_{3}$ : hypotensive effect of endothelium-dependent and -independent vasodilators in different hypertensive animals models. Nitric Oxide, v. 7, p. 50-56, 2002.

[62] ZANICHELLI, P. G.; ESTRELA, H. F. G.; SPADARI-BRATFISCH, R. C.; GRASSI-KASSISSE, D. M.; FRANCO, D. W. The effects of ruthenium tetraammine compounds on vascular smooth muscle. Nitric Oxide, 2007.

[63] PERRIN, D. D.; AMAREGO, W. L. F.; PERIN, D. R. Purification of laboratory chemicals, $2^{\text {nd }}$ edition, Pergamon Press, Elmsford, New York, 1980.

[64] SHRIVER, D. E. The manipulation of air sensitive compounds, Editora Mc Graw Hill Co, New York, 1969.

[65] ARNELLE, D. R.; STAMLER, J. S. NO ${ }^{+}, \mathrm{NO}^{\circ}$, and NO- donation by Snitrosothiols: implications for regulation of physiological functions by $\mathrm{S}$-nitrosylation and acceleration of disulfide formation. Archives of Biochemistry and Biophysics, v. 318, p. 279-289, 1995.

[66] VOGT JR, L. H.; KATZ, L.; WIBERLEY, S. E. The crystal and molecular structure of ruthenium-sulfur dioxide coordination compounds. I. Chlorotetraammine(sulfur dioxide) ruthenium (II) clroride. Inorganic Chemistry, v. 4, p. 1157-1163, 1965.

[67] SILVA, H. A. S.; MCGARVEY, B. R.; SANTOS, R. H. A.; BERTOTTI, M.; MORI, V.; FRANCO, D. W. Sulfate as a ligand in ruthenium (II) and (III) ammines. Canadian Journal of Chemistry, v. 79, p. 679-687, 2001.

[68] ZANICHELLI, P. G.; MIOTTO, A. M.; ESTRELA, H. F. G.; SOARES, F. R.; GRASSI-KASSISSE, D. M.; SPADARI-BRATFISCH, R. C.; CASTELLANO, E. E.; RONCAROLI, F.; PARISE, A. R.; OLABE, J. A.; BRITO, A. R. M. S.; FRANCO, D. W. The $[\mathrm{Ru}(\mathrm{Hedta}) \mathrm{NO}]^{0,1-}$ system: structure, chemical reactivity and biological assays. Journal of Inorganic Biochemistry, v. 98, p. 1921-1932, 2004.

[69] DIAMANTIS, A. A.; DUBRAWSKI, J. V. Preparation and structure of ethylenediaminetetraacetate complexes of ruthenium (II) with dinitrogen, carbon monoxide, and other $\pi$-acceptor ligands. Inorganic Chemistry, v. 20, p. 1142-1150, 1981. 
[70] LANG, D. R.; DAVIS, J. A.; LOPES, L. G. F.; FERRO, A. A.; VASCONCELLOS, L. C. G.; FRANCO, D. W.; TFOUNI, E.; WIERASZKO, A.; CLARKE, M. J. A controlled NO-releasing compound: synthesis, molecular structure, spectroscopy, electrochemistry, and chemical reactivity of $\mathrm{R}, \mathrm{R}, \mathrm{S}, \mathrm{S}-\operatorname{trans}-[\mathrm{RuCl}(\mathrm{NO})(\mathrm{cyclam})]^{2+}$ (1,4,8,11- tetraazacyclotetradecane). Inorganic Chemistry, v. 39, p. 2294-2300, 2000.

[71] BONAVENTURA, D.; OLIVEIRA, F. S.; TOGNIOLO, V.; TEDESCO, A. C.; SILVA, R. S.; BENDHACK, L. M. A macrocyclic nitrosyl ruthenium complex is a NO donor that induces rat aorta relaxation. Nitric Oxide, v. 10, p. 83-91, 2004.

[72] FRANCO, D. W.; TAUBE, H. Triethyl phosphite as a ligand on ruthenium (II). Inorganic Chemistry, v. 17, 571-578, 1978.

[73] LOPES, L. G. F.; CASTELLANO, E. E.; FERREIRA, A. G.; DAVANZO, C. U.; CLARKE, M. J.; FRANCO, D. W. Reactivity of trans-[Ru( $\left.\left(\mathrm{NH}_{3}\right)_{4} \mathrm{P}(\mathrm{OEt})_{3} \mathrm{NO}\right] \mathrm{X}_{3}(\mathrm{X}=$ $\left.\mathrm{PF}_{6}{ }^{-}, \mathrm{CF}_{3} \mathrm{COO}^{-}\right)$: modulation of the release of $\mathrm{NO}$ by the trans-effect. Inorganica Chimica Acta, v. 358, p. 2883-2890, 2005.

[74] FRANCO, D. W. The aquation and trans-influence of phosphites in complexes of ruthenium (II). Inorganica Chimica Acta, v. 48, p. 1-7, 1981.

[75] JIN, B.; LIU, P.; WANG, Y.; ZHANG, Z.; TIAN, Y.; YANG, J.; ZHANG, S.; CHENG, F. Rapid-scan time-resolved FT-IR spectroelectrochemistry studies on the electrochemical redox process. Journal Physical Chemistry B, v. 111, p. 15171522, 2007.

[76] GALE, R. J. Spectroelectrochemistry: theory and practice. Editora Plenum Press, New York, 1988.

[77] BARD, A. J.; FAULKNER, L. R. Electrochemical Methods fundamentals and Aplications, John Wiley \& sons, Inc., New York, 1980.

[78] ALEIXO, L. M. Voltametria: conceitos e técnicas. Chemkeys.

[79] KULPA, S. H.; FRANKENTHAL, R. P. Electrochemical Methods fundamentals and Aplications, Journal Electrochemical Society, v. 124, p. 1977, 1977.

[80] OSTERYOUNG, J. G.; OSTERYOUNG, R. A. Square wave voltammetry, Analytical Chemistry, v. 57, p. 101-110, 1985.

[81] CABRAL, M. F.; SOUZA, D.; ALVES, C. R.; MACHADO, S. A. S. Estudo do comportamento eletroquímico do herbicida ametrina utilizando a técnica de voltametria de onda quadrada. Eclética Química, v. 28, p. 41-47, 2003.

[82] SOUZA, D.; MACHADO, S. A. S.; AVACA, L. A. Voltametria de onda quadrada. Primeira parte: Aspectos teóricos. Química Nova, v. 26, p. 81-89, 2003.

[83] FRISCH, M. J.; TRUCKS, G. W.; SCHLEGEL, H. B.; SCUSERIA, G. E.; ROBB, M. A.; CHEESEMAN, J. R.; MONTGOMERY Jr., J. A.; VREVEN, T.; KUDIN, K. N.; 
BURANT, J. C.; MILLAM, J. M.; IVENGAR, S. S.; TOMASI, J.; BARONE, V.; MENNUCI, B.; COSSI, M.; SCALMANI, G.; REGA, N.; PETERSSON, G. A.; NAKATSUJI, H.; HADA, M.; EHARA, M.; TOYOTA, K.; FUKUDA, R.; HASEGAWA, J.; ISHIDA, M.; NAKAJIMA, T.; HONDA, Y.; KITAO, O.; NAKAI, H.; KLENE, M.; Li, X.; KNOX, J. E.; HRATCHIAN, H. P.; CROSS, J. B.; BAKKEN, V.; ADAMO, C.; JARAMILLO, J.; GOMPERTS, R.; STRATMANN, R. E.; YAZYEV, O.; AUSTIN, A. J.; CAMMI, R.; POMELLI, C.; OCHTERSKI, J. W.; AYALA, P. Y.; MOROKUMA, K.; VOTH, G. A.; SALVADOR, P.; DANNENBERG, J. J.; ZAKRZEWSKI, V. G.; DAPPRICH, S.; DANIELS, A. D.; STRAIN, M. C.; FARKAS, O.; MALICK, D. K.; RABUCK, A. D.; RAGHAVACHARI, K.; FORESMAN, J. B.; ORTIZ, J. V.; CUI, Q.; BABOUL, A. G.; CLIFFIRD, S.; CIOSLOWSKI, J.; STEFANOV, B. B.; LIU, G.; LIASHENKO, A.; PISKORZ, P.; KOMAROMI, I.; MARTIN, R. L.; FOX, D. J.; KEITH, T.; AL-LAHAM, M. A.; PENG, C. Y.; NANAYAKKARA, A.; CHALLACOMBE, M.; GILL, P. M. W.; JOHNSON, B.; CHEN, W.; WONG, M. W.; GONZALEZ, C.; POPLE, J. A. Gaussian 03, Revision C.02, Gaussian, Inc, Wallingford CT, 2004.

[84] MIERTUS, S.; SCROCCO, E.; TOMASI, J. Journal Chemistry Physical, v. 55, p. $117,1982$.

[85] MIERTUS, S.; TOMASI, J. Journal of Chemical Physics, v. 65, p. 239, 1981.

[86] GLENDENING, E. D.; BADENHOOP, J. K.; REED, A. E.; CARPENTER, J. E.; BOHMANN, J. A.; MORALES, C. M.; WEINHOLD, F. NBO 5.0: Theoretical Chemistry Institute, University of Wisconsin, Madison, 2001.

[87] DENNINGTON II, R.; KEITH, T.; MILLAM, J.; EPPINNETT, K.; HOVELL, W. L.; GILLILAND, R. Gauss View, version 3.07, Semichem, Inc., Shawnee Mission, KS, 2003.

[88] REZENDE, N. M. S.; MARTINS, S. C.; MARINHO, L. A.; SANTOS, J. A. V.; TABAK, M.; PERUSSI, J. R.; FRANCO, D. W. Triethyl phosphite as a ligand on $\mathrm{Ru}(\mathrm{III})$. Synthesis, characterization and properties of trans-

$\left[\mathrm{Ru}\left(\mathrm{NH}_{3}\right)_{4} \mathrm{P}(\mathrm{OEt})_{3}\left(\mathrm{H}_{2} \mathrm{O}\right)\right]\left(\mathrm{CF}_{3} \mathrm{SO}_{3}\right)_{3}$. Inorganica Chimica Acta, v. 182, p. 87-92, 1991.

[89] TOLEDO JR, J. C.; LOPES, L. G. F.; ALVES, A. A.; SILVA, L. P.; FRANCO, D. W.; Release of $\mathrm{NO}$ by a nitrosyl complex upon activation by the mitochondrial reducing power. Journal of Inorganic Biochemistry, v. 89, p. 267-271, 2002.

[90] SMITH, E. T.; FEINBERG, B. A. Redox properties of several bacterial ferredoxins using square wave voltammetry. The Journal of Biological Chemistry, v. 265, p. 14371-14376, 1990.

[91] LOVRIC, M.; KOMORSKY-LOVRIC, S. Square-wave voltammetry of an adsorbed reactant. Journal Electroanalytical Chemistry, v. 248, p. 239-253, 1988.

[92] BRETT, C. M. A.; BRETT, A. M. O. Electrochemistry: principles, methods, and applications. Ed. Oxford Science Publications, 1993. 
[93] TOLEDO, R. A. T.; MAZO, L. H.; SANTOS, M. C.; HONÓRIO, K. M.; SILVA, A. B. F.; CAVALHEIRO, E. T. G. Estudo eletroquímico e químico quântico da oxidação do antidepressivo tricíclico amitriptilina. Química Nova, v. 28, 456-461, 2005.

[94] LEE, J.; RICHTER-ALDO, G. B. A nitrosyl hydride complex of a heme model $[\mathrm{Ru}(\mathrm{ttp})(\mathrm{HNO})(1-\mathrm{Melm})]$ (ttp = tetratolylporphyrinato dianion). Journal of Inorganic Biochemistry, v. 98, p. 1247-1250, 2004.

[95] CROSS, D. G.; HARVEY, F. F. The mechanism of glutamate dehydrogenase reaction. The Journal of Biological Chemistry, v. 245, p. 2612-2621, 1970.

[96] BATES, D. J.; FRIEDEN, C. Full time course studies on the oxidation of reduced coenzyme by bovine liver glutamate dehydrogenase. The Journal of Biological Chemistry, v. 248, p. 7885-7890, 1973.

[97] TIAN, J.; BRYK, R.; ITOH, M.; SUEMATSU, M.; NATHAN, C. Variant tricarboxylic acid cycle in mycobacterium tuberculosis: identification of $\alpha$ ketoglutarate decarboxylate. Proceedings of the National Academy of Sciences, v. 102, p. 10670-10675, 2005.

[98] RACKIS, J. J.; KALNITSKY, G. The non-enzimatic oxidation of $\alpha$-ketoglutarate. II. The products of the reaction. The Journal of Biological Chemistry, v. 225, p. 751-758, 1957.

[99] LOACH, P. A. Handbook of Biochemistry and Molecular Biology, CRC Press, Cleveland, 1968.

[100] MOTTA, V. T. Fosforilação oxidativa. Bioquímica Básica. Autolab Análises Clínicas, p. 208-234.

[101] ANNET, R. G.; KOSICKI, G. W. Oxalacetate keto-enol tautomerase: purification and characterization. The Journal of Biological Chemistry, v. 244, p. 2059-2067, 1969.

[102] VISWANATHAN, T. S.; JOHNSON, R. E.; FISHER, H. F. a-Ketoglutaric acid: solution structure and the active form for reductive amination by bovine liver glutamate dehydrogenase. Biochemistry, v. 21, p. 339-345, 1982.

[103] JONHSON, K. E.; SAWYER, D. T. The electrochemical reduction of nitrous oxide in alkaline solution. Electroanalytical Chemistry and Interfacial electrochemistry, v. 49, p. 95-103, 1974.

[104] KOZLOWSKI, J.; ZUMAN, P. Acid-base, hydration-dehydration and keto-enol equilibria in aqueous solutions of $\alpha$-ketoacids: study by spectroscopy, polarography and linear sweep voltammetry. Bioelectrochemistry and Bioenergetics, v. 28, p. 43-70, 1992.

[105] Comparison of UV and ELS detection of succinic acid. Application Notebook, Polymer Laboratories - http://www.polymerlabs.com 
[106] NASCIMENTO FILHO, J. C.; REZENDE, J. M.; LIMA NETO, B. S. Ruthenium (II) tetraamines a useful model to compare trans-effect and trans-influence of phosphanes. Inorganica Chimica Acta, v. 145, p. 111-115, 1988. 


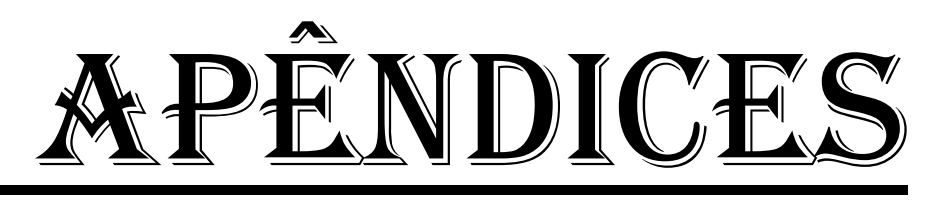




\section{7- APÊNDICE - Eletroquímica}

As figuras a seguir apresentam os voltamogramas cíclicos dos seguintes complexos:

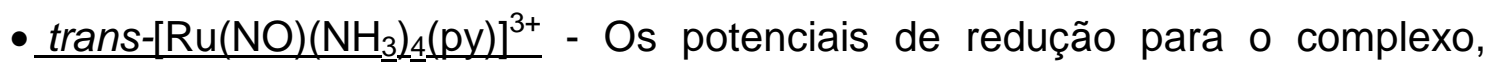
determinado por voltametria cíclica são a $-0,29 \vee$ (pico A) e $-1,05 \vee$ (pico B) (vs ECS). A primeira onda de redução é formalmente atribuída à redução monoeletrônica do par $\mathrm{Ru}^{\mathrm{II}} \mathrm{NO}^{+} / \mathrm{Ru}^{\prime \prime} \mathrm{NO}^{0}$. A segunda onda catódica provavelmente não é uma redução monoeletrônica.

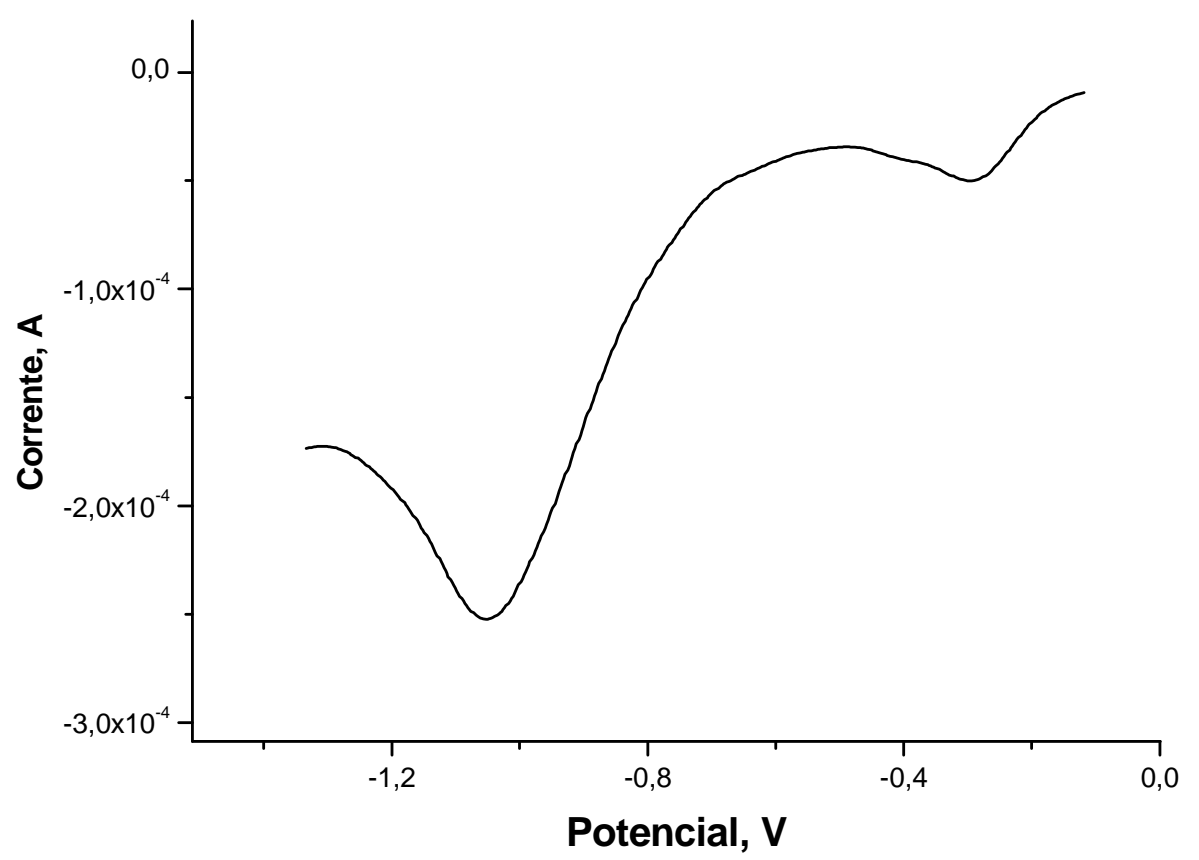

Figura 7.1 - Voltamograma de pulso diferencial do íon complexo trans$\left[\mathrm{Ru}\left(\mathrm{NH}_{3}\right)_{4} \mathrm{NO}(\mathrm{py})\right]^{3+} \cdot \mathrm{pH}=3,5 ; \mathrm{T}=25^{\circ} \mathrm{C} ; \mathrm{C}_{\mathrm{Ru}}=5,0 \times 10^{-3}$ molL; NaTFA; $\mu=0,1$ molL; $v$ $=0,05 \mathrm{~V} \cdot \mathrm{s}^{-1}$. 


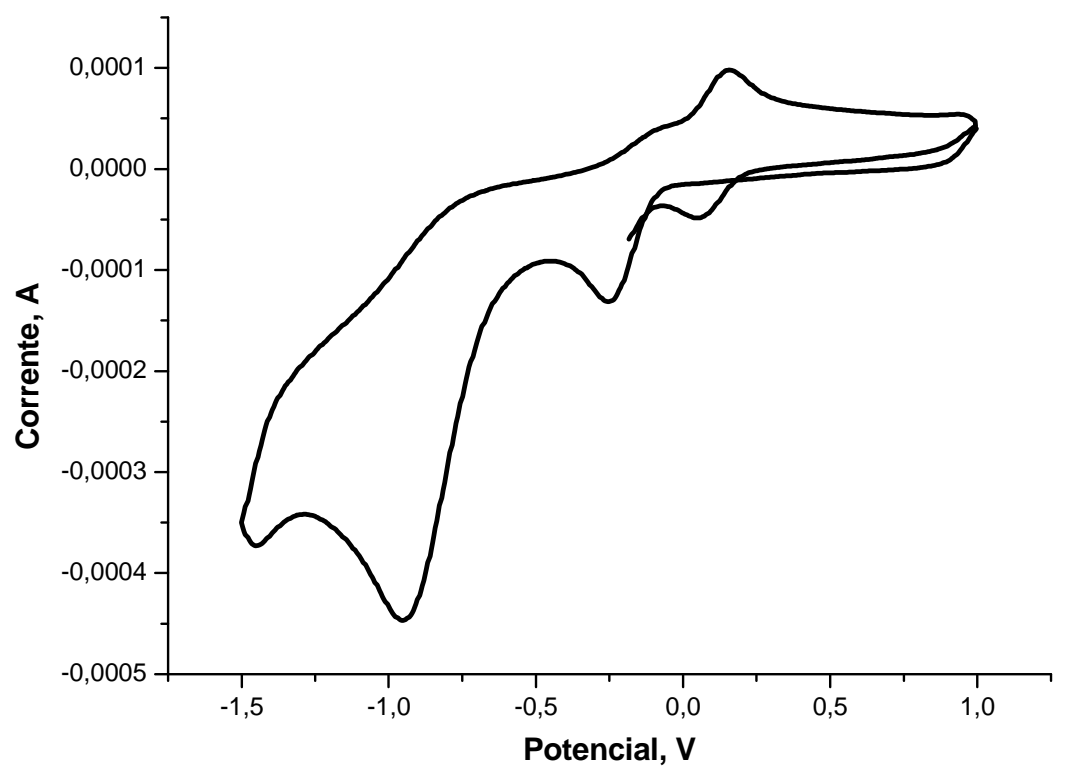

Figura 7.2 - Voltamograma cíclico $(0,5 \mathrm{~V} / \mathrm{s})$ do íon complexo trans$\left[\mathrm{Ru}\left(\mathrm{NH}_{3}\right)_{4} \mathrm{NO}(\mathrm{py})\right]^{3+}$. $\mathrm{C}_{\mathrm{Ru}}=3,4 \times 10^{-3} \mathrm{molL} ;$ Tampão acetato; $\mu=0,2 \mathrm{molL} ; \mathrm{pH}=3,5$; $E_{\text {inicial }}=1,0 \mathrm{~V} ; \mathrm{E}_{i}=1,0 \mathrm{~V} ; \mathrm{E}_{\mathrm{f}}=-1,5 \mathrm{~V} ; \mathrm{T}=25^{\mathrm{C}} \mathrm{C}$.

- trans-[Ru(NO) $\left.\left(\mathrm{NH}_{3}\right)_{4}(\mathrm{Isn})\right]^{3+}$ - Não se observa uma segunda onda catódica bem definida sob as condições experimentais.

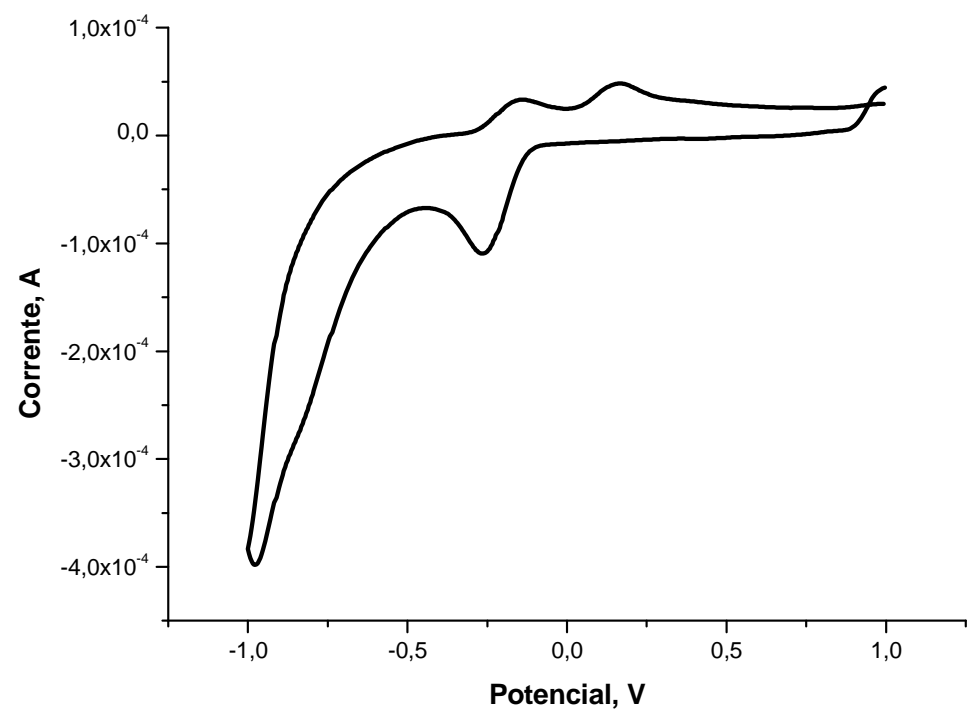

Figura 7.3 - Voltamograma cíclico do íon complexo trans-[Ru(NO)(NH$)_{4}($ isn $\left.)\right]^{3+}$. $\mathrm{pH}$ $=3,5 ; \mathrm{T}=25{ }^{\circ} \mathrm{C} ; \mathrm{C}_{\mathrm{Ru}}=5,0 \times 10^{-3} \mathrm{molL} ;$ Tampão acetato; $\mu=0,3 \mathrm{molL} ; \mathrm{E}_{\text {inicial }}=1,0 \mathrm{~V} ; \mathrm{v}$ $=0,2$ V.s. ${ }^{-1}$. 


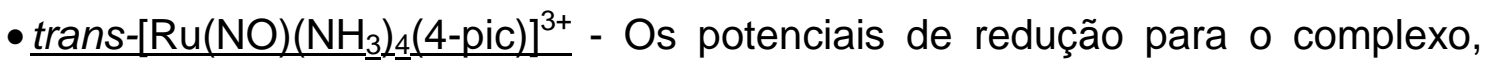
determinado por voltametria cíclica são a -0,3 V (pico A) e -1,07 V (pico B) (vs ECS). A primeira onda de redução é formalmente atribuída à redução monoeletrônica do par $\mathrm{Ru}^{\prime \prime} \mathrm{NO}^{+} / \mathrm{Ru}^{\prime \prime} \mathrm{NO}^{0}$. A segunda onda catódica provavelmente não é uma redução monoeletrônica.

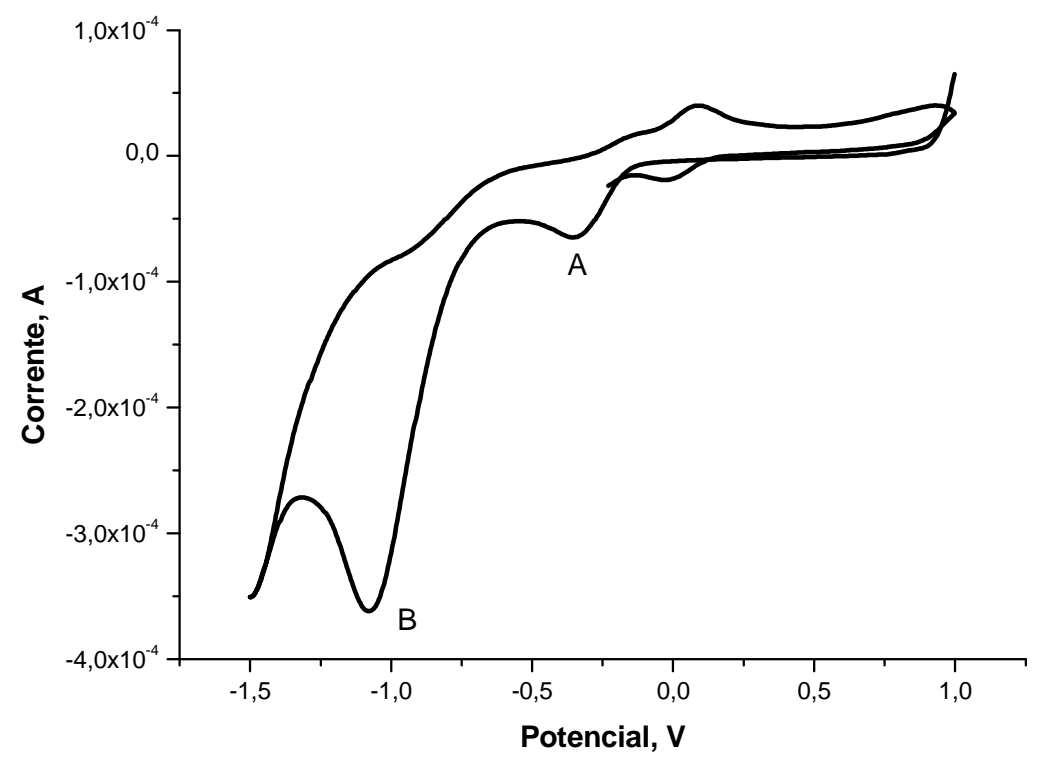

Figura 7.4 - Voltamograma cíclico $(0,2 \mathrm{~V} / \mathrm{s})$ do íon complexo trans- $\left[\mathrm{Ru}(\mathrm{NO})\left(\mathrm{NH}_{3}\right)_{4}(4-\right.$ pic) $]^{3+} . \mathrm{pH}=2,0 ; \mathrm{T}=25^{\circ} \mathrm{C} ; \mathrm{C}_{\mathrm{Ru}}=5,1 \times 10^{-3}$ molL; NaTFA; $\mu=0,1 \mathrm{molL}$. 


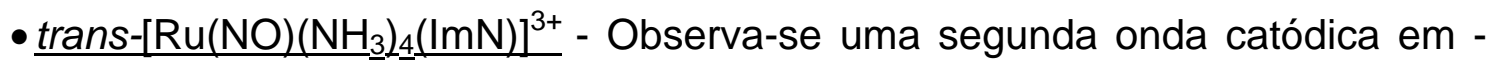
1,1 vs ECS a $25^{\circ} \mathrm{C}$.

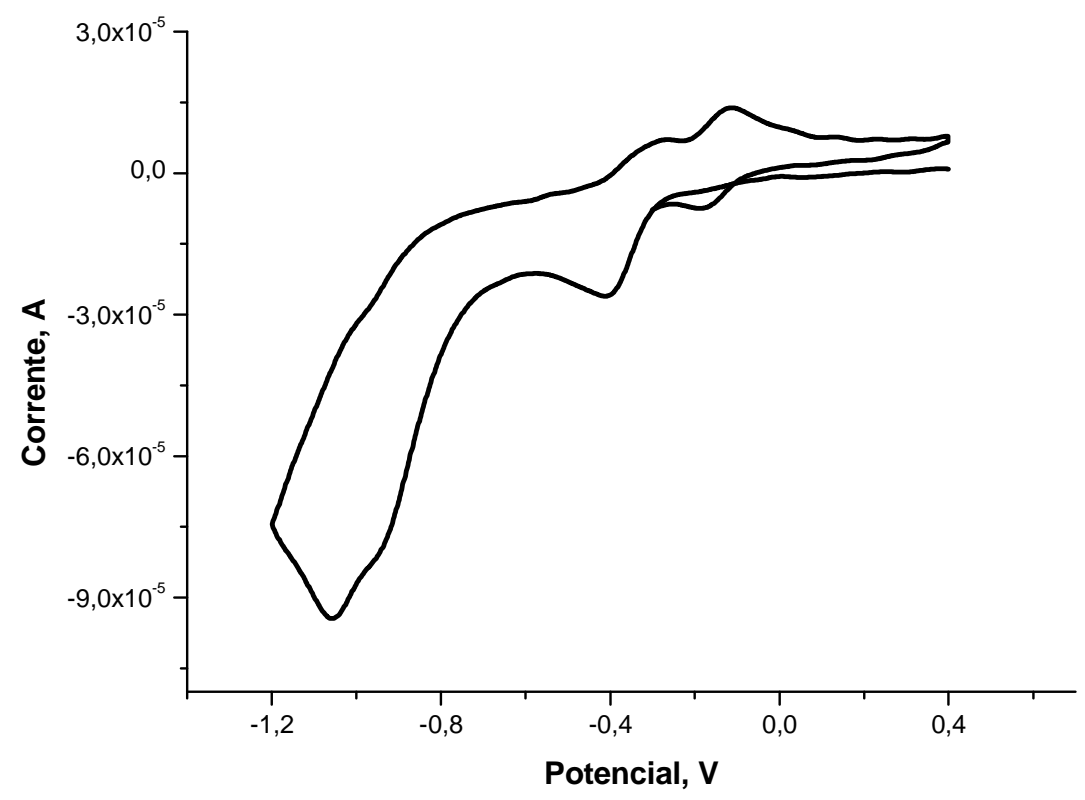

Figura 7.5 - Voltamograma cíclico $(0,2 \mathrm{~V} / \mathrm{s})$ do íon complexo trans$\left[\mathrm{Ru}\left(\mathrm{NH}_{3}\right)_{4} \mathrm{NO}(\mathrm{ImN})\right]^{3+}$. NaTFA; $\mu=0,2 \mathrm{molL} ; \mathrm{pH}=3,8 ; \mathrm{C}_{\mathrm{Ru}}=1,2 \times 10^{-3} \mathrm{molL} ; \mathrm{T}=25{ }^{\circ} \mathrm{C}$. 


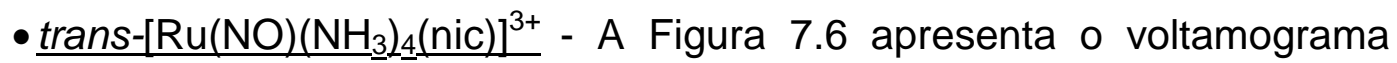
cíclico de uma solução aquosa contendo íons do complexo, $25^{\circ} \mathrm{C}$. Este complexo apresenta a segunda onda catódica a um potencial de redução de $0,95 \vee$ vs ECS.

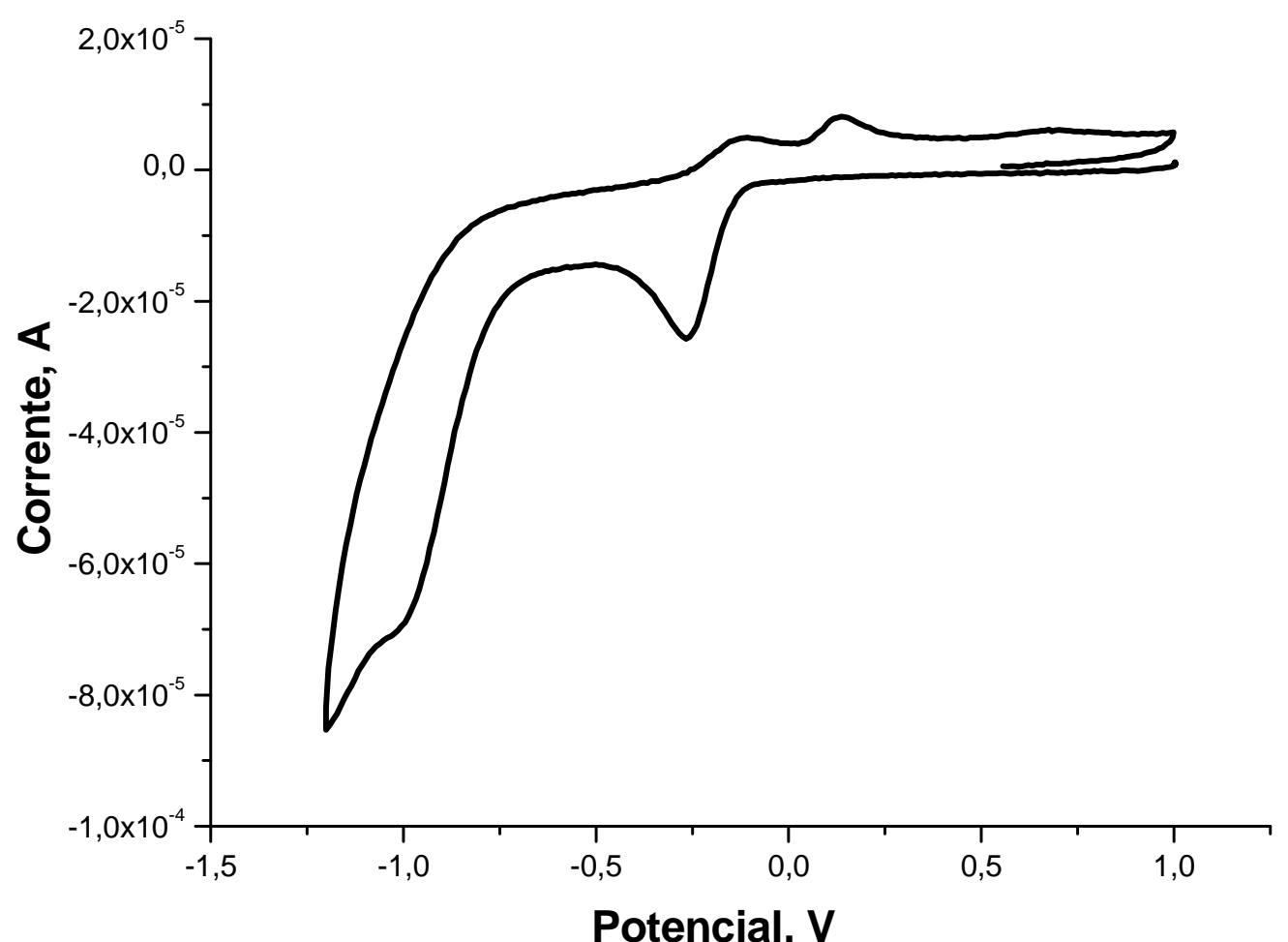

Figura 7.6 - Voltamograma cíclico $(0,5 \mathrm{~V} / \mathrm{s})$ do íon complexo trans$\left[\mathrm{Ru}\left(\mathrm{NH}_{3}\right){ }_{4} \mathrm{NO}(\text { nic })\right]^{3+} . \mathrm{pH}=3,0 ; \mathrm{T}=25^{\circ} \mathrm{C} ; \mathrm{C}_{\mathrm{Ru}}=1,6 \times 10^{-3}$ molL; Tampão fosfato; $\mu=$ 0,3 molL; $E_{\text {inicial }}=1,0 \mathrm{~V}$. 
- trans-[Ru(NO)Cl(cyclam) $]^{2+}$ - A Figura 7.7 apresenta o voltamograma cíclico de uma solução aquosa contendo íons do complexo, $25^{\circ} \mathrm{C}$, onde se pode observar a segunda onda catódica a um potencial de -0,86 vs ECS.

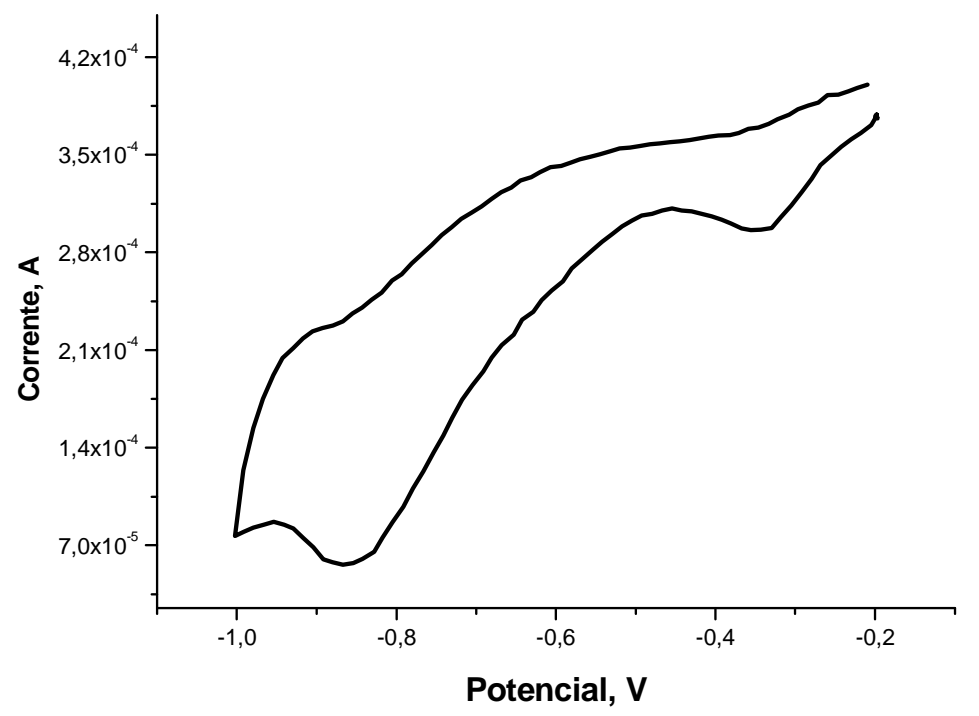

Figura 7.7 - Voltamograma cíclico $(0,2 \mathrm{~V} / \mathrm{s})$ do íon complexo trans$[\mathrm{Ru}(\mathrm{NO}) \mathrm{Cl}(\text { cyclam })]^{2+} . \mathrm{pH}=3,1 ; \mathrm{T}=25^{\circ} \mathrm{C} ; \mathrm{C}_{\mathrm{Ru}}=1,4 \times 10^{-3}$ molL; NaTFA; $\mu=0,1 \mathrm{molL}$ 


\section{APÊNDICE - Cálculo de DFT}

Tabela 7.1- Caráter, energias e estrutura de contorno dos LUMOs e HOMOs do sistema trans-[RuL($\left.\left(\mathrm{NH}_{3}\right)_{4} \mathrm{P}\left(\mathrm{OC}_{2} \mathrm{H}_{5}\right)_{3}\right]^{3+}$, onde $\mathrm{L}=\mathrm{NO}^{+}$, calculado por TFD.

\begin{tabular}{|c|c|c|}
\hline Orbital & Caráter do orbital & Energia (eV) \\
\hline LUMO +5 & $100 \% \mathrm{sp} \mathrm{POC}_{2} \mathrm{H}_{5}$ & $-0,7$ \\
\hline LUMO +4 & $\begin{array}{l}9 \% d_{z}^{2} \\
91 \% \text { sp } \mathrm{POC}_{2} \mathrm{H}_{5}\end{array}$ & $-1,6$ \\
\hline LUMO +3 & $100 \% d_{x}^{2}-y^{2}(R u)$ & $-2,8$ \\
\hline LUMO +2 & $\begin{array}{l}66 \% \mathrm{Ru} \\
5 \% \mathrm{NO}, \mathrm{NH}_{3} \\
29 \% \text { sp } \mathrm{POC}_{2} \mathrm{H}_{5}\end{array}$ & $-3,5$ \\
\hline LUMO +1 & $\begin{array}{l}35 \% d_{x y}(R u) \\
65 \% \pi^{\star}(N O)\end{array}$ & $-4,5$ \\
\hline LUMO & $\begin{array}{l}36 \% d_{x y}(R u) \\
63 \% \pi^{*}(N O)\end{array}$ & $-4,5$ \\
\hline HOMO & $100 \% d_{x y}(R u)$ & $-8,9$ \\
\hline HOMO -1 & $100 \% p_{y} \mathrm{POC}_{2} \mathrm{H}_{5}$ & $-9,3$ \\
\hline HOMO -2 & $100 \% \mathrm{p}_{z} \mathrm{POC}_{2} \mathrm{H}_{5}$ & $-9,7$ \\
\hline HOMO -3 & $100 \% \mathrm{p}_{z} \mathrm{POC}_{2} \mathrm{H}_{5}$ & $-9,7$ \\
\hline HOMO -4 & $\begin{array}{l}64 \% d_{x y}(R u) \\
35 \% p_{x}(N O)\end{array}$ & $-9,9$ \\
\hline HOMO -2 & $\begin{array}{l}67 \% d_{y z}(R u) \\
33 \% p_{x}(N O)\end{array}$ & $-9,9$ \\
\hline
\end{tabular}


Tabela 7.2- Caráter, energias e estrutura de contorno dos LUMOs e HOMOs do sistema trans-[RuL $\left.\left(\mathrm{NH}_{3}\right)_{4} \mathrm{P}\left(\mathrm{OC}_{2} \mathrm{H}_{5}\right)_{3}\right]^{2+}$, onde $\mathrm{L}=\mathrm{NO}$, calculado por TFD.

\begin{tabular}{|c|c|c|}
\hline Orbital & Caráter do orbital & Energia $(\mathrm{eV})$ \\
\hline LUMO +4 & $\begin{array}{l}100 \% \mathrm{~d}_{\mathrm{yz}}-\mathrm{sp}\left(\mathrm{Ru}, \mathrm{NO}, \mathrm{NH}_{3} \epsilon\right. \\
\left.\mathrm{POC}_{2} \mathrm{H}_{5}\right)\end{array}$ & $-0,4$ \\
\hline LUMO +3 & $100 \% d_{y z}(R u)$ & $-1,0$ \\
\hline LUMO +2 & $\begin{array}{l}49 \% d_{x}^{2}-y^{2}(R u) \\
50 \%\left(N O, \mathrm{NH}_{3} \text { e } \mathrm{POC}_{2} \mathrm{H}_{5}\right)\end{array}$ & $-1,1$ \\
\hline LUMO +1 & $\begin{array}{l}15 \% d_{z}^{2}(R u) \\
85 \% \pi^{*}(\mathrm{NO})\end{array}$ & $-3,0$ \\
\hline LUMO & $\begin{array}{l}16 \% d_{x}^{2}-y^{2}(R u) \\
80 \% \pi^{*}(N O)\end{array}$ & $-3,3$ \\
\hline HOMO & $100 \% d_{x y}(R u)$ & $-6,9$ \\
\hline HOMO -1 & $100 \% d_{x z}(R u)$ & $-7,4$ \\
\hline HOMO -2 & $100 \% d_{y z}(R u)$ & $-7,7$ \\
\hline HOMO -3 & $100 \% \mathrm{p}_{\mathrm{x}} \mathrm{POC}_{2} \mathrm{H}_{5}$ & $-8,5$ \\
\hline HOMO -4 & $100 \% \mathrm{p}_{\mathrm{y}} \mathrm{POC}_{2} \mathrm{H}_{5}$ & $-8,9$ \\
\hline
\end{tabular}


Tabela 7.3- Caráter, energias e estrutura de contorno dos LUMOs e HOMOs do sistema trans-[RuL $\left.\left(\mathrm{NH}_{3}\right)_{4} \mathrm{P}\left(\mathrm{OC}_{2} \mathrm{H}_{5}\right)_{3}\right]^{3+}$, onde $\mathrm{L}=\mathrm{NO}^{-}$, calculado por TFD.

\begin{tabular}{|c|c|c|}
\hline Orbital & Caráter do orbital & Energia $(\mathrm{eV})$ \\
\hline LUMO +4 & $\begin{array}{l}74 \% d_{x}^{2}-y^{2}(R u) \\
16 \% s p\left(\mathrm{NH}_{3}\right)\end{array}$ & 0,3 \\
\hline LUMO +3 & $\begin{array}{l}90 \% \mathrm{dz}_{\mathrm{z}}^{2}(\mathrm{Ru}) \\
6 \% \mathrm{sp}\left(\mathrm{NH}_{3}\right) \\
4 \% \mathrm{p}_{\mathrm{x}}\left(\mathrm{POC}_{2} \mathrm{H}_{5}\right)\end{array}$ & 0,1 \\
\hline LUMO +2 & $\begin{array}{l}76 \% \mathrm{~d}_{\mathrm{xz}}-\mathrm{sp}\left(\mathrm{Ru}-\mathrm{NH}_{3}\right) \\
8 \% \pi^{*}(\mathrm{NO}) \\
16 \% \mathrm{p}_{\mathrm{x}}\left(\mathrm{POC}_{2} \mathrm{H}_{5}\right)\end{array}$ & $-0,03$ \\
\hline LUMO +1 & $\begin{array}{l}64 \% \mathrm{~d}_{\mathrm{xy}} \text {-sp }\left(\mathrm{Ru}-\mathrm{NH}_{3}\right) \\
36 \% \mathrm{p}_{\mathrm{x}}\left(\mathrm{POC}_{2} \mathrm{H}_{5}\right)\end{array}$ & $-0,2$ \\
\hline LUMO & $\begin{array}{l}20 \% d_{x y}(\mathrm{Ru}) \\
70 \% \pi^{\times}(\mathrm{NO}) \\
9 \% \mathrm{p}_{\mathrm{x}}\left(\mathrm{POC}_{2} \mathrm{H}_{5}\right)\end{array}$ & $-1,8$ \\
\hline HOMO & $\begin{array}{l}27 \% d_{x z}(R u) \\
73 \% p_{z}(N O)\end{array}$ & $-4,8$ \\
\hline HOMO -1 & $100 \% d_{x z}(R u)$ & $-5,5$ \\
\hline HOMO -2 & $\begin{array}{l}89 \% d_{y z}(R u) \\
11 \% p_{z}(N O)\end{array}$ & $-5,7$ \\
\hline HOMO -3 & $\begin{array}{l}83 \% d_{x y}(R u) \\
7 \% p_{z}(N O)\end{array}$ & $-6,1$ \\
\hline HOMO -4 & $9 \% \mathrm{p}_{\mathrm{x}}\left(\mathrm{POC}_{2} \mathrm{H}_{5}\right)$ & $-7,8$ \\
\hline
\end{tabular}


Tabela 7.4- Caráter, energias e estrutura de contorno dos LUMOs e HOMOs do sistema trans-[RuL $\left.\left(\mathrm{NH}_{3}\right)_{4} \mathrm{P}\left(\mathrm{OC}_{2} \mathrm{H}_{5}\right)_{3}\right]^{3+}$, onde $\mathrm{L}=\mathrm{HNO}$, calculado por TFD.

\begin{tabular}{|c|c|c|}
\hline Orbital & Caráter do orbital & Energia (eV) \\
\hline LUMO +4 & $\begin{array}{l}36 \% d_{y z}-s p\left(R u-N_{3}\right) \\
54 \% p_{x}\left(\mathrm{POC}_{2} \mathrm{H}_{5}\right)\end{array}$ & $-0,2$ \\
\hline LUMO +3 & $\begin{array}{l}41 \% d_{y z}-\mathrm{sp}\left(\mathrm{Ru}-\mathrm{NH}_{3}\right) \\
59 \% \mathrm{p}_{\mathrm{x}}\left(\mathrm{POC}_{2} \mathrm{H}_{5}\right)\end{array}$ & $-0,3$ \\
\hline LUMO +2 & $100 \% d_{y z}-s p\left(R u-N_{3}\right)$ & $-0,7$ \\
\hline LUMO +1 & $\begin{array}{l}81 \% d_{x}^{2}-y^{2}(R u) \\
7 \% \pi^{*}(N O) \\
12 \% p_{x}\left(P^{2} C_{2} H_{5}\right)\end{array}$ & $-1,2$ \\
\hline LUMO & $\begin{array}{l}36 \% d_{x z}(R u) \\
64 \% \pi^{*}(\mathrm{NO})\end{array}$ & $-3,5$ \\
\hline HOMO & $100 \% d_{y z}(R u)$ & $-6,7$ \\
\hline HOMO -1 & $100 \% d_{x z}(R u)$ & $-7,1$ \\
\hline HOMO -2 & $\begin{array}{l}64 \% d_{x z}(R u) \\
36 \% p_{x}(N O)\end{array}$ & $-7,3$ \\
\hline HOMO -3 & $\begin{array}{l}51 \% p_{z}(\mathrm{NO}) \\
49 \% p_{x}\left(\mathrm{POC}_{2} \mathrm{H}_{5}\right)\end{array}$ & $-7,8$ \\
\hline HOMO -4 & $\begin{array}{l}18 \% p_{z}(\mathrm{NO}) \\
82 \% p_{x}\left(\mathrm{POC}_{2} \mathrm{H}_{5}\right)\end{array}$ & $-8,5$ \\
\hline
\end{tabular}


Tabela 7.5 - Parâmetros geométricos do Complexo $\left[\mathrm{Ru}\left(\mathrm{NH}_{3}\right)_{4} \mathrm{P}\left(\mathrm{OC}_{2} \mathrm{H}_{5}\right)_{3} \mathrm{~L}\right]^{\mathrm{n}+}$ $\left(\mathrm{L}=\mathrm{NO}, \mathrm{NO}^{+}, \mathrm{NO}^{-}\right.$e $\left.\mathrm{HNO}\right)$

\begin{tabular}{|c|c|c|c|c|}
\hline & $\mathrm{NO}^{+}$ & NO & $\mathrm{NO}^{-}$ & HNO \\
\hline & \multicolumn{4}{|c|}{ 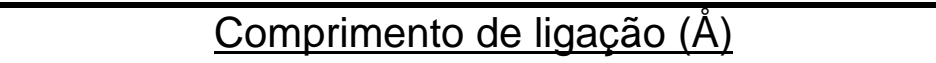 } \\
\hline $\mathrm{Ru}-\mathrm{N}(2)$ & 2,176 & 2,189 & 2,186 & 2,17104 \\
\hline $\mathrm{Ru}-\mathrm{N}(5)$ & 2,173 & 2,176 & 2,176 & 2,16736 \\
\hline $\mathrm{Ru}-\mathrm{N}(8)$ & 2,178 & 2,182 & 2,202 & 2,19302 \\
\hline $\mathrm{Ru}-\mathrm{N}(11)$ & 2,183 & 2,193 & 2,205 & 2,19380 \\
\hline $\mathrm{Ru}-\mathrm{N}(14)$ & 1,815 & 1,915 & 1,926 & 1,93826 \\
\hline $\mathrm{Ru}-\mathrm{P}(20)$ & 2,495 & 2,483 & 2,515 & 2,46273 \\
\hline$N(14)-O(15)$ & 1,170 & 1,213 & 1,282 & 1,28204 \\
\hline \multirow[t]{2}{*}{$P(20)-O(15)$} & 1,687 & 1,707 & 1,740 & 1,70804 \\
\hline & \multicolumn{4}{|c|}{$\underline{\text { Ângulo de ligação (em grau) }}$} \\
\hline $\mathrm{N}\left(\mathrm{NH}_{3}\right)-\mathrm{Ru}-\mathrm{N}\left(\mathrm{NH}_{3}\right)$ & 89,7 & 90,0 & 90,0 & 90,0 \\
\hline $\mathrm{N}\left(\mathrm{NH}_{3}\right)-\mathrm{Ru}-\mathrm{N}(\mathrm{NO})$ & 95,3 & 91,4 & 87,9 & 91,4 \\
\hline $\mathrm{N}\left(\mathrm{NH}_{3}\right)-\mathrm{Ru}-\mathrm{P}$ & 84,7 & 88,7 & 92,1 & 88,5 \\
\hline$N(N O)-R u-P$ & 178,7 & 176,2 & 176,3 & 177,2 \\
\hline Ru-N(NO)-O & 177,9 & 141,6 & 116,9 & 122,7 \\
\hline
\end{tabular}


A partir da Figura 7.8 observa-se que os orbitais $\pi^{*}$ do $\mathrm{NO}^{*}$ são os que apresentam maior contribuição para a formação do LUMO sendo, portanto, este o sítio de extrema importância no processo de redução da espécie [Ru $\left.\mathrm{RO}^{\mathrm{II}}\right]^{2+}$.

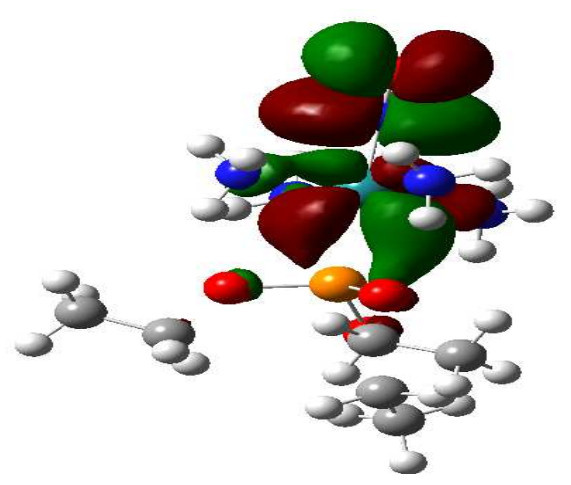

Figura 7.8- Representação gráfica do LUMO para a espécie [Ru"NO²] ${ }^{2+}$.

A Tabela 7.6 apresenta as energias de solvatação e relativa no vácuo das várias espécies do complexo.

Tabela 7.6- Energias relativas e de solvatação do sistema trans$\left[\mathrm{RuL}\left(\mathrm{NH}_{3}\right)_{4} \mathrm{P}\left(\mathrm{OC}_{2} \mathrm{H}_{5}\right)_{3}\right]^{3+}$, onde $\mathrm{L}=\mathrm{NO}^{+}, \mathrm{NO}, \mathrm{NO}^{-}$e HNO em kcal.mol ${ }^{-1}$.

\begin{tabular}{ccccc}
\hline Energia $\left(\right.$ kcal.mol $\left.^{-1}\right)$ & NO $^{+}$ & NO & NO $^{-}$ & HNO \\
Relativa & 684,0 & 376,5 & 175,7 & 0,0 \\
Solvatação em água & $-300,1$ & $-116,3$ & $-16,7$ & $-121,1$ \\
\hline
\end{tabular}

